\title{
ELEMENTS
}

\author{
OF
}

\section{NATURAL PHILOSOPHY,}

ARRANGED UNDER THE FOLLOWING

\section{HEADS :}

Matter and Motion,

The Universe,

The Solar System,

The Fixed Stars,

The Earth consiclered as a Planet,

The Atmosphere,

Meteors,

Springs, Rivers, and the Sea Fossils,

Plants,

Animals,

The Human Frame,

And

THE HUMAN UNDERSTANDING.

I see a mighty arm, by man unseen,

"Resistless, not to be controll'd, that guides,

"In solitude of unshar'd energies,

"All these thy ceaseless miracles, O world!"

C. LAME.

\section{NEW-YORK:}

Printed by D. \& G. Bruce,

FOR J. OSBORN, BOOKSELIER, 13 PARK,

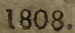





\section{Q158 \\ 54 \\ CONTENTS: \\ Case

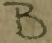 \\ *}

Chap. I. Matter and Motion......... 11

II. The Universe $\ldots \ldots \ldots \ldots \ldots 24$

III. The Solar System . . . . . . 37

IV. The Fixed Stars . . . . . . . 57

V. The Earth considered as a Planet . . 68

VI. The Atmosphere ......... 90

VII. Meteors . . . . . . . . . 105

VIII. Springs, Rivers, and the Sea . . . . 124

IX. Fossils . . . . . . . . 141

X. Plants . . . . . . . . 177

XI. Animals . . . . . . . . 200

XII. The Human Frame ......... 234

XIII. The Human Understanding . . . . 260 .

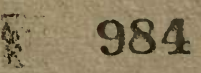





\section{PREFACE.}

IN an age like the present, when the growth of every production conducive to the interests of morality, and a more extensive knowledge of the Creator through the medium of his zcorks, is recommended and publicly encouraged, but little need be offered by way of apology for the present compilation. One imporlant object of the following pages was to present, in a very compact and comprehensive form, an interesting and connected account of those laws and operations in the material world, which, under the elaborate pens of philosophicul authors, cover an extent of scientific ground too enlarged for the commercial and labouring individual to travel over;-but more particularly has this little compendium been arranged for the juvenile inquirer, who either 
from a premature wish to anticipate the result of dcep calculations, or from. other contingent occupations, would have a general, yet clear, idea of objects, which without the aid of phitosophy he cannot understand. To enable him to accomplish this desirable end, the following pages are, as far as possible, divested of the techinical difficulties which but too often form impenetrable barriers to the expansion of the rising mind. While, however, they endeavour to exhibit in a familiar manner that chain of connexion which binds and unites all nature, they will by no means supersede an encouragement to penetrate into thosesciences whence the axioms, laws, and calculations which relate to matter and motion are ascertained.

Having notified the design of this little mamuel, it is unnecessary to enforce the importance of the subject of which it treats. No employment sure- 
2y yields so rich a harvest of instruction and delight to a rational being as that of surveying the wonderful works of the Great Creator, as displayed in the various parts of the universe. Such employment is a source of never-failing satisfaction to persons of every age; and it is only by acquiring a knowoledge of nature, and observing the contrivance and shill conspicuous in every department of creation, that we are enabled to form an adequate idea of the attributes and character of the Suprene Being:

In proportion as we attain a knowledge of the objects around us they become interesting and important. That which to the careless and unenlightened spectator, appears solitary and detached, having no other connection with the rest of the universe but the shadowy and fleeting relation of co-existence, will, to him who takes a glimpse into the general economy. 
of nature, declare themselics to be parts of a great and harmonious whole, connected by general laws, and tending to one general and beneficent purpose, and cannot fail of impressing him with a wish to co-operate in this glorious plan, by acting worthy of the place he holds among the worlis of $G \circ d$.

Thus is the study of nature calculated to exal the mind, and reduce the sum of human pride and ignorance, and comes in aid of that selfabasement which the greal duties of Christianity impose, by teaching man that, though he stands a pinnacle of power, and grasps in intellect all the prodigious worls of creation, he is but a link in an immeasurable chain that serves 10 suspend and give motion to the reorks of Him who

Connects each being, greatest with the least, Made beast in aid of man, and man of beast.

Nor is it as a moral agent only. 
that man is benefited by a knowledge of natural philosophy; it teaches fim to employ the powers of nature to the greatest advantage for the embellishment and comfort of life, and extends his empire over the material universe.

Knowledge of this kind, therefore, is the most valuable that man can acquire: it enriches his life with conveniences, enlarges his views, and lays a foundation for the most rational. and exalted piety. "The universe (says Boyle) is the magnificent temple of its great Author; and man is ordained, by his powers and qualifications, the high-priest of nature, to celebrate divine service in this temple of the universe."

Let him then, aspiring to the dignity of his station, assisted by the roritings of modern authors, devote his noblest powers to the investigation of the laws of nature; and evince that he is not in vain given ability to be 
wiser than the fowls of heaven, and to have more understanding than the beasts which perish. 


\section{ELEMENTS}

OE

\section{NATURAL PHILOSOPHY.}

\section{$\overline{-}$ \\ CHAP. I. \\ Of Matter and Motion.}

MATTER is an extended solid* suhstance; which being comprehended under distinct surfaces, makes so many particular distinct bodies.

* Solidity is not here considered as opposed to fluidity, but as that property which every body possesses of not permitting any other substance to occupy the same place witli it at the same time; so that both water and air, and every other fluid, are equally solid, in this sense of the word, with the hardest body. By solidity, in common language, is understood the property of not being easily separated into parts ; and therefore the reader must be careful not to confound the meaning of the popular with the philosophical terno. 
Motion is so well known by the sight and touch, that to use words to give a clearer idea of it would be in vain.

Matter, or body, is indifferent to motion or rest.

There is as much force required to put a body, which is in motion, at rest; as there is to set a body, which is at rest, into motion.

No parcel of matter can give itself either motion or rest ; and therefore a body at rest will remain so eternally, except some external cause puts it in motion; and a body in motion will move eternally, except some external cause stops it.

A body in motion will always move on in a straight line, unless it be turned out of it by some external cause ; because a body can no more alter the determination of its motion than it can begin it, alter or stop its motion itself.

The velocity of motion is estimated by the time employed in moving over a certain space, or by the space moved over in a certain time. The less the time, and the greater the space moved over, the greater is the velocity; on the contrary, 
the greater the time, and the less the space. moved over, the less is the velocity. Every body in motion must have a determinate velocity. To ascertain the degree of this swiftness or velocity, the space run over must be divided by the time. For example, suppose a body moves over 1000 yards in 10 minutes, its velocity will be 100 yards per minute, because 100 is the quotient of 1000 , divided by 10. If we would compare the velocity of twu bodies $A$ and $B$, of which $A$ moves over 54 yards in 9 minutes, and B 96 yards in 6 minutes, the velocity of $A$ will be to that of $B$, in the proportion of 6 (the quotient of 54 divided by 9) to 16 (the quotient of 96 divided by 6. )

To know the space run over, the velocity must be multiplied by the time; for it is evident, that if either the velocity or the time be increased, the space run over will be greater. If the velocity be doubled, then the body will move over twice the space in the same time; or if the time be twice as great, then the space will be doubled: but if the velocity and time be both doubled, then will the space be four times as great. 
It follows from this, that when two bodies move over unequal spaces in unequal times, their velocities are to each other as the quotients arising from dividing the spaces run over by the times. If two bodies move over unequal spaces in the same time, their velocities will be in proportion to the spaces passed over. And if two bodies move over equal spaces in unequal times, then their respective velocities will be inversely as the time employed ; that is, if $\mathrm{A}$ in one minuite, and $\mathrm{B}$ in two minutes, run over 100 yards, the velocity of $A$ will be to that of $B$ as 2 to 1 .

It appears, as far as human obervation reaches, to be a settled law of nature, that "all bodies have a tendency, attraction, or gravitation towards one another." The same force applied to two different bodies, produces always the same quantity of motion in each of them. For instance, let a boat, which with its lading is one tun, be tied at a distance, to another vessel, which with its lading is twenty-six tuns; if the rope that ties them together be pulled either in the less or bigger of these vessels, the less of the 
two, in their approach one to another, will move twenty-six foot, while the other moves but one foot.

Wherefore the quantity of matter in the earth being twenty-six times more than in the moon, the motion in the moon towards the earth, by the common force of attraction, by which they are impelled towards one another, will be twenty-six times as fast as in the earth; that is, the moon will move twenty-six miles towards the earth, for every mile the earth moves towards the moon.

This attraction is the strongest, the nearer the attracting bodies are to each other; and in different distances of the same bodies, is reciprocally in the duplicate proportion of those distances. For instance, if two bodies, at a given distance, attract each other with a certain force, at half the distance, they will attract each other with four times that force; at one third of the distance, with nine times that force; and so on.

Two bodies, at a distance, will put one another into motion by the force of attraction; which is inexplicable by us, though made evident tu us by experience, 
and so to be taken as a principle in na tural philosophy.

Supposing then the earth the sole bos dy in the universe, and at rest; if God should create the moon, at the same distance that it is now from the earth, the earth and the moon would presently begin to move one towards another in a straight line, by this motion of attraction or gravitation.

If a body, that by the attraction of another would move in a straight line towards it, receives a new motion any ways oblique to the first, it will no longer move in a straight line, according to $\mathrm{e}^{\mathrm{i}}$ ther of those directions, but in a curve, that will partake of both; and this curve will differ, according to the nature and quantity of the forces that concurred to produce it; as, for instance, in many cases it will be such a curve as ends where it began, or recurs into itself; that is, make up a circle, or an ellipsis, or oval very little differing from a circle.

Attraction may be divided, with respect to the law it observes, into two kinds. That which takes place at a sensible distance, and that which does not extend to 
sensible distances. The first is called the attraction of gravity, or, by mathematicians, the centripetal force.

This is the species of attraction whose laws we have endeavoured to elucidate. It is one of the most universal principles in nature. We see and feel it operate in bodies near the earth, and find by observation that the same power (i.e. a power which acts in the same manner, and by the same rules, viz. always proportionally to the quantities of mattter, and inversely as the squares of the distances) does also obtain in the moon, and the other planets, both primary and secondary, as well as in the comets; and even that this is the very power by which they are all retained in their orbits. This mighty principle forms the earth into a round and dense ball, holds every thing animate and inanimate to its surface, and makes its whole surface its general top.

From this attraction arises all the motion, and consequently all the mutation, in the great world. By this heavy bodies clescend, and light ones ascend; by this projectiles are directed, vapours and exhalations rise, and rains fall; by this 
rivers glide, the ocean swells, the air presses, \&rc.

2d. That which does not extend to sensible distances. Such is found to obtain in the minute particles of which bodies are composed, attracting each other at or extremely near the point of contact, with forces often much superior to that of gravity, but which at any distance decrease much faster than the power of gravity. This power a late ingenious author calls the attraction of cohesion, as being that by which the atoms or insensibie particles of bodies are united into sensible masses.

The laws of motion, percussion, \&c. in sensible bodics, under various circum stances, as falling, projected, \&rc. do not reach those more recluse intestine mo. tions in the component particles of the same bodies, on which depend the chan * ges in the texture, colour, properties, \&c. of bodies. So that our philosophy, if it were cnly founded on the principle of gravitation, and even carried as far as this would lead us, would still be very deficient. But, besides the common laws of sensible masses, the minute parts they 
are composed of are found subject to some others, which have but lately been noticed, and are even yet imperfectly known. Newton himself, to whose happy penetration we owe the hint, limits himself with establishing that there are such motions in the minima naturce, and that they flow from certain powers or forces, not reducible to any of those in the great world, and from hence he accounts for an infinity of phenomena, otherwise inexplicable, to which the principle of gravity is inadequate. Thus, adds Sir Isaac, "will nature be found very conformable to herself, and very simple; performing all the great motions of the heavenly bodies by the attraction of gravity, which intercedes those bodies, and almost all the small ones of their parts, by some other attractive power diffused through their particles. Without such principles, there never would have been any motion in the world; and without the continuance of it, motion would soon perish, there being otherwise a great decrease or dimirution, of it, which is only supplied by these active principles." By the attraction of cohesion are form- 
ed stones, metals, woods, salts, and every thing that may be denominated body. The effects of solders, glue, cements, \&c. are all from the same cause. So jewels, hard stones, stalactites, petrifactions, porcelain, pottery, bricks, flags, glass, cements, artificial stones, and plastic earthy compositions, which preserve their figure in drying, all are children of this great agent; and as this power is much greater in some bodies than in others, there arises an infinite variety in the strength, the weight, the texture, \&c. of metals, stones, \&c. for we have powerful reasons to believe that the original particles of all matter are of the same weight ; and that it is this principle that makes thegreat difference in their specific weight. To minds not used to philosophical investigation, it must appear a bold assertion to say, that the particles of gold are not one whit heavier than the particles of cork ; but experiment and observation shew this to be really the case.

The grand antagonist principle of the attraction of cohesion is fire (or caloric in the new language of chemistry.) These two opposing powers keep nature in a state 
of perpetual motion. When the attractive force is strongest, the body continues in a state of solidity ; but if, on the contrary, heat has so far removed the particles of it, as to place them beyond the sphere of attraction they lose their adhesion, and the body becomes fluid. Water, when cooled below 32 degrees of Fahrenheit's thermometer, becomes solid, and is called ice. Above that temperature, its particles not being held together, it becomes liquid; but when raised to 212 degrees, its particles give way to the repulsive power of fire, and, flying off, assume an aeriform state, called steam; the same may be affirmed of all bodies in nature, for even diamonds, the hardest substance we know, are capable of being dispersed by a common culinary fire.

It may therefore be considered as an axiom, that all bodies are capable in certain circumstances, of the three states of solidity, fluidity, and gas.

The atoms of which bodies are formed, are concealed from us by their minuteness, and though they are the active parts of matter, and the great instruments of nature, on which depend all its operations, B2 
we can form no idea of them, for whether we view animate or inanimate matter, the corpuscles of which it is formed are so infinitely small, as not only to escape the scrutiny of the highest magnifying powers in glasses, but even imagination itself is incapable of forming an idea of an original particle of matter: One pound of gold is capable of covering a wire that will circumscribe the globe, nay, so infinite is this divisibility that Lewenhoeck discovered more living animalcula in the milt of one single cod-fish than there are men, women, and children on the face of the earth! and those so small that many thousands may stand upon the point of a needle. And if we suppose that these animalculæ are furnished with blood, like other animals, and if the globules of their blood bear the same proportion to their buik as those of a man bear to his body, it may be proved, that the smallest visible grain of sand would contain more of these globules than 10,256 of the largest mountains in the world would contain grains of sand.

When we consider these things we seem to look down into infuity; and as, 
in the contemplation of the starry heavens, we can conceive no term to the extension of space; so, in regarding the minute parts of creation we see no end to the divisibility of matter. We are lost in wonder when we attempt to comprehend either the vastness or the minuteness of creation, and are necessarily made to feel that it belongs only to the one great and incomprehensible Power, who worketh in ways past finding out. 


\section{$\underline{1}$ \\ CHAP. II. \\ Of the Unizerse.}

TO any one, who looks about him in the world, there are obvious sereral distinct masses of matter, separate from one another ; some whereof have discernable motions. These are the sun, the fixed stars, the comets, and the planets, amongst which this earth, which we inhabit, is one. All these are visible to our naked eyes.

Besides these, telescopes have discovered several fixed stars, invisible to the naked eye; and several other bodies moving about some of the planets; all which were invisible and unknown, before the use of prospective glasses was found.

The vast distances between these great bodies, are called intermundane spaces ; in which though there may be some fiuid matter, yet it is so thin and subtile ; and there is so little of that in respect of the 
great masses that move in those spaces, that it is as much as nothing.

These masses of matter are, either luminous, or opaque or dark.

Luminous bodies, are such as give light of themselves; and such are the sun, and the fixed stars.

Dark or opaque bodies, are such as emit no light of themselves, though they are capable of reflecting it, when it is cast upon them from other bodies: and such are the planets.

There are some opaque bodies, as for instance the comets, which besides the light, that they may have from the sun, seem to shine with a light that is nothing else but an accension, which they receive from the sun, in their near approaches to it, in their respective revolutions.

The fixed stars are so called, because they always keep the same distance one from another.

On a view of the visible system of nature, by us called the universe, the grandest and most admired object is the great luminary of day. Its splendour, its heat, and its beneficial influence have always 
excited the particular attention of the human species, and have obtained the adoration of all thóse nations which have not been blessed with revelation.

Those who are not accustomed to astronomical calculation, will be surprized at the real magnitude of this luminary; which, on account of its distance from us, appear's to the eye not much larger than the moon, which is only an attendant on our earth. When looking at the sun, we are viewing a globe, whose diameter is 890,000 English miles; whereas the earth is no more in diameter than 7,970 miles: so that the sun is about $1,392,500$ times bigger than the earth. Thus as it is the fountain of light and heat to all the planets, so it also far surpasses them in its bulk.

The sun has several spots, which are visible on its surface. These spots were entirely unknown before the invention of telescopes, though they are sometimes of sufficient magnitude to be discerned by the naked eye. There is a great variety in their magnitudes; some have been so large, as by computation to be capable of covering the continents of Asia and Af- 
rica ; nay, the whole surface of the earth, or even five times its surface.

The nature and formation of the solar spots have been the subject of much speculation and conjecture. The latest observations on them, and on the nature and construction of the sun, are those of Dr. Herschel : he considers the sun as a most magnificent habitable globe, surrounded by a double set of clouds. Those which are nearest its opaque body, are less bright, and more closely connected together than those of the upper stratum, which form the luminous apparent globe we behold. This luminous external matter is of a phosphoric nature, having several accidental openings in it, through which we see the sun's body, or the more opaque clouds beneath. Those openings form the spots we see.

Next to the sun, the moon is the most splendid and shining globe in the heavens; and by dissipating, in some measure, the darkness and the horrors of the night ; subdividing the year into months, and regulating the flux and reflux of the sea, she not only becomes a pleasing, but 
a welcome object ; affording much for speculation to the contemplative mind, and of real use to the navigator, the traveller, and the husbandman. The Hebrews, the Greeks, the Romans, and in general, all the ancients, used to assemble at the time of the new moon, to discharge the duties of piety and gratitude for its manifold uses.

When we view this attendant on our earth in its nightly course, we seldom form an adequate idea either of its magnitude, or its motion. While it seems to take some hours in getting half a yard from a star which it touched, we never reflect that this is an immense mass of matter, of 2180 miles in diameter, driving through the heavens at the rate of considerably more than two thousand miles an hour, which is more than double of that with which a ball is shot off from the mouth of a cannon.

The face of the moon is greatly diversified with inequalities, and parts of different colours, some brighter, and some darker than the other parts of her disk. When viewed through a telescope, her face is evidently diversified with hills and valleys : and the same is also shewn by 


\section{The Universè.}

the edge or border of the moon appearing jagged, when so viewed, especially about the confines of the illuminated part when the moon is either horned or gibbous.

M. Schroeter, of the Royal Society of Gottingen, in the year 1792 , seems to have taken great pains to investigate the truth of this matter. According to him, the surface of the moon appears to be much more unequal than that of our earth; and these inequalities have great varicty both in form and magnitude. There are large irregular plains, on which are observed. long and narrow strata of hills running in a serpentine direction: some of the mountains form extensive chains; others, which are in general the highest, stand alone, and are of a conical shape: some have craters ; others form a circular ring inclosing a plain. The most lofty mountain on the surface of our globe is supposed to be Chimboraco, which is not twenty thousand feet in height : but there are many in the moon which are much higher: that which is distinguished by the name of Leibnitz, is not less than 25,000 feet. 
The craters of the moon are circular. and surrounded with an annular bank of hills : they are remarkable for their width, many of them being from four to fifteen geographical miles in diameter : some are not deeper than the level of the moon's surface ; others are 9000, 12,000, and 15,000 feet in depth; that of one which M. Schroeter calis Bernouilli, is above 18,000 feet.

On the face of the moon are likewise volcanoes which appear to the observer as lighted coals, and illuminate the neighbouring mountains.

With respect to the nature and construction of the moon and the probability of its being inhabited, Dr. Herschel, in his papers published in the Philosophical Transactions of 1795 , concludes, after tracing the great similarity between it and the earth, as follows: "There seems only to be wanting, in order to complete the analogy, that it should be inhabited. To this it may be objected, that we perceive no large seas in the moon; that its atmosphere (the existence of which has even been doubted by many) is extremely rare, and unfit for the purposes of ani- 
mal life ; that its climates, its scasons, and the length of its days, totally differ from ours; that without dense clouds (which the moon has not) there can be no rain; perhaps no rivers, no lakes. In short, that, notwithstanding the similarity which has been pointed out, there seems to be a decided difference in the two planets we have compared. My answer to this will be, that that very difference which is now objected will rather strengthen the force of my argument than lessen its value; we find, even upon our globe, that there is the most striking difference in the situation of the creatures that live upon it. While man walks upon the ground, the birds fly in the air, and fishes swim in water; we can certainly not object to the conveniences afforded by the moon, if those that are to inhabit its regions are fitted to their conditions as well as we on this globe are to ours. An absolute or total sameness seems rather to denote imperfections, such as nature never exposes to ourview; and, on this account, I believe the antiogies that have been mentioned fully sufficient to establish the high probability of the moon's being inhabited like the earth." 
- Lastly of the earth on which we dwell. Speck as this may appear in the immensity of creation, it is nevertheless to us of the highest importance; we only wish to obtain a knowledge of other planets and systems, that we may find out their relation to this, and from thence learn our connection with the universe at large.

The external part of the earth either exhibits inequalities, as mountains and valleys; or it is plane and level; or dug in channels, fissures, beds, \&c. for rivers, lakes, seas, \&c.- These inequalities in the face of the globe most naturalists suppose have arisen from a rupture or subversion of the earth, by the force either of the subterraneous fires or waters. The earth in its natural and original state, it has been supposed by Des Cartes, and after him Burnet, Steno, Woodward, Whiston and others, was perfectly round, smooth, and equable; and they account for its present rude and irregular form, principally from the great deluge; but from whatever cause those inequalities may have arose, or at what period, they seem a necessary part of the economy of 


\section{The Universe.}

nature. It is the intermediate space between the mountain's top and the seashore that forms the habitation of plants and animals. - While there is sea-shore and high ground, there is that which is required in the system of the world; take that away, and there would remain an aqueous globe in which the world would perish.

What the internal or central part of the earth is composed of is utterly unknown to us, though many opinions have been formed respecting it ; the utmost depth to which it hath been penetrated by human art not being more than 2400 feet, or less than half a mile, which, when compared with the length of the diameter, is a very short distance indeed. From its mean density, however, which is to that of water as 9 to 2 , and to common stone as 9 to 5 , it is presumed that it contains great quantities of metals.

The figure of the earth is that of a spheroid, having its equatorial diameter longer than its polar diameter. It is consequently flattest at the poles, and more protuberant at the equator.

With respect to the magnitude of the C2 
earth, this has been variously determined by different authors, both ancient and modern.- The following dimensions may be taken as near the truth.

The circumference . 25,000 miles. The polar diameter • 7893 miles, The equatorial diameter $r 928$ miles, The superficies $198,944,206$ sq. miles, The solidity $263,930,000,000$ cubic $\mathrm{m}$. Also the seas, and unknown parts of the earth, by a measurement of the best maps, contain 160,522,026 square miles; the inhabited parts, $38,922,180$; of which Europe contains $4,4.56,065$; Asia, 10,768,823; Africa, 9,654,807; and America, $14,110,874$ square miles.

Of the divisions of the Earth.-In taking a view of the terraqueous globe the most obvious divisions that present themselves, are those that are sketched by the yielding water on the crooked shore, called continents, islands, seas, \&c.

A continent is a large tract of land not separated by the sea; as Europe, Asia, \&c. An ocean is a vast collection of water not separated by land; as the Atlantic, Pacific, \&c. - A sea is a smaller collection of water communicating with the 
ocean; as the Mediterranean, the Baltic. An island is a tract of land surrounded by water ; as Great Britain, Ireland, \&c. A lake is water surrounded by land; as the Lake of Geneva.

A cape or promontory is a point of land running far into the sea; as the Cape of Good Hope. A bay is a part of the ocean running far into the land; as the Bay of Biscay.

A peninsula is land almost surrounded with water; as the Morea. A gulph is a part of the sea almost surrounded with land; as the Gulph of Venice.

An isthmus is the narrow part of land which joins the peninsula to any country; as the Isthmus of Suez. A Strait is a narrow passage from one sea to another; as the Strait of Gibraltar.

The earth is also divided into four quarters; Europe, Asia, Africa, and America.

Besides these, there are other divisions of a more varying character ; such are the political boundaries that separate kingdoms and empires.

Kingdoms, provinces, towns, \&c. are divisions of the earth that change with the 
36 The Universe.

affairs of the nations that have made them; and accordingly in different ages, they alter their appearances. 
Solar System.

\section{CHAP. III.}

\section{Of the Solar System.}

OUR solar system consists of the sun, and the planets, and comets moving about it.

The planets are bodies which appear to us like stars; not that they are luminous bodies, that is, have light in themselves; but they shine by reflecting the sun.

They are called planets from a Greek word, which signifies wandering; because they change their places, and do not always keep the same distance with one another, nor with the fixed stars, as the fixed stars do.

There are two kinds of planets, prima$r y$ and secondary. The first move round the sun, and respect him only as the center of their motions. The secondary planets, called also satellites, or moons, are smaller planets, revolving round the 
primary, while they, with the primary planets about which they move, are carried round the sun. The planets move round the sun at various distances, some being much nearer to him than our earth, and others being much further off.

There are nine primary planets, which are situated with respect to their distances from the sun as follows:
૪̧
q
$\oplus$
$\pi$

Mercury, Venus, The Earth, Mars, Ceres, Pallas, $4 \quad h$

Fupiter, Saturn, and Herschel, or the Georgium Sidus.

Of these, our earth is accompanied by one moon, Jupiter has four moons, Saturn has seven moons, and the Georgium planet has six moons. None of these moons, except our own, can be seen without a good telescope. The other five planets do not appear to have any satellites or moons.

All the planets move round the sur from west to east, and in the same direction do the moons revolve round their primaries, excepting those of the Georgium planet, which seem to move in a contrary direction. The paths in which they move round are called their orbits. 


\section{Solar System. $\quad \rightarrow \quad 39$}

They perform their revolutions also in very different periods of time. The time of performing the ir revolutions round the sun is called their year, and the time of performing their revolutions on their axes their day.

The axis of a planet is an imaginary line conceived to be drawn through its center, about which it revolves as if on a real axis. The extremities of this line, terminating in opposite points of the planet's surface are called its poles. A bowl whirled from one's hand into the open air turns round such a line within itself, whilst it moves forward; and such are the lines we mean when we speak of the axes of the heavenly bodies.

Venus and Mercury being nearer to the sun than our earth, are called inferior planets, and all the rest, which are without the earth's orbit, are called superior planets.

The sun is placed near the common center, or rather in the lower* focus of

* If a thread be tied loosely round two pinz stuck in a table, and moderately stretched by the point of a black-lead pencil carried round by an even motion and light pressure of the hand, ais 
the orbits of all the planets and comets, and turns round his axis in 25 days 6 hours, as is evident by the motion of spots seen on his surface. By the various attractions of the circumvolving planets, he is agitated by a small motion. round the center of gravity of the system.

Let us suppose the earth's orbit to be a thin, even, solid plane; cutting the sun through the center, and extended out as far as the starry heavens, where it will mark the great circle called the Ecliptic. This circle we suppose to be divided into 12 equal parts, called Signs; each sign into 30 equal parts, called Degrees; each degree into 60 equal parts called Minutes; and every minute into 60 equal parts, called Seconds; so that a second is the 60 th part of a minute; a minute the 60th part of a degree; and a degree the $360 \mathrm{th}$ part of a circle, or 30 th part of a Sign. The planes of the orbits of all the other

oval ellipsis will be described; the two points where the pins are fixed being called the foci or focuses thereof. The orbits of all the planets are elliptical, and the sun is placed in or near one of the foci of each of them; and that in which he is placed is called the lower focus. 


\section{Solar System.}

planets likewise cut the sun in halves; but extended to the heavens, form circles different from one another, and from the ecliptic; one half of each being on the north side, and the other on the south side of it. Consequently the orbit of each planet crosses the ecliptic in two opposite points, which are called the planet's Nodes.

Mercury is the first planet in the order of the system. It is computed to be about $37,000,000$ miles distant from the sun, and to move at the rate of 105,000 miles an hour, completing its orbit in about 88 of our days, or little less than three months, which is the length of its year. It is not much larger than the moon, being about 3200 miles in diameter.

Venus is the second planet from the sun, remarkable for its brightness, it is computed to be $68,000,000$ miles from it, and to move round it at the rate of 76,000 miles an hour, completing its annual revolution in 224 days 17 hours, or above $7 \frac{1}{2}$ months. Its diameter is 7700 miles, and its diurnal revolution is performed in 23 hours 22 minutes. 
When it is to the west of the sun, it is a morning star; when to the east, it is an evening star.

Our Earth is the third planet in the order of our system. Its diameter is 7970 miles, and it turns round on its axis in the course of a day. Its distance from the sun is $95,000,000$ miles, and moves at the rate of 58,000 miles an hour, completing its orbit in the course of a year.

Mars is the fourth planet from the sun, from which it is distant about $144,000,000$ miles. It moves at the rate of 55,000 miles an hour, and completes its orbit in a little less than two of our years. Its diameter is 4200 miles, and its rotation on its axis is performed in about 24 hours and 39 minutes.

Cieres Ferdinandea is the fifth planet from the sun. Its diameter is $\mathbf{1 6 0}$ miles, and its distance from the sun is $260,000,000$ miles. It was discovered. on the first day of the present century by IMr. Piazzi, an Italian astronomer.

Pallas is the sixth planet in the order of the system. It was discovered by Dr. Olbers of Bremen, on the 28th of March, 1802. Its distance from the sun 


\section{Solar System.}

is $266,000,000$ miles, and its diameter 80 miles.

This planet and the last Dr. Herschel proposes to call asteroids, because they are so much smaller than any of the other planets.

Fupiter is the seventh planet in the order of our system, and the largest that has yet been discovered, being nearly a thousand times as large as our earth. $\mathrm{He}$ is computed to be about $490,000,000$ miles from the sun, to go at the rate of 29,000 miles an hour, and to be 89,000 miles in diameter. He finishes his annual period in eleven of our years 314 days and 12 hours, and turns round his axis in 9 hours 56 minutes: so that his year contains 10,470 days. From this planet's turning so swiftly on its axis, its figure is more oblate than that of the earth, being more than six thousand miles longer in its equatorial than in its polar diameter; this swiftness of its diurnal motion also draws its clouds and vapours into streaks or lines over its equatorial parts, forming what is called Jupiter's belts.

Saturn is the eighth planet from the 
sun, and is about $900,000,000$ miles distant from it ; it is carried along its orbit at the rate of 22,000 miles an hour, which it completes in $29^{1}$ of our years. Its diameter is computed to be 79,000 miles ; its rotation on its axis has been discovered by Herschel to be completed in about ten hours and a quarter. There is a ring, or a broad circular arch, encompasses the body of this planet, without touching it, somewhat similar to the wooden horizon of an artificial globe ; only that the interior space occupied by the planet is very considerable. It is about 21,000 miles in breadth; which is equal to its distance from Saturn on all sides. It appears like a large luminous arch in the heavens, as if it did not belong to the planet.

Herschel is the ninth planet in the order of our system, and is twice as far distant as Saturn from the sun, and will be nearly 83 years in going round it. It is ninety times as large as the earth, and is visible to the naked eye on a clear evening, if the moon be absent.

These with their moons we consider as the regular bodies of our system, so 


\section{Solar System.}

regular indeed, that their phenomena may be pretty exactly calculated for ages. There may be other planets, which human observation has not yet discovered, and which, perhaps, it never may.

All the planets move nearly in the direction of the ecliptic; and that space on each side of it, which bounds their utmost deviations, is called the Zodiac. It is a broad circle or belt in the starry heavens; and is about 16 degrees in breadth, and the ecliptic equally divides it in two all round, so that the planets are always found amongst some of the contellations, which form the twelve signs of the zodiac.

The reason of their motions in curve lines, is the attraction of the sun, or their gravitations towards the sun (call it which you please;) and an oblique or side-long impulse or motion ; the former is commonly called the centripetal force, and the latter the centrifugal force.

These two motions or tendencies, the one always endeavouring to carry them in a straight line from the circle they move in, and the other endeavouring to draw 
them in a straight line to the sun, make that a curve line they revolve in.

From the great analogy there is between the other planets and our earth it is generally supposed by astronomers that they are inhabited, and indeed we can never bring ourselves to think, that an infinitely wise Creator should dispose of all his animals and vegetables here, leaving the other magnificent planets, with all their noble attendance of moons, bare and destitute of rational creatures. To suppose that he had any view to our benefit, in creating these moons, and giving them their motions round Jupiter, $\mathrm{Sa}-$ turn and Herschel; to imagine that he intended these vast bodies for any advantage to us, when he well knew that they could never be seen but by a few astronomers peeping through telescopes; and that he gave to the planets regular returns of days and nights, and different seasons to all where they would be convenient; but of no manner of service to us, except only what immediately regards our own planet the earth; to imagine that he did all this on our account, would be charging him impiously with having 


\section{Solar System.}

done much in vain; and as absurd, as to imagine that he has created a little sun and a planetary system within the shell of our earth, and intended them for our use. These considerations amount to little less than a positive proof, that all the planets are inhabited; for if they are not, why all this care in furnishing them with so many moons, to supply those with light which are at the greater distances from the sun? Do we not see, that the farther a planet is from the sun, the greater apparatus it has for that purpose? save only Mars, which being but a small planet, may have moons too small to be seen by us. We know that the earth goes round the sun, and turns round its own axis, to produce the vicissitudes of summer and winter by the former, and of day and night by the latter motion, for the benefit of its inhabitants. May we not then fairly conclude, by parity of reason, that the end and design of all the other planets is the same? and is not this agreeable to the beautiful harmony which exists throughout the universe? Surely it is; and raises in us the most magnificent ideas of the Supreme Being, 
who is every where, and at all times present; displaying his power, wisdom and goodness among all his creatures! and distributing happiness to innumerable ranks of various beings!

Of Comets.-Of all the celestial bodies, comets have given rise to the greatest number of speculations and conjectures. Their strange appearance has in all ages been a matter of terror to the uninformed, who have generally looked upon them to be evil omens, and forerunners of war, pestilence, \&c.

The existence of an universal connection between all parts of the siderial heavens is now generally admitted. Comets undoubtedly form a part of this great chain; but of the part they occupy, and of the uses for which they exist, we are in a great measure ignorant. It is a portion of science whose perfection is reserved for some distant day, when these bodies, and their vast orbits, may, by long and accurate observation, be added to the known parts of the solar system; when astronomy will appear with new lights, after all our discoveries, great as we at 
present imagine them to be. Upon the whole, the astronomy of comets is very imperfect; for but little can be known with certainty where but little can be seen. Comets afford few observations. on which to ground conjecture, and are for the greatest part of their course beyond the reach of human vision.

Like the planets, they are observed to be opaque bodies, shining only by the influence of the sun, and like them are carried along in their orbits, by the combination of the centripetal and centrifugal forces ; sometimes seeming to go forwards, sometimes backwards, and some times to be stationary. The great eccentricity of their orbits make them liable to suffer considerable alterations, from the attraction of the planets, and of each other.

They are called comets, from their having a long tail, somewhat resembling the appearance of hair. This, however, is not always the case ; for some comets have appeared, which were as well defined, and as round as planets; but in general, they have luminous matter diffused around them, or projecting out from them. 
50

Solar System.

From the beginning of our era to this time, it is probable, according to the best accounts, that there have appeared about 500 comets. Before that time about 100 others are recorded to have been seen, but it is probable, that not above half of them were comets. And, when we consider, that many others may not have been perceived, from being too near the sun, from appearing in moonlight, from being in the other hemisphere, from being too small to be perceived, or which may not have been recorded, we might imagine the whole number to be considerably greater: but it is likely, that of the comets $w$ hich are recorded to have been seen, the same may have appeared several times, and therefore the number may be less than is here stated.

Of the Moon.-The moon goes round the earth from change to change in 29 days 12 hours and 4.4 minutes ; and round the sun with it every year. The moon's diameter is 2180 miles; and her distance from the earth's center 240,000 miles. She goes round her orbit in 27 days 7 hours 43 minutes, moving about 


\section{Solar System.}

2290 miles every hour; and turns round her axis exactly in the time that she goes round the earth, which is the reason of her keeping always the same side towards us, and that her day and night taken together is as long as our lunar month.

The moon is an opaque globe like the earth, and shines only by reflecting the light of the Sun; therefore whilst that half of her which is towards the sun is enlightened, the other half must be dark and invisible. Hence she is incessantly varying her appearance; sometimes she looks full upon us, and her visage is all lustre; sometimes she shews only half her enlightened face, soon she appears as a radiant crescent, in a little time all her brightness vanishes, and she becomes a beamless orb. The full moon, or opposition, is that state in which her whole disk is enlightened, and we see it all bright, and of a circular figure. The new moon is when she is in conjunction with the sun ; in this state, the whole surface turned towards us is dark, and is therefore invisible to us. The first quarter of the moon she appears in the form of a semicircle, whose circumference is 
turned towards the west. At the last quarter she appears again under the form of a semicircle, but with the circumference turned towards the east. These phases may be illustrated in a very pleasing manner, by exposing an ivory ball to the sun, in a variety of positions, by which it may present a greater or small- er part of its illuminated surface to the observer. If it be held nearly in opposition, so that the eye of the observer be almost immediately between it and the sun, the greatest part of the enlightened side will be seen; but if it be moved in a circular orbit, towards the sun, the visible enlightened part will gradually decrease, and at last disappear, when the ball is held directly towards the sun. Or to apply the experiment more immediately to our purpose ; if the ball, at any time when the sun and moon are both visible, be held directly between the eye of the observer and the moon, that part of the ball on which the sun shines, will appear exactly of the same figure as the moon itself.

The moon has scarce any difference of seasons ; her axis being almost perpen- 
dicular to the ecliptic. What is very singular, one half of her has no darkness at all ; the earth constantly affording it a strong light in the sun's absence; while the other half has a fortnight's darkness and a fortnight's light by turns.

Our earth is a moon to the moon, waxing and waning regularly, but appearing thirteen times as big, and affording her thirteen times as much light, as she does to us. When she changes to us, the earth appears full to her; and when she is in her first quarter to us, the earth is in its third quarter to her; and vice versa.

Of Eclipses.-When any of the heavenly bodies is obscured or darkened by the shadow of another falling upon it, or by the interposition of any body, it is said to be eclipsed.

An eclipse of the moon is, when the earth, being between the sun and the moon, hinders the light of the sun from falling upon and being reflected by the moon. If the light of the sun is kept off from the whole body of the moon, it is a total eclipse ; if from a part only, it is a partial one. 
An eclipse of the sun is, when the moon, being between the sun and the earth, hinders the light of the sun from coming to us. If the moon hides from us the whole body of the sun, it is a total eclipse, if not, a partial one.

The eclipses of the sun and the moon, though expressed by the same word, are in nature very different; the sun, in reality, loses nothing of its native lustre in the greatest eclipses, but is all the while incessantly sending forth streams of light every way around him, as copiously as before. Some of these streams are, however, intercepted, in their way towards our earth, by the moon coming between the earth and the sun ; and the moon having no light of her own, and receiving none from the sun on that half of the globe which is towards our eye, must appear dark, and make so much of the sun's disk appear so, as is hid from us by her interposition. What is called an eclipse of the sun, is therefore, in reality, an eclipse of the earth, which is deprived of the sun's light, by the moon's coming between, and casting a shadow upon it. The earth being a globe, only that half 


\section{Solar System.}

it, which at any time is turned towards the sun, can be enlightened by him at that time: it is some part of this enlightened half of the earth that the moon's shadow falls on in a solar eclipse.

In any year the number of eclipses of both luminaries cannot be less than two, nor more than six. Eclipses of the sun are more frequent than of the moon, because the sun's ecliptic limits are greater than the moon's; yet we have more visible eclipses of the moon than of the sun, because eclipses of the moon are seen from all parts of that hemisphere of the earth which is next them, and are equally great to each of those parts ; but' the sun's eclipses are visible only to that small portion of the hemisphere where the moon's shadow falls.

An eclipse of the moon can never happen but at the time of full moon.

An eclipse of the sun always begins on the western, and ends on the eastern side ; because the moon, moving in her orbit from west to east, necessarily first arrives and touches the sun's western limb, and goes off at the eastern; that of the 
56

moon commences at the eastern and ends at the western.

The Satellites, or moons, are often eclipsed by the planets to which they belong.

A digit is the 12 th part of the sun or moon's diameter, and is a term often used in speaking of eclipses. The disk of the sun or moon is its round face, which, on account of the great distance of the object, appears flat. The edge or border of the disk is called the limb.

The immersion of a heavenly body, is the time when an eclipse begins; itc emersion is when it begins to re-appear. 


\section{CHAP. IV.}

\section{Of the Fixed Stars.}

NO part of the universe affords such exalted ideas of the structure and magnificence of the heavens, as the consideration of the number, magnitude, nature, and distance of the fixed stars. We admire indeed, with propriety, the vast bulk of our own globe; but, when we consider how much it is surpassed by most of the heavenly bodies, what a poin $t$ it degenerates into, and how little more even the vast orbit in which it revolves would appear, when seen from some of the fixed stars, we begin to conceive more just ideas of the extent. of the universe, and of the infinity of creation.

The fixed stars comprehend all the celestial objects, excepting the sun, the moon, and the planets, and some comets which now and then appear. 
The stars, on account of their apparently various magnitudes, have been distributed into several classes or orders. Those which appear largest, are called stars of the first magnitude; the next to them in lustre, stars of the second magnitude; and so on to the sixth, which are the smaliest that are visible to the bare eye. This distribution having been made long before the invention of telescopes, the stars which cannot be seen without the assistance of these instruments, are distinguished by the name of telescopic stars.

They are likewise distinguished, with regard to their situation, into asterisms, or constellations; which are nothing but assemblages of several neighbouringstars considered as constituting some determinate figure, as of an animal, \&c. from which it is therefore denominated.

The number of constellations in the northern hemisphere is 35 ; in the southern 32 ; and in the ecliptic 12. Those stars which are not included in the constellations, are called unformed stars; those clusters of stars which are so distant as not to be distinctly seen, are, from their cloudy appearance, comprised un- 
der the name of nebulce; and that lightcoloured irregular circle or band which encompasses the heavens, and is distinguishable from the etherial blue by its brilliancy; that shining zone, which owes its splendour to the innumerable stars of which it is formed, and which passes through many of the constellations in its ample range, is called the Galaxy, the via lactea, or the milky way.

The idea of classing the stars under well known forms probably originated with the Egyptian shepherds, who during the silent watches of the night (as they slept in the open air) had no other objects to contemplate than those which the starry heavens presented; among these, assisted by the powers of a fertile imagination, they discovered a distant resemblance of such things as they were most familiar with. The shepherds thus conceiving the figures of things in the firmament, the poets embellished the ilIusion with the fictions of mythology, tili the heavens were, as it were, filled with these imaginary creatures, and these. were increased in after ages, and served astronomers in their accounts of the star- 
60

ry heavens, as the present divisions of the earth help geographers in the description of the globe.

The twelve constellations which surround the ecliptic, commonly called the twelve signs of the zodiac, are the following-Aries the Ram, Taurus the Bull, Gemini the Twins, Cancer the Crab, Leo the Lion, Virgo the Virgin, Libra the Balance, Scorpio the Scorpion, Sagittarrius the Archer, Capricormus the Goat, Aquarius the Water-bearer, and Pisces the $F$ ishes; and they are noted on globes, \&c. in the following manner :-

Aries. Taurus. Gemini. Cancer. Leo. Virgo,-Libra. $\gamma \gamma$ II $\sigma 0 \Omega$ mर $\cong$

Scorpio. Saggittarrius. Capricornus. Aquarius. Pisces. m 7 vo $\mathrm{m}_{m} \quad \forall$

The former six are called northern, and the latter southern signs; because the former possess that half of the ecliptic which lies to the northward of the equinoctial; and the latter that which lies to the southward. The northern are our summer signs, the southern our winter ones.

As these twelve signs answer to the twelve months in the year, it is a very 


\section{Fixed Stars.}

probable conjecture that the figures under which they are represented are descriptive of the seasons of the year, $\mathrm{Or}^{2}$ months, in the sun's path; thus, the first sign Aries, denotes, that, about the time when the sun enters that part of the ccliptic, the lambs begin to follow the sheep; that on the Sun's approach to the second constellation, Taurus the Bull, is about the time of the cows bringing forth their young. The third sign, now Gemini, was originally two kids, and signified the time of the goats bringing forth their young, which are usually two at a birth, while the former, the sheep and cow, commonly produce only one. The fourth sign, Cancer, the Crab, an animal that goes side-ways and backwards, was placed at the northern solstice, the point where the sun begins to return back again from the north to the southward. The fifth sign, Leo, the Lion, as being a very furious animal, was thought to denote the heat and fury of the burning sun, when he has left Cancer, and entered the next sign Leo. The succeeding constellation, the sixth in order, received the sun at the time of ripening corn and approaching 
harvest; which was aptly expressed by one of the female reapers, with an ear of corn in her hand, viz. Virgo, the Maid. The ancients gave to the next sign, Scorpio, two of the twelve divisions of the zodiac ; autumn, which affords fruits in great abundance, affords the means and causes of diseases, and the succeeding time is the most unhealthy of the year ; expressed by this venomous animal, here spreading out its long claws into one sign, as threatening mischief, and in the other brandishing his tail to denote the completion of it. The fall of the leaf was the season of the ancient hunting; for which reason the stars which marked the sun's place at this season, into the constellation Sagittary, a huntsman with his arrows and his club, the weapon of destruction for the large creatures he pursued. The reason of the Wild Goat's being chosen to mark the southern solstice, when the sun has attained his extreme limit that way, and begins to return and mount again to the northward, is obvious enough; the character of that animal being that it is mostly climbing, and ascending some mountain, as it browses. There yet re- 
main two of the signs of the zodiac to be considered with regard to their origin, viz. Aquarius and Pisces. As to the former, it is to be considered that the winter is a wet and uncomfortable season ; this therefore was expressed by Aquarius, the figure of a man pouring out water from an urn. The last of the zodiacal constellations was Pisces, a couple of fishes tied together, that had been caught; the lesson was, The severe season is over; your flocks do not yet yield their store, but the seas and rivers are open, and there you may take fish in abundance.

With respect to the distances of the fixed stars, they are so extremely remote, that we have no distances in the planetary system to compare to them.

The distance of the star Draconis (a star of the fifth magnitude) appears, by Dr. Bradley's observations, to be at least 400,000 times that of the sun, and the distance of the nearest fixed star not less than 4.0,000 diameters of the earth's annual orbit ; that is, the distance from the earth, of the former at least $38,000,000$,000,000 miles, and the latter not less than 
G*

Fixed Stars.

$7,600,000,000,000$ miles. As these distances are immensely great, it may both be amusing, and help to a clearer and more familiar idea, to compare them with the velocity of some moving body, by which they may be measured.

The swiftest motion we know of, is that of light, which passes from the sun to the earth in about eight minutes; and yet this would be above six years traversing the first space, and near a year and a quarter in passing from the nearest fixed star to the earth. But a cannon-ball, moving on a medium at the rate of about twenty miles in a minute, would be $3,800,000$ years in passing from Draconis to the earth, and 760,000 years passing from the nearest fixed star. Sound, which moves at the rate of about thirteen miles in a min. would be $5,600,000$ years traversing the former distance, and $1,128,000$ in passing through the latter. The celebrated Huygens pursued speculations of this kind so far, as to believe it not impossible, that there may be stars at such inconceivable distances, that their. light has not yet reached the earth since the creation. 
Though the number of the stars appears to be immensely great; yet have astronomers long since ascertained the number of such as are visible to the eye, which are much fewer than at first sight could be imagined. Of the 3000 contained in Flamstead's catalogue, there are many that are only visible through a telescope; and a good eye scarcely ever sees more than a thousand at the same time in the clearest heaven; the appearance of innumerable more, that are frequent in clear winter nights, arising from our sight's being deceived by their twinkling, and from our viewing them confusedly, and not reducing them to any order. But a good telescope, directed indifferently to almost any point of the heavens, discovers multitudes that are lost to the naked eye ; particularly in the milky way. And F. de Rheita affirms, that he has observed above 2000 stars in the single constellation of Orion. The same author found above 188 in the Pleiades. Galileo found eighty in the space of the belt of Orion's sword, twenty-one in the nebulous star of his head, and above 500 in another part of him, within the com- 
66

Fixed Stars.

pass of one or two degrees of space, and more than forty in the nebulous star Prrsepe, and the recent discoveries of Dr. Herschel have proved the fixed stars to be immense, their regions unbounded, and perhaps infinite!

As the stars, contrary to the moon and planets, shine like our sun, by their own native light, astronomers suppose that each of them is a sun, with its system of inhabited worlds revolving round it. Under this idea or persuasion, of how innumerable a family do we seem to make a part! The immensity of the universe becomes peopied with fellow beings, and we feel an interest in what appears to be going on at distances so vast, that what we see, as in time present, we have reason to believe (swift, as is the progress of light, darting from the spheres) must have happened many ages ago. Under the idea of the universe being replenished with human beings, how magnificent, how awful, are the spectacles that present themselves to the observer of the heavens! The creature of a day, of a few fleeting moments, seems to obtain a glimpse of a nęw creation, a glimpse of 


\section{Fixed Stars.}

the end of time, in the passing away of a system.

What an amazing conception, if human imagination can conceive it, does this give of the works of the Creator! Thousands of thousands of suns, multiplied without end, and ranged all around us, at immense distances from each other, attended by ten thousand times ten thousand worlds, all hung loose, as it were, in boundless space,-upheld by nothing, confined by nothing, -yet preserved in their rapid course, calm, regular and harmonious, invariably keeping the paths assigned them by the sovereign Artificer. 
68 The Earth considered as a Planet.

\section{$=$ \\ CHAP. V.}

Of the Earth considered as a Planet.

THE Earth goes round the sun in 365 days 5 hours 49 minutes, from an equinox or solstice to the same again; but from any fixed star to the same again, as seen from the sun, in 365 days, 6 hours and nine minutes; the former being the length of the tropical year, and the latter the length of the sidereal.

The motion of the earth in common with the rest of the planets about the sun, is in the order of the signs of the zodiac; that is, from west to east. This zone or belt, as has been mentioned, goes round the heavens; and along the middle. of it is the ecliptic, or circle which the earth describes annually as seen from the sun; and which the sun appears to describe as seen from the earth.

Besides this annual revolution of the earth about the sun, in the ecliptic; the 
The Earth considered as a Planet. 69

earth turns round upon its own axis in 24. hours.

The turning of the earth upon its own axis every 24. hours, whilst it moves round the sun in a year, we may conceive by the running of a bowl on a bowling green; in which not only the center of the bowl hath a progressive motion on the green; but the bowl in its going forward, from one part of the green to another, turns round about its own axis.

The turning of the earth on its axis, makes the difference of day and night; it being day in those parts of the earth, which are turned towards the sun; and night in those parts which are in the shade, or turned from the sun.

The annual revolution of the earth in the ecliptic, is the cause of the different seasons, and of the several lengths of days and nights, in every part of the world, in the course of the year.

But before we enter upon the more particular illustration of the diurnal and annual motions of the earth, together with the different lengths of days and nights, and all the beautiful variety of seasons, depending on those motions, it 


\section{The Earth considered as a Planet.}

may be necessary to make the reader acquainted with the principle circles of the globe, as they will greatly assist him in comprehending those phenomena.

This information he may attain sufficiently for his present purpose in a quarter of an hour, if he sets the ball of a terrestrial globe before him, or looks at the figure of it, wherein these circles are drawn and named.

The Poles are the two extremities of the earth's axis; or those points where the imaginary line, round which it performs its daily revolutions, meets the earth's surface; that which is directed towards the most northern point of the heavens, being called the north pole; and that which is directed towards the most southern point, the south pole; so that they are diametrically opposite to each other, and always preserve the same relative situation. It is also to be observed, that these two points have not been arbitrarily assumed by geographers and astronomers, to answer their particular purposes, as they are pointed out to us by the nature and constitution of the globe, and are easily distinguished from all 
The Earth considered as a Planet. 71

others. The nearer we approach to them, the more we find the earth becomes barren and inhospitable; so that, under the poles, the cold is so excessive, that the country must be nearly uninhabitable. Imagine now a circle to be drawn round the globe, exactly in the middle, between these two points, and this will be the Equator; which, properly speaking, is a great circle of the earth, that separates the northern from the southern hemisphere, and is every where at an equal distance from the poles. This circle is also no less remarkable, on account of its situation, than the poles; the heat being here almost as intense as the cold is there. Every place is said to have north or south latitude as it is on the northern or southern side of this great circle.

The Tropics are lesser circles parallel to the equator, and each of them is $23 \frac{1}{2}$ degrees from it; a degree in this sense being the 360 th part of any great circle which divides the earth into two equal parts. The northern tropic touches the ccliptic at the beginning of Cancer, and is thence called the Tropic of Cancer; the southern tropic, touching the ecliptic 


\section{The Earth considered as a Planet.}

at the beginning of Capricorn, is therefore called the Tropic of Capricorn.

The Arctic Circle has the north pole for its centre, and is just as far from the north pole as the tropics are from the equator; and the Antarctic Gircle (hid by the supposed convexity of the figure) is just as far from the south pole, every way round. it.

The circles 12.1.2.3. 4. \&c. are meridians to all places they pass through; and we must suppose thousands more to be drawn, because every place that is ever so little to the east or west of any other place, has a different meridian from that other place. All the meridians meet in the poles; and whenever the sun's center is passing over any meridian, in his apparent motion round the earth, it is mid-day or noon to all places on that meridian. The longitude of a place is its distance east or west from the first meridian, reckoned in degrees, minutes, \&c. upon the equator. Supposing we call London the first, it will cut the equator in two opposite points at the distance of one hundred and eighty degrees each way; and as the equator is the boundary 
The Earth considered as a Planet. 73

which separates the northern hemisphere from the southern, so this circle may be considered as the boundary which separates the eastern hemisphere from the western.

Tise broad space lying between the tropics, like a girdle surrounding the globe, is called the Torrid Zone, because the sun is at one time or other perpendicular over every part of it, and extremely torrifies or heats it. The space between the tropic of Cancer and arctic circle is called the North Temperate Zone; that between the tropic of Capricorn and the antarctic circle, the South Temperate Zone: from their enjoying a mean or moderate degree of heat; and the two circular spaces bounded by the polar circles are the two Frigid Zones; so named because of the intense cold which reigns in those regions the greatest part of the year; and they are denominated north or south, from that pole which is in the center of the one or the other of them.

Of the Seasons, $\mathcal{E}^{2} c .-N a t u r e$ is always grand in her designs, sublimity and simplicity are the striking characteristics of 


\section{The Earth considered as a Planet.}

her workmanship. From a few simple principles she produces the most astonishing effects, and charms us no less by the infinite diversity of her operations, than by the skill and contrivance which are manifested in the performance of them. Of all the effects resulting from her laws none is more simple nor more pleasing to a philosophic mind than the provision that is made for the alternate succession of day and night, and the regular return of the seasons. The phenomena depend upon the most simple and evident principle. We have the one merely from the rotation of our globe on its axis, and the other from the inclinaof that axis to the plane of its orbit.

The axis of the earth being inclined $23 \frac{1}{2}$ degrees to the plane of its orbit, makes it, in moving round the sun, have sometimes one of its poles and sometimes the other nearer that luminary.

The absence of the sun's light produces a proportionable degree of cold; hence the seasons are, in the northern and southern parts of the globe, distinctly marked by different degrees of heat and cold. It is this annual turning of the 
The Earth considered as a Planet. 75

poles towards the sun, that occasions the very long days in the northern and southern parts. It is owing to the same cause, that the sun seems to rise higher in the heavens during summer than in winter; and this alternate sinking and rising is perceptible over the whole globe.

In order to illustrate this subject let us now take a view of the earth in its annual course round the sun, considering its orbit as having no inclination; and its axis as inclining $23 \frac{1}{2}$ degrees from a line perpendicular to the plane of its orbit, and keeping the same oblique direction in all parts of its annual course ; or, as commonly termed, keeping always parallel to itself.

In Fig. 2 let $S$ represent the sun, the four globes the earth in different parts of its orbit, receiving from its changing position the varying seasons. $N s$ its axis, $N$ its north pole, $s$ its south pole. As it goes round the sun, according to the order of the signs of the zodiac, its axis $N s$ keeps the same obliquity, and is still parallel to itself.

We shall commence its annual round at the first point of Libra, when the sun, as 


\section{The Earth considered as a Planet.}

seen from the earth will appear to enter Aries. At this time, namely the 20th of March, the sun will be in the equinoctial, and all parts of the earth will be equally enlightened from pole to pole, and the days and nights equal all over the world, for every part comes into the light at six in the morning, and goes into the dark at six in the evening. As the earth passes on in the order of the signs, in about three months, viz. on the 21 st of June, it will arrive at the beginning of Capricorn, and the sun, as seen from the earth, will appear at the beginning of Cancer; during which time, by the inclined position of the earth's axis, the north pole will have gradually advanced into the enlightened hemisphere; so that the whole northern polar circle will be therein, while the southern pole is immerged in obscurity; the northern parts of the world will enjoy long days, while they are short in the southern parts. In this situation of the earth the tropic of Cancer is in the light from five in the morning till seven at night, the parallel of London from a quarter before four till a quarter after eight; and the polar circle just touches the dark, so 


\section{The Earth considered as a Planet. 77}

that the sun has only the lower half of his disk hid from the inhabitants on that circle for a few minutes about midnight.

After this the days begin to shorten in the northern parts of the world, and the nights lengthen in proportion as the earth advances to the first point of Aries, at which it arrives on the $23 \mathrm{~d}$ of September, when the sun, as seen from the earth, will appear in Libra. On this day the sun will be in the equinoctial again, and the days and nights will again be equal all over the globe. As the earth proceeds on its orbit from this point, the north pole gradually goes into the dark ; and the south pole advances into the errlightened hemisphere; and on the $22 \mathrm{~d}$ of December, when the earth enters Cancer, and the sun appears at Capricorn, the north pole will be as far as it can be in the dark, which is $23 \frac{1}{2}$ degrees, equal to the inclination of the earth's axis from a perpendicular to its orbit: and then, the northern parts are as much in the dark as they were in the light on the 21 st of Fune; the winter nights being as long as the summer days, and the winter days as short as the summer nights. 
78 The Earth considered as a Planet.

Thus we see while the earth is moving from Libra through Capricorn to Aries, the north pole remains in the illuminated hemisphere, and will therefore have six months of continual day. But in the other half year, while the earth is moving from Aries through Cancer to Libra, the north pole is turned from the sun, and therefore in darkness, but the south pole is in the illuminated hemisphere. Hence it is easy to perceive, that the inhabitants of the southern hemisphere have the same vicissitudes with those of the northern, though not at the same time, it being winter in one hemisphere when it is summer in the other.

During this annual course of the earth there are four days in her orbit particularly to be remarked; these astronomers have distinguished by the names of the solstitial and equinoctial days. The solstitial days are those on which the sun appears most to the northward and the southward; they are our longest and shortest days, and are called the winter and summer solstices. The equinoctial days are those on which the sun appears in the equator, and the days are equal to 
The Earth considered as a Planet. 79

the nights, which is twice in every annual revolution of the earth, and are called the autumnal and vernal eqiinoxes.

The earth's annual motion causes an apparent daily declination of the sun, or in other words, he appears at different distances from the equator every diurnal turn of the earth on its axis. Thus, about the $22 \mathrm{~d}$ of December, when the earth is in Cancer, the sun will be over the tropic of Capricorn ; and consequently, by the earth's rotation on its axis, the inhabitants of every part of this circle will successively have the sun in their zenith, or, in other words, he will be vertical to them. that day at noon. About the 20th of March the earth is at Libra, and the sun will then appear in Aries ; a central solar ray will terminate upon the surface of the earth in the equator; and therefore the sun appears to be carried round in the celestial equator, and is successively vertical to those who live under that circle. About the 21st of June, when the earth is in Capricorn, a central solar ray terminates on the surface of the earth, in the northern tropic, and for that day the sun appears to be carried round in the tro. 


\section{The Earth considered as a Planet.}

pic of Cancer, and is vertical to those who live under that circle. A About the $23 \mathrm{~d}$ of September the earth is in Aries, and the sun in Libra, and the central solar ray again terminates at the equator ; consequently the sun again appears in the celestial equator, and is vertical to those who live under it.

We have seen, that, as the sun appears to move in the ecliptic, from the vernal equinox to the tropic of Cancer, it gets to the north of the equator, or its declination towards our pole increases. Therefore, from the vernal equinox, when the days and nights are equal, till the sun comes to the tropic of Cancer, our days lengthen, and our nights shorten; but, when the sun comes to the tropic of $\mathrm{Can}$ cer, it is then in its utmost northern limit, and returns in the ecliptic to the equator again. During this return of the sun, its declination tow ards our pole decreases, and consequently the days decrease, and the nights increase, till the sun is arrived in the equator again, and is in the autumnal equinoctial point, when the days and nights will again be equal. As the sun moves from thence towards the tro- 
The Earth considered as a Planet. 81

pic of Capricorn, it gets to the south of the equator; or its declination towards the south pole increases. Therefore, at that time of year, our days shorten, and our nights lengthen, till the sun arrives at the tropic of Capricorn: but, when the sun is arfived there, it is then at its utmost southeren limit, and returns in the ecliptic to the equator again. During this return, its distance from our pole lessens, and consequently the days will lengthen, as the nights will shorten, till they become equal, when the sun is come round to the vernal equinoctial point.

The earth's orbit being elliptical, and the sun constantly keeping in its lower focus, which is $1,377,000$ miles from the middle point of the longer axis, the earth comes twice so much, or 2,754,000 miles nearer the sun at one time of the year than at another: for the sun appearing under a larger angle in our winter than summer, proves that the earth must be nearer the sun in the former season than in the latter. How then does it happen that we have not the hottest weather when we are at the least distance from the sun:-The earth is above $2,000,000$ of 
82 The Earth considered as a Planet.

miles nearer to the sun in December than it is in June, and yet in June it is the middle of summer, and in December the depth of winter, which seems a paradox.

To obviate this apparent contradiction, it may be observed that the eccentricity of the earth's orbit bears no greater proportion to the earth's mean distance from the sun than about 1 to 60 , and therefore this small difference of distance cannot occasion any great variation in the heat and cold of the different seasons. But the principal cause of this difference is, that in winter the sun's rays fall so ob. liquely upon us, that any given number of them is spread over a much greater portion of the earth's surface where we live; and therefore each point must then have fewer rays than in summer.Moreover, there comes a greater degree of cold in the long winter nights, than there can return of heat in so short days; and on both these accounts the cold must increase. But in summer the sun's rays fall more perpendicularly upon us, and therefore come with greater force, and in greater numbers on the same place ; and by their long continuance, a much great- 
The Earth considered as a Planet. 83

er degree of heat is imparted by day than can fly off by night, so that the heat, on all these accounts, will continue to increase.

Thus we see by what simple principles the bountiful Author of Nature has provided us with such a pleasing succession of scenes,-summer, winter, spring, and autumn, lead us insensibly through the varied circle of the year; and are no less pleasing to the mind, than necessary towards bringing to maturity the various productions of the earth. Whether the sun flames in the solstice, or pours his mild effulgence from the equator, we equally rejoice in his presence, and adore that omniscient Being who gave him his appointed course, and prescribed the bounds which he cannot pass.

When by the daily mation of the earth the rising sun comes within 18 degrees of the horizon, we perceive a faint light begin to appear, which increases, and the magnificent theatre of the universe opens gradually to our view - being fully risen, he rides in all his brightness through the vauit of heaven, and approaches the west- 
84. The Earth considered as a Planet.

ern boundary of our sight, when the light begins to decrease, and gradually diminishes till he is 18 degrees below the horizon, when dark night commences. This intermediate light is called the crepusculum, or the morning and evening twilight.

As the sun enlightens only one half of the earth at once as it turns round its axis, he rises to some places at the same moments of absolute time when he sets to others; and when it is mid-day to some places, it is mid-night to others.

To every place 15 degrees eastward from any given meridian, it is noon an hour sooner than on that meridian; because their meridian comes to the sun an hour sooner; and to all places 15 degrees westward, it is noon an hour later because their meridian comes an hour later to the sun, and so on: every 15 degrees of motion causing an hour's differ ence of time. Therefore they who have noon an hour later than we, have their meridian, that is, their longitude, $15 \mathrm{de}-$ grees westward from us: and they who have noon an hour sooner than we, have their meridian 15 degrees eastward from ours; and so for every hour's difference 
The Earth considered as a Planet. 85

of time 15 degrees difference of longitude. Consequently, if the beginning or ending of a lunar eclipse be observed, suppose at London, to be exactly at midnight, and in some other place at 11 at night, that place is 15 degrees westward from the meridian of London; if the same eclipse be observed at one in the morning at another place, that place is $15 \mathrm{de}$ grees eastward from the said meridian.

Of the Precession of the Equinoxes, $\mathcal{E}^{2} \mathrm{c}$. - Beside the changes in the length of the days already described in the different seasons, there is anuther sort of change, not so obviously noticeable. The day and night together, or, in general, 24 hours, form the natural or solar day ; and this period of time also varies in its length. The inequality of the solar day is produced by two causes, either of which singly would yield the effect; these are the obliquity of the ecliptic, and the earth's unequal motion therein. The earth's motion on its axis being uniform and equal at all times of the year, its days would be equal, if its orbit were a perfect circle, and its axis perpendicular to the 


\section{The Earth considered as a Planet.}

plane of its orbit ; but the earth's annual motion in an elliptic orbit, causes the sun's apparent motion in the heavens to be unequal. When the sun's annual motion in the heavens appears slowest, it is noon, or 12 on the sun-dial, before it is the same hour on a true-going clock; and when quickest, it is 12 by the clock before the sun be over our meridian.

Although the earth be said to complete an orbit round the sun in the course of a year, it does not return exactly to the place it set out from, neither is its circuit completed exactly in a year. Aciopting, therefore, the apparent motion instead of the real; if the sun set out as from any star, or other fixed point in the heavens, at the moment it is departing from the equinoctial, or from either tropic, it will come to the same equinox, or tropic again, 20 min. $17 \frac{1}{2}$ sec. of time, or 50 sec. of a degree, betore it completes its circuit round the heavens, so as to arrive at the same fixed star or point from whence it sets out; for the equinoctial points recede 50 seconds of a degree westward every year, contrary to the sun's annual progressive motion. This is called the Precession of the Equinoxes. 


\section{The Earth considered as a Planet. 87}

When the sun arrives at the same equinoctial or solstitial point, he finishes what we call the tropical year; which, by obseryation, is found to contain 365 days 5 hours 4.8 minutes 57 seconds: and when he arrives at the same fixed star again, as seen from the earth, he completes the sidereal year, which contains 365 days 6 hours 9 minutes $14 \frac{1}{2}$ seconds. The sidereal year is therefore $20 \mathrm{~min}$ utes $17 \frac{1}{2}$ seconds longer than the solar or tropical year, and 9 minutes $14 \frac{1}{2}$ seconds longer than the fulian or civil year, which we state at 365 days 6 hours : so that the civil year is almost a mean betwixt the sidereal and tropical.

The anticipation of the equinoxes, and consequently of the seasons, is by no means owing to the precession of the equinoctial and solstitial points in the heavens (which can only affect the apparent motions, places and declinations of the fixed stars) but to the difference between the civil and solar year, which is 11 minutes 3 seconds ; the civil year containing 365 days 6 hours, and the solar year 365 days 5 hours 48 minutes 57 seconds. 
88 The Earth considered as a Planet.

The above 11 minutes 3 seconds, by which the civil or Julian year exceeds the solar, amounts to 11 days in 1433 years, and so much our seasons have fallen back with respect to the days of the months, since the time of the Nicene Council in A.D. 325, and therefore in order to bring back all the fasts and festivals to the days then settled, it was requisite to suppress 11 nominal days. And that the same seasons might be kept to the same times of the year for the future, to leave out the bissextile-day in February at the end of every century of years not divisible by 4; reckoning them only common years, as the 17 th, 18 th, and 19 th centuries, viz. the years $1700,1800,1900$, \&c. because a day intercalated every fourth year was too much, and retaining the bissextile-day at the end of those centuries of years which are divisible by 4 , as the 16 th, 20 th, and 24 th centuries ; viz. the years $1600,2000,2400$, \&c. Otherwise, in length of time, the seasons would be quite reversed with regard to the months of the year; though it would have required near 23,783 years to have brought about such a total change. 
The Earth considered as a Planet. 89

This new form of reckoning was ordained by Pope Gregory, and is therefore called the Gregorian, or the new style, and has been adopted by almost all the enlightened nations of the world; there are some, however, who still reckon according to the old style, viz. as if no alteration had been made by Pope Gregory. 


\section{$\Longrightarrow$ \\ CHAP. VI.}

\section{Of the Air and Atmosphere.}

WE have already considered the earth as a planet, or one of the great masses of matter moving about the sun; we shall now consider it as it is made up of its several parts, abstracting from its diurnal and annual motions.

The exterior part of this our habitable world is the air or atmosphere ; a light, thin fluid, or springy body, that incompasses the solid earth on all sides, and partakes of all its motions, buth annual and diurnal.

The composition of that part of our atmosphere properly called air, was till lately but very little known. Formerly it was supposed to be a simple, homogeneous, and elementary fluid. But the experiments of Dr. Priestley and others have discovered, that even the purest kind of air, which they call vital or de- 
phlogisticated, is in reality a compound, and might be artificially produced in various ways. This dephlogisticated air, however, is but a small part of the composition of our atmosphere. By accurate experiments, the air we usually breathe, is composed of only one-fourth part of this dephlogisticated air, or perhaps less, the other three parts, or more, consisting of what Dr. Priestly calls phlogisticated, and M. Lavoisier, in the new chemistry, mephitic, or azotic air, which cannot be breathed, and in which animals die.

Though air seems to be a kind of repository, wherein all the poisonous effuvia arising from putrid and corrupted matters are lodged ; yet it has a wonderful facility of purifying itself, and of depositing those vapours contained in it; so that it never becomes noxious except in particular places, and for a short time; the general mass remaining upon all occasions pretty much the same. The way in which this purifaction is effected is different, according to the nature of the vapour with which the air is loaded. That which most universally prevails is water: 
and from experiments it appears, that the quantity of aqueous vapour contained in the atmosphere is immense. Dr. Halley, from an experiment on the evaporation from a fluid surface heated to the same degree with that given by our meridian sun, has calculated, that the evaporation from the Mediterranean Sea in a summer's day is 5280 millions of tons of water, which is more than it receives from all the nine large rivers that empty themselves into it. Dr. Watson, in his Chemical Essays, has given an account of some experiments made with a view to determine the quantity of the water raised from the earth itself alone in time of drought. He informs us, that when there had been no rain for above a month, and the grass was become quite. brown and parched, the evaporation from an acre was not less than 1600 gallons in twenty-four hours. Making afterwards two experiments, when the ground had been wetted by a thunder-shower the day before, the one gave 1973 , the other 1905 gallons, in twelve hours. From this the air is every moment purified by the ascent of the vapour, which, flying off in- 
to the clouds, thus leaves room for the exhalation of fresh quantities; so that as the vapour is considerably lighter than the common atmosphere, and in consequence ascends with great velocity, the air during all this time is said to be dry, notwithstanding the vast quantity of aqueous fluid that passes through it.

In the physical economy also, another provision is made for the continual renovation of the atmosphere. Plants derive subsistence from the very air that is unfit for animal life, and in return, actually emit that vital or dephlogisticated air, upon the enjoyment of which the latter depends. Thus we see a constant circulation of benefits maintained between the two great provinces of organized nature. The plant purifies what the animal has poisoned; in return, the contaminated air is more than ordinarily nutritious to the plant. A gitation with water appears to be another of these restoratives. The foulest air shaken in a bottle with water for a sufficient length of time, recovers a great degree of its purity. Here, then again, allowing for the scale upon which nature works, we see the salutary effects 
of storms and tempests. The yesty waves, which confound the heaven and the sea, are doing the very thing which is done in the bottle, and are a perpetual source of freshness to our atmosphere.

The atmosphere, as we have seen, contains a great deal of water, together with a vast heterogeneous collection of particles raised from all bodies of matter on the surface of the earth, by effluvia, exhalations, \&c. so that it may be considered as a chaos of the particles of all sorts of matter confusedly mingled together. And hence the atmosphere has been considered as a large chemical vessel, in which the matter of all kinds of sublunary bodies is copiously floating; and thus exposed to the continual action of that immense surface, the sun; from whence proceed innumerable operations, sublimations, separations, compositions, digestions, fermentations, putrefactions, \&c.

There is, however, one substance, nam$1 y$, the electrical fluid, which is very distinguishable in the mass of the atmosphere. To measure the absolute quantity of this fuid, either in the atmosphere, or any other substance, is perhaps impos- 


\section{Atmosphere.}

sible ; and all that we know on this subject is that the electric fluid pervades the atmosphere; that it appears to be more abundant in the superior than the inferior regions; that it seems to be the immediate bond of connection between the atmosphere and the water which is suspended in it ; and that, by its various operations, the phenomena of the meteors are occasioned.

It is the opinion of the most celebrated philosophers of the present day, that the electric fluid is no other than the light of the sun ; that it issues from that luminary in the pure state of electricity, that joining the particles of our atmosphere, it becomes light, and uniting with the grosser earth fire.-The evaporation of water is attended with an absorption of this fluid from the'surface of our globe, and, on the other hand, the conversion of steam into water, is attended with a deposition of this subtle fluid ; so that there is a circulation in the electric fluid as there is in the water. It descends originally from the sun; pervades the whole substance of the globe; and perspiring, as it were, at every pore, ascends beyond 
96

Atmosphere.

the clouds; and, passing the extreme boundaries of our atmosphere, returns to the sun from whence it came.

The uses of the atmosphere are so many and great, that it seems indeed absolutely necessary, not only to the comfort and convenience of men, but even to the existence of all animal and vegetable life, and to the very constitution of all kinds of matter whatever, and without which they would not be what they are; for by it we live, breathe, and have our being ; and by insinuating itself into all the vacuities of bodies, it becomes the great spring of most of the mutations here below, as generation, corruption, dissolution, \&c. and without which none of these operations could be carried on. Without the atmosphere, no animal could exist, or indeed be produced; neither any plant, all vegetation ceasing without its aid; there would be neither rain nor dews to moisten the face of the ground: and, though we might perceive the sun and stars like bright specks, we should be in utter darkness, having none of what we call day-light, or even twilight: nor would either fire or heat exist without it. In 


\section{Atmosphere.}

short, the nature and constitution of all matter would be changed and cease; wanting this universal bond and constituting principle.

As to the rueight and pressure of the air, it is evident that the mass of the atmosphere, in common with all other matter, must be endued with weight and pressure; and this principle was asserted by almost all philosophers, both ancient and modern. But it was only by means of the experiments made with pumps and the barometrical tube; by Galileo and Torricelli, that we came to the proof, not only that the atmosphere is endued with a pressure, but also what the measure and quantity of that pressure is. Thus it is found, that the pressure of the atmosphere sustains a column of quicksilver, in the tube of the barometer, of about thirty inches in height: it therefore follows, that the whole pressure of the atmosphere is equal to the weight of a column of quick silver, of an equal base, and thirty inches height: and, because a cubical inch of quicksilver is found to weigh nearly half a pound avoirdupois, therefore the whole thirty inches, or the weight of the atmos: 
phere on every square inch of surface is equal to $15 \mathrm{lb}$. Again, it has been found that the pressure of the atmosphere balances, in the case of pumps, \&c. a column of water of about $34 \frac{1}{2}$ feet high ; and the cubical foot of water weighing just 1000 ounces, or $6: \frac{1}{2}:$ b. $34 \frac{1}{2}$ times $62 \frac{1}{2}$, or 2158 lb. will be the weight of the column of water, or of the atmosphere, on a base of a square foot; and consequently the 144 th part of this, or $15 \mathrm{lb}$. is the weight of the atmosphere on a square inch; the same as before. Hence Mr. Cotes computed, that the pressure of this ambient fluid on the whole surface of the earth, is equivalent to that of a globe of lead of sixty miles in diameter. And hence also it appears, that the pressure upon the human body must be very considerable; for as every square inch of surface sustains a pressure of $15 \mathrm{lb}$. every square foot will sustain 144 times as much, or 21601 b. then, if the whole surface of a man's body be supposed to contain fifteen square feet, which is pretty near the truth, he must sustain 15 times 2160 , or $32400 \mathrm{lb}$. that is near $14 \frac{1}{2}$ tons weight for his ordinary load. By this enormous pressure we should un- 
doubtedly be crushed in a moment, if all parts of our bodies were not filled either with air or some other elastic fluid, the spring of which is just sufficient to counterbalance the weight of the atmosphere. But, whatever this fluid may be, it is certain that it is just able to counteract the weight of the atmosphere, and no more : for if any considerable pressure be superadded to that of the air, as by going into deep water, or the like, it is always severely felt, let it be ever so equable, at least when the change is made suddenly; and if, on the other hand, the pressure of the atmosphere be taken off from any part of the human body, as the hand for instance, when put over an open receiver, from whence the air is afterwards extracted, the weight of the external atmosphere then prevails, and we imagine the hand strongly sucked down into the glass.

The difference in the weight of the air which our bodies sustain at one time more than another, is also very considerable, from the natural changes in the state of the atmosphere. This change takes place chiefly in countries at some distance from the equator; and, as the barometer 
varies at times from twenty-eight to thirty-one inches, or about one tenth of the whole quantity, it follows, that this difference amounts to about a ton and a half on the whole body of a man, which he therefore sustains at one time more than at another. On the increase of this natural weight, the weather is commonly fine, and we feel ourselves what we call braced, and more alert and active; but, on the contrary, when the weight of the air diminishes, the weather is bad, and people feel a listlesness and inactivity about them. And hence it is no wonder that persons suffer very much in their health, from such changes in the atmosphere especially when they take place very suddenly.

The weight of the atmosphere has great influence on a number of physical phenomena. It compresses all bodies, and opposes their dilatation. It is an obstacle to the evaporation of fluids. The water of the sea is by this cause preserved in its liquid state, without which it would take the vaporous form, as we see in the vacuum of the air pump. The pressure of the air on our bodies preserves the state 
both of the solids and fluids; and from the want of this due pressure it is that on the summits of lofty mountains the blood often issues from the pores of the skin, or from the lungs.

Various attempts have been made to ascertain the height to which the atmosphere is extended all round the earth. These commenced soon after it was discovered by means of the Torricellian tube that air is endued with weight and pressure. And had not the air an elastic power, but were it every where of the same density, from the surface of the earth to the extreme limit of the atmosphere, like water, which is equally dense at all depths it would be a very easy matter to determine its height from its density and the column of mercury it would counterbalance in the barometer tube : for, it having been observed, that the weight of the atmosphere is equivalent to a column of thirty inches or $2 \frac{1}{2}$ feet of quicksilver and. the density of the former to that of the latter, as 1 to 11040 ; therefore the height of the uniform atmosphere would be 11040 times $2 \frac{1}{2}$ feet, that is, 27600 feet, or little more than $5 \frac{1}{4}$ miles. But the air, 
by its elastic quality, expands and contracts; and it being found, by repeated experiments in most nations of Europe, that the spaces it occupies, when compressed by different weights, are reciprocally proportional to the weights themselves ; or, that the more the air is pressed, so much the less space it takes up; it follows that the air in the upper regions of the atmosphere must grow continually more and more rare, as it ascends higher; and indeed that, according to that law, it must necessarily be extended to an indefinite height. At the height of $3 \frac{1}{2}$ miles the density of the atmosphere is nearly 2 times rarer than it is at the surface of the earth; at the height of seven miles, 4 times rarer; and so on, according to the following table.

Height in miles. Number of times rarer.

$$
\begin{aligned}
& 3 \frac{1}{2} \ldots \ldots . .2 \\
& 7 \ldots \ldots . . . .4 \\
& 14 \ldots \ldots \ldots 16 \\
& 21 \ldots \ldots 64 \\
& 28 \ldots \ldots 256 \\
& 35 \ldots \ldots 1024 \\
& 42 \ldots \ldots . .4096 \\
& 49 \ldots \ldots . . .16384
\end{aligned}
$$




$$
\begin{aligned}
& 56 \ldots \ldots 65536 \\
& 63 \ldots \ldots 262144 \\
& 70 \ldots \ldots 1048576
\end{aligned}
$$

By pursuing these calculations, it might be easily shewn, that a cubic inch of the air we breathe would be so much rarefied at the height of 500 miles, that it would fill a sphere equal in diameter to the orbit of Saturn. Hence we may perceive how very soon the air becomes so extremely rare and light, as to be utterly imperceptible to all experience ; and that hence, if all the planets have such atmospheres as our earth, they will, at the distances of the planets from one another, be so extremely attenuated, as to give no sensible resistance to the planets in their motion round the sun for many, perhaps hundreds or thousands of ages to come. Even at the height of about fifty miles, it is so rare as to have no sensible effect on the rays of light.

Mr. Boyle in his physico-mechanical experiments concerning the air, declares it probable that the atmosphere may be several hundred miles high; which is easy to be admitted, when we consider, what he proves in another part of the 
same treatise, viz. that the air here about the surface of the earth, when the pressure is taken from it, dilates into 10,000 , and even at last into 13,679 times its space; and this altogether by its own expansive force, without the help of fire. In fact, it appears, that the air we breathe is compressed by its own weight into at least the 13,679 th part of the space it would possess in vacuo. But, if the same air be condensed by art, the space it would take up when dilated, to that it possecses when condensed, will be, according to the same author's experiments, as 550,000 to 1 .

Our direct experiments, however, not reaching to any great heights into the regions of the atmosphere, and not knowing how far air may be expanded, we are incapable of determining to what height the atmosphere is actually extended. 


\section{$=$ \\ CHAP. VII. \\ Of the Meteors.}

WE have seen that the atmosphere is a vast laboratory, in which nature operates immense analyses, solutions, precipitations, and combinations ; it is a grand receiver, in which all the attenuated, volatilized productions of terrestrial bodies are received, mingled, agitated, combined and separated. Considered in this view, the atmospheric air is a chaos, an indeterminate mixture of mineral, vegetable, and animal effluvia, which the electric fluid is pervading and traversing continually. The grand changes it experiences, and of which we are sensible in extensive spaces by the appearance of water, light, or noise, are called meteors. As the state of the atmosphere is ever varying, the meteors assume different forms ; some delighting us with their appearance, while others wear a terrifying 
aspect. In this repository is collected the gentle dew and hoar-frost; here clouds are gathered and carried along by the wind, to refresh the earth in falling showers, give rise to rivers, spread vast inundations of water over the fields, or lay them under a covering of snow or hail ; here mock-suns, mock-moons, haloes, and rainbows make their gaudy but transitory appearance ; and here the water-spout, dreadful to the mariner; here rolls the dreadful thunder, here lightnings dart their vivid flames, and sometimes, striking upon the earth, destroy its productions, fill its inhabitants with terror, and sometimes strike them dead; here the aurora, or streamers, the ignes fatui, or wandering fires, called also Jack with the Lantern; here falling stars, as they are ignorantly termed, or fiery balls of various sizes, appear with splendour during the gloom of night, and astonish mankind, who too often seem willing, with superstitious awe, to find portentous omens of dire calamities in these curious phenomena, rather than investigate their causes or discover their uses. 
To account for these various appearances in a satisfactory manner, it is plain that we ought to have an intimate acquaintance with the constitution of the atmosphere ; with the nature of those powerful agents by which it appears to be principally influenced, viz. fire, light, and electric fluid; and with their peculiar modes of operation and action upon one another and upon the atmosphere, and this in every possible variety of circumstances. Nor is even all this sufficient: the various phenomena of rain, wind, snow, thunder, heat, cold, $\mathcal{E}^{2} c$. are known to depend very much upon the situation of different places on the surface of the earth ; and the occasional variations are with great reason suspected to proceed, partly at least, from changes which take place in the bowels of the earth: whence we ought not only to be perfectly well acquainted with geography, but with mineralogy also: and that to an extent at which human knowledge will probably never arrive.

In a subject so very difficult, it is not to be supposed that any thing like a certain and established theory can be laid down. 
in this little elementary work. As evaporation, however, seems particularly to be concerned in the production of the meteors, we shall take a view of that operation of nature, the extent of which we have noticed in the preceding chapter. This process may be reckoned in a particular manner the effect of heat. Upon this principle vapour is shown to be a compound of water and fire; and such it is supposed to be by philosophers of the highest rank. In considering this operation, however, as carried on by nature, we shall soon find, that it proceeds in a manner very different from what takes place in our chemical operations. In the latter, evaporation is merely the effect of heat; and the process cannot go on without a considerable degree of it. In the natural way, on the contrary, the process goes on under almost every degree of cold we know ; the vapours ascend to a height which has never yet been determined; and, from the extreme cold which they sustain, show evidently that they are connected with our atmosphere by means of some other agent besides heat. From the continual ascent of vapour indeed, if the 
operations of nature were of the same kind with those of art, the upper parts of our atmosphere would be always involved in a fog, by reason of the condensation of the vast quantity which continually ascends thither: but so far is this from being the case, that in those elevated regions to which the vapours continually ascend, the air is much drier than at the surface of the ground.

From many experiments, indeed, it is evident, that water, after being reduced into a state of vapour, is capable of undergoing a certain change, by which it lays aside its fluidity entirely, and even to appearance its specific gravity; so that it becomes, as far as we can judge, a substance totally different from what it was before. After water has attained to this state, our inquiries concerning it must in a great measure cease; but as it is not in the immediate product of evaporation that rain has its source, and as vapours change their nature in the atmosphere, so as to be no longer sensible to the hygrometer or to the eye, and do not become vapour again till clouds appear, we must acknowledge it to be very probable, 
that the intermediate state of vapour is no other than air ; and that the clouds do not proceed from any distinct fluid in the atmosphere, but from a decomposition of a part of the air itself, perfectly similar to the rest.

Granting this to be the case, and we can scarcely hope for a more probable conjecture on the subject, the decomposition of the vapour will be easily accounted for. If by any natural process the water can be converted into air, and if the latter is only water partially decomposed; then, by an inversion of the process, air may be instantly re-converted into water, and will become visible in fog or mist, or be condensed into rain, consisting of greater or smaller drops, according to the degree to which this inverted process is carried.

It is generally supposed by meteorologists, from all the clouds, fogs, hail, rain, and snow, being electrified, that the electric fluid is the agent employed in the formation of these meteors, and that it is this fluid which acts in the re-conversion of air into water. This process may be particularly observed in the summer season, 
when the horizon is suddenly overcast, and a copious torrent of rain ensues, which cannot be from the rising of any aqueous vapours at the time, but must be from a precipitation of water that existed in an invisible state in the atmosphere.

Water may therefore exist in air ; 1st, in an invisible state, which is the case when the dissolving power of air is consideran ble; 2 dly, in a state of incipient separation, in which case it forms clouds, mists, or fogs ; $3 \mathrm{dly}$, and lastly, in a state of actual separation, in which case it forms either rain, properly so called, or snow, or hail.

Clonds are those well known assemblages of vapours that float in the atmosphere, have different degrees of opacity, which arise from their extent and density, and generally have pretty well defined boundaries. Their height above the surface of the earth (we mean not above the mountains) is various, but hardly ever exceeds a mile or a mile and a half. In hot weather, or hot climates, the clouds, being: more rarefied, are lighter, and ascend much higher than they do in colder climates, or colder weather : and indeed, in 
cold weather the clouds frequently touch the very surface of the earth; for a fog may with propriety be called a cloud close to the ground.

A mist is a very indefinite word. It means an incipient formation of clouds, or haziness; and it often denotes a very small rain, or deposition of water in particles so small as not to be visible singly.

The snow is formed when the atmosphere is so cold as to freeze the particles of rain as soon as they are formed, and the adherence of several of those particles to each other, which meet and cling to each other as they descend through the air, forms the usual fleeces of snow, which are larger, (since they are longer in descending, and have a greater opportunity of meeting) when the clouds are higher than when they are lower.

The hail differs from snow in its consisting of much more solid, and much more defined pieces of congealed water. It is su posed that the water, already formed into considerable drops, is driven and detained a considerable time through a cold region of the atmosphere, by the wind, which almost always accom- 
panies a fall of hail. But the globes of ice, or hail-stones, in a fall of hail, sometimes far exceed the usual size of the drops of rain; which shews that by the action of the wind, the congealed particles must be forced to adhere to each oth$\mathrm{er}$; and, in fact, though the small hailstones are more uniformly solid and globular, the large ones almost always consist of a harder nucleus, which is surrounded by a softer substance, and sometimes by various distinct pieces of ice. just agglutinated. Their shape is seldom perfectly globular.

The phenomena of dew and hoar-frost seem to proceed from a quantity of aqueous and undecomposed vapour which always exists in the atmosphere; and which, being raised by mere heat, is condensed by mere cold, without undergoing that process by which water is changed into air.

If the cold be very intense, hoar-frost appears instead of dew; which is nothing more than the dew frozen after it falls upon the ground, in the same manner that the vapour in a warm room congeals on the inside of the windows in 2 frosty night. 
Iightning is found to be a flash, produced by the electrical fluid rushing from one part into another; and thunder the sound of the rushing torrent, reverberated among the clouds. The aurora borealis, or northern dawn, is likewise an electrical phenomenon. It is a lambent or flashing light, seen at night in some periods more often than in others, especially about the poles. The fiery-balls, which are seen shooting through the atmosphere in the night, of various magnitudes and of different forms, seem all to rise from inflammable vapours, taking fire from their fermenting, or effervescing in the air.

The Rainbow is one of the most surprising of the works of God, which the Hebrews called the bow of God, and the Greeks the Daughter of Wonder. This phenomenon is seen in the falling rain or dew, and not in the cloud whence that rain or dew proceeds; it is caused by a reflection and refraction of the sun's ray 3 from the globular particles of rain. The face of this beautiful iris, or bow, is ting ed with all the primogenial colours in their natural order; viz. violet, indigo, 
bive, green, yellow and red. It always appears in that part of the heavens opposite the sun.

The Halos, are circles somewhat akin to the rainbow, which appear about the sun and moon, and are sometimes variously coloured. They never appear in a rainy sky, but in a rimy and frosty one, and are formed by the refraction of the rays of light, without any reflection as in the rainbow.

Mock-suns and mock-moons are representations of the face of the true sun and. moon by reflection in the clouds.

The weight and pressure of the atmospherical air have been explained in the preceding chapter. We shall now examine the particulars relative to its progressive motion, which we denominate rvind.

Wind is a stream or current of air ; as the air is a fluid, its natural state is that of rest, which it endeavours always to keep or retrieve by an universal equilibrium of all its parts. When, therefore, this natural equilibrium of the atmosphere happens by any means to be destroyed in any part, there necessarily follows a mo- 
tion of all the circumjacent air towards that part to restore it ; and this motion of the air is what we call zuind.

Hence, with respect to that place where the equilibrium of the air is disturbed, we see the wind may blow from every point of the compass at the same time; and those who live northwards of that point have a north wind ; those who live southwards, a south wind; and so of the rest: But those who live on the spot, where all these winds meet and interfere, are oppressed with turbulent and boisterous weather, whirlwinds and hurricanes; with rain, tempest, lightning, thunder, $\mathcal{E}^{2} c$.

Many are the particular causes which produce wind by interrupting the equipoise of the atmosphere; but the most general causes are two, viz. heat, which, by rarefying the air, makes it lighter in some places than it is in others; and cold which, by condensing it, makes it heavier. Hence it is, that in all parts over the torrid zone, the air being more rarefied by a greater quantity of the solar rays, is much lighter than in the other parts of the atmosphere, and most of all over the equatorial parts of the earth. And since 
the parts at the equator are most rarefied which are near the sun ; and those parts are, by the earth's diurnal rotation eastward, continually shifting to the west; it follows, that the parts of the air which lie on the west side of the point of greatest rarefaction, and, by flowing towards it, meet it, have less motion than those parts on the east of the said point, which follow it ; and therefore the motion of the eastern air would prevail against that of the western air, and so generate a continual east wind, if this were all the effect of that: rarefaction. But we are to consider that as all the parts of the atmosphere are so greatly rarefied over the equator, and all about the poles greatly condensed by extreme cold, this heavier air from either pole is constantly flowing towards the equator, to restore the balance destroyed by the rarefaction and levity of the air over those regions; hence, in this respect alone, a constant north and south wind would be generated.

Now it is easy to understand, that by a composition of these two directions of the air from the east and north, a constant north-east wind will be generated in the 
northern hemisphere, and a constant southeast wind in the southern hemisphere, to a certain distance on each side the equator, all round the earth. And this case we find to be verified in the general trade winds, which constantly blow from the north-east and south-east, to about thirty degrees on each side the equator, where those parts are over the open occan, and not affected with the reflection of the sunbeams from the heated surface of the land, for in this case the wind will always set in upon the land, as on the coast of Guinea, and other parts of the torrid zone, we know it does.

The temperature of a country with respect to heat or cold, is increased or diminished by winds, according as they come from a hotter or colder part of the world. The north and north-easterly winds, in this country and all the western parts of Europe, are reckoned cold and drying winds. They are cold because they come from the frozen region of the north pole, or over a great tract of cold land. Their drying quality is derived from their coming principally over land, $*$ and from a

* This is not true with regard to the United States; for here the north-east wind, coming over the ocean, instead of land, brings along with it so great a degree of humidity as always 
well known property of the air, namely, that warm air can dissolve, and keep dissolved, a greater quantity of water than colder air: hence the air which comes from colder regions being heated over warmer countries, becomes a better solvent of moisture, and dries up with great energy the moist bodies it comes in contact with; and, on the other hand, warm air coming into a colder region deposits a quantity of the water it kept in solution and occasions mists, fogs, clouds, rains, \&.c.

In warm countries sometimes the winds which blow over a great tract of highly heated land, become so very drying, scorching and suffocating, as to produce dreadful effects. These winds under the name of solanos, are often felt in the deserts of Arabia, in the neighbourhood of the Persian gulph, in the interior of Africa, and in some other places. There are likewise in India, part of China, part of Africa, and elsewhere, other winds, which deposit so much warm moisture as to soften, and actually to dissolve glue, salts, and almost every article which is soluble in water.

to produce rain or snow, according to the temperature of the air; whereas, as here stated, in Europe the same wind blowing over land, it always produces dry, fair weather. 
It is impossible to give any adequate account of irregular winds, especially of those sudden and violent gusts which come on at very irregular periods, and generally continue for a short time. They sometimes spread over an extensive tract of country, and at other times are confined within a remarkably narrow space. Their causes are by no means rightly understood though they have been vaguely attributed to peculiar rarefactions, to the combined. attractions of the sun and moon, to earthquakes, to electricity, $\mathcal{E}^{2} c$. They are called in general hurricanes, or they are the principal phenomenon of a hurricane, that is, of a violent storm.

Almost every one of those violent winds is attended with particular phenomena, such as droughts or heavy rains, or hail, or snow, or thunder and lightning, or several of those phenomena at once. They fiequently shift suddenly from one quarter of the horizon to another, and then come again to the former point. In this case they are called tornadoes. In some parts of the Indian ocean there are winds which blow one way during one half of the year, and then blow the contrary way during the other half 
of the year. These winds are called monsoons, and owe their origin to causes similar to what has been pointed out.

When the gusts of wind come from different quarters at the same time, and meet in a certain place, there the air acquires a circular, or rotatory, or screwlike motion, either ascending or descending, as it were, round an axis, and this axis sometimes is stationary, and at other times moves on, in a particular direction. This phenomenon, which is called a zohirlwind, gives a whirling motion to dust, sand, water, part of a cloud, and sometimes even to bodies of great weight and bulk ; carrying them either upwards or downwards, and lastly scatters them about in different directions.

The water-spout has been attributed principally, if not entirely, to the meeting of different winds. In that case the air in its rotation acquires a centrifugal motion; whence it endeavours to recede from the axis of the whirl, in consequence of which a vacuum, or, at least a considerable rarefaction of air, takes place about the axis, and, when the whirl takes place at sea, or upon water, the water ri- 
ses into that rarefied place; for the same reason which causes it to ascend into the exhausted tube, and forms the water-spout or pillar of water in the air. The water-spouts generally break about their middle, and the falling waters occasion great damage, either to ships that have the misfortune of being under them, or to the adjoining land; for such spouts are sometimes formed on a lake, or river, or on the sea close to the land.

As the motion of the air has a greater or lesser velocity, the wind is stronger or weaker; and it is found from observation, that the velocity of the wind is various, from the rate of 1 to 100 miles per hour. The following particulars respecting the velocity, $\mathcal{E}^{2} c$. of the wind are extracted from a table which appeared in the 51 st volume of the Philosophical Transactions, by Mr. J. Smeaton, the celebrated engineer.-

When the velocity of the wind is one mile per hour it is hardly perceptible.

From 2 to 3 just perceptible.

4 - 5 gentle pleasant wind, or breezes.

$10-15$ pleasant brisk gale.

$20-25$ very brisk.

$30-35$ high winds. 
$40-45$ very high.

50 miles per hour a storm or tempest.

$60 \ldots \ldots \ldots$ a great storm.

$80 \ldots \ldots \ldots$ a hurricane.

$100 \ldots \ldots\left\{\begin{array}{l}\text { a hurricane that tears up trees } \\ \text { carries buildings before it, \&c. }\end{array}\right.$

The winds are of immense and indispensable use. Besides their more obvious effects in driving of ships, wrirdmills, $\mathcal{E}^{2} c$. they preserve, by mixing, the necessary purity of the air. The winds, likewise drive away vapours, clouds fogs, and mists from those parts in which they are copiously formed, to others which are in want of moisture; and thus the whole surface of the earth is supplied with water. It is the winds which diminish the heat, and augment the moisture of the torrid zone, and produce. contrary effects on those of the polar regions, so as to render those districts of the globe, which the ancients deemed totally unfit for the abode of man, and other animals, by reason of excessive heat, not only habitable, but salutary and pleasing to man and beast, and yielding great variety and abundance of the choice productions of nature. 
124 Springs, Rivers, and the Seas

\section{CHAP. VIII.}

\section{Of Springs, Rivers, and the Sea.}

HAVING viewed water as it takes its departure from the bosom of the deep and forms the watery meteors, we shall now survey it as it rises in the salient spring, and gives birth to the gurgling rill, or uniting, gives coolness to the landscape in the magnificent stream, that in its ample range fertilizes its neighbourhood.

Various have been the theories, or rather hypotheses relating to the origin of springs; but it seems the general opinion of those who have made this branch of natural philosophy their study, that the true principles which supply the waters of fountains or springs, are melted snow, rain water, and condensed vapours. 


\section{Springs, Rivers, and the Sea. 125}

The prodigious quantity of vapours raised by the sun's heat, and otherwise, being carried by the winds over the low lands to the very ridges of mountains, as the Pyrenean, the Alps, the Apennine, the Carpathian, in Europe; the Taurus the Caucasus, Imans and others in Asia; Atlas the Montes Luna, or mountains of the moon, with other unknown ridges in Africa; the vapours being compelled. by the stream of air to mount up with it to the top of those mountains, where the air becoming too light to sustain them, and condensed by cold they strike against their summits; which causes an union of their particles, and are precipitated in water, which gleets down by the crannies of the stone; and entering into the caverns of the hills, gathers, as in an alembic, into the basons of stone it finds, which being once filled, all the overplus of water that comes thither, runs over by the lowest places, and breaking out by the sides of the hills forms single spings.

Many of these springs running down by the vallies, between the ridges of the hills, and coming to unite, form little rivulets, or brooks; many of these again 
126 Springs, Rivers, and the Sea.

meeting in one common valley, and gaining the plain ground, being grown less rapid, become a river; and many of these being united in one common channel, make such enormous streams as the Rhine, the Rhone and the Danube. And it may almost pass for a rule, that the magnitude of a river, or the quantity of water it discharges, is proportional to the length and heights of these very ridges from whence the fountains arise.

The several sorts of springs observed are common springs, which either run continually, and then they are called perennial springs; or else run only for a time, or at certain times of the year, and then they are called temporary springs. Intermitting springs, or such as flow and then stop, and flow and stop again, by regular alternations or intermissions. Reciprocating springs, whose waters rise and fall, or flow and ebb, by regular intervals, or reciprocations of the surface.

If those reservoirs of water in the body of mountains be situated where mineral ores abound, or the ducts or feeding streams run through mineral earth, it is easy to conceive the particles of metal 
Springs, Rivers, and the Sea. 127

will mix with, and be absorbed by the water, which being saturated therewith, becomes a mineral spring or well. If salt, sulphur, and lime-stone abound in the strata through which the water passes, it will then be saline, sulphureous, and lime-water. If sulphur and iron should both abound in the parts of the hill, whence the waters come, the waters will partake of the warmth or heat, which is occasioned by the mixture of two such substances in the earth, where they are found.

Having noticed the different kinds of springs, we shall say a few words respecting the various phenomena which take place in rivers.

A large collection of water which runs in consequence of its gravity from a higher to a lower part of the surface of the earth, in a channel generally open at top, is called a river.

A river which flows uniformly, and preserves the same height in the same place, is said to be in a permanent state; such rivers are very rare.

The water of a river does not flow with the same velocity through the 
128 Springs, Rivers, and the Sea.

whole width of the river. The line in which the water moves with the greatest velocity is called the thread of the river, and this thread seldom lies in the middle of the river, but it generally comes nearer to one side than the other, according to the nature of the impediments, and the configuration of the banks. The velocity of rivers is likewise less at the bottom of their channels, than at their surface; owing to the resistance which the bed makes to the water as it flows.

The running of rivers is upon the same principle as the descent of bodies on inclined planes; for water no more than a solid can move on a horizontal plane, the re-action of such a plane being equal and contrary to gravity entirely destroys it, and leaves the body at rest; here we speak of a plane of small extent, and such as coincides with the curved surface of the earth. But if we consider a large extent or long course of water, then we shall find that such water can never be at rest but when the bottom of the channel coincides every where with the curved surface of the earth. In rivers that are made it is usual to allow the fall of 1 foot in 300 , but 
- Springs, Rivers, and the Sea. 129

the declivity of those formed by nature is various and uncertain.

The velocity of the water of a river ought to increase in proportion as it recedes from its source: but the numerous causes of retardation, which occur in rivers, are productive of very great irregularities; and it is impossible to form any general rules for determining such irregularities.

The unequal quantities of water (arising from rains, from the melting of snow \&c.) which are conveyed by rivers at different seasons, enlarge or contract their widths, render them more or less rapid, and change more or less the form of their beds. But independent of this, the size and form of a river is liable to be continually altered by the usual flowing of its waters, and by local peculiarities. The water constantly corrodes its bed wherever it runs with considerable velocity, and rubs off the sand, or other not very coherent parts. The corrosion is most remarkable in that part of the bottom, which is under the thread of the river, or where the water descends suddenly from an eminence, as in a cascade or water-fall. 
130 Springs, Rivers, and the Sea.

The sand thus raised is deposited in places where the water slacks its velocity, and there by degrees an obstacle, a bank, and even an island, is formed, which in its turn produces other changes. Thus a river sometimes forms itself a new bed, or it overfoows the adjacent grounds.

In some places we find that an obstacle or a bent on one side will occasion a corrosion on the opposite bank, by directing the impetus of the stream towards that bank.-Thus, from divers causes, whose concurrence in different proportions, and at different times, forms an infinite variety, the velocity of rivers is never steady or uniform.

The following curious calculation respecting the river Thames was made by $\mathrm{Dr}$ Halley." In order to estimate the quantity of water, which passes daily through the Thames, the Doctor assumes the breadth of the river at Kingston bridge, (where the flood seldom reaches) to be 100 yards, and the depth 3 ; so that the section of the channel is 300 square yards, and allowing the velocity of the water to be at the rate of 2 miles per hour, there will run in 24 hours, the length of 4.8 miles 
Springs, Rivers, and the Sea. 131

or 84480 yards ; therefore $84480 \times 300=$ $25,344,000$ cubic yards, which make 203,000,000 tons which the river Thames yields per diem.

The proportional lengths of course of some of the most noted rivers in the world are shewn nearly by the following numbers, extracted from Mr. Rennell's paper 71 st vol. Phil. Trans.

\section{European Rivers.}

Thames........ 1

Rhine........ 5 $\frac{1}{4}$

Danube........ $7^{4}$

Wolga ........ $9 \frac{1}{2}$

Asiatic Rivers.

. Indus ........ $5 \frac{1}{4}$

Euphrates ...... $8 \frac{1}{2}$

Ganges........ 9 $\frac{1}{2}$

Burrampooter .....99

Nou Kian, or Ava River . . $9 \frac{1}{2}$

Jennisea ...... 10

Oby.......... $10 \frac{1}{2}$

Amoor ......... 11

Lena ....... $11 \frac{1}{2}$

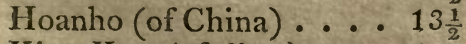

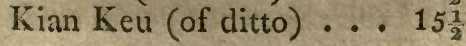


132 Springs, Rivers, and lite Sea.

$$
\begin{aligned}
& \text { African River. }
\end{aligned}
$$

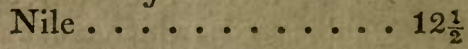

When we reflect on the immense length of these rivers, and their origin, we are naturally directed to the contemplation of the round which water travels; and by which, without suffering adulteration or waste, it is continually offering itself to the wants of the habitable globe. From the sea are exhaled those vapours which form the clouds ; these clouds descend in refreshing showers of rain, which sinking deep into the earth, form springs, and springs uniting form rivers, which rivers in return feed the ocean. So there is an incessant circulation of the same fluid; and not one drop probably more or less now than there was at the creation. In fact, "look nature through, 'tis revolution all" wherever we turn our eyes, all seems continually in a state of change or circulation. "The sun," saith Solomon, "ariseth, and the sun goeth down, and pants 
Springs, Rivers, and the Sea. 13 s

for the place from whence he arose; all rivers run into the sea, yet the sea is not full ; unto the place from whence the rivers came, thither they return again."

The Sea is a vast collection of waters in the deep and unfathomable valleys of the earth. This great abyss occupies nearly three quarters of the whole surface of our globe; which has been thought by some too great a proportion ; but it is probably no more than sufficient to fertilize the land.

The saltness of the sea is a property in that element, which appears to have excited the curiosity of naturalists in all ages. This property is very rationally judged to arise from great multitudes both of mines and mountains of salt, dispersed here and there in the depths of the sea; the salt being continually diluted and dissolved by the waters, the sea becomes impregnated with its particles throughout ; and for this reason the saltness of the sea can never be diminished.

The saltness of the sea preserves its waters pure and sweet, which otherwise would corrupt and stink like a filthy lake, and consequently none of the myriads of 
134. Springs, Rivers, and the Sea.

creatures which now live therein, could then have being; from hence also the sea water becomes much heavier ; and therefore ships of greater size and quantity may be used thereon. Salt water also doth not freeze so soon as fresh water, whence the seas are more free for navigation.

The most remarkable thing in the sea, is that motion of the water called tides. It is a rising and falling of the water of the sea. The cause of this is the attraction of the moon, whereby the part of the water in the great ocean which is nearest the moon being most strongly attracted, is raised higher than the rest ; and the part opposite to it, on the contrary side, being least attracted, is also higher than the rest. And these two opposite rises of the surface of the water in the great ocean, following the motion of the moon from east to west, and striking against the large coasts of the continents that lie in their way, from thence rebound back again, and so make floods and ebbs in narrow seas, and rivers remote from the great ocean.

As the earth, by its daily rotation round its axis, goes from the moon to the moon 
Springs, Rivers, and the Sea. 135

again (or the moon appears to move round the earth from a given meridian to the same again) in about 24 hours, hence in that period there are two tides of flood and two of ebb, and this alternate ebbing and flowing continues without intermission. For instance, if the tide be now at high-water-mark, in any port, or harbour, which lies open to the ocean, it will presently subside, and flow regularly back, for about six hours, when it will be found at low-water-mark. After this, it will again gradually advance for six hours, and then return back, in the same time, to its former situation; rising and falling alternately; twice a day, or in the space of about twenty-four hours.

The interval between its flux and reflux is, however, not precisely six hours, but about eleven minutes more; so that the time of high water does not always happen at the same hour, but is about three quarters of an hour later every day, for thirty days; when it again recurs as before. For example, if it be high water, at any place, to day at noon, it will be low water at eleven minutes after six in the evening; ; and. consequently, after two changes more, the 


\section{Springs, Rivers, and the Sea.}

time of high water the next day will be about three quarters of an hour after noon; the day following it will be at about half an hour after one ; the day after that at $a$ quarter past two; and so on for thirty days when it will again be found to be high water at noon, the same as on the day the observation was first made. And this exactly answers to the motion of the moon; she rises every day about three quarters of an hour later than upon the preceding one; and, by moving in this manner round the earth, completes her revolution in about thirty days, and then begins to rise again at the same time as before.

To make the matter still plainer ; suppose, at a certain place, it is high water at three o'clock in the afternoon, upon the day of the new moon; the following day it will be high water at about three quarters of an hour after three ; the day after that at about half an hour past four; and so on, till the next new moon; when it will again be high water about three o'clock, the same as before. And by observing the tides continually at the same place, they will always be found to follow the same rule; the time of high water, 
Springs, Rivers, and the Sea. 137

upon the day of every new moon, being mearly at the same hour ; and three quarters of an hour later every succeeding day.

The attraction of the sun also produces a similar rising and falling of the water of the ocean, but on account of its distance, not near so considerable as that which is produced by the moon. It will be readily understood that according to the different situations of the sun and the moon, the tides which are raised by their respective attraction, will either conspire with, or counteract each other in a greater or lesser degree. When they conspire together the tides rise higher, and their mutual action produces what are called spring tides. On the contrary, when they counteract each other they produce neap tides.

From a slight consideration of what has been said, we might be led to imagine that the time of high water at any place, would be when the moon is over the meridian of that place. But this is by no means the case ; it being usually about three hours afterwards: the reason of which may be shown as follows. The moon, when she is on the meridian, or M 


\section{Springs, Rivers, and the Sect.}

nearest to the zenith of any place, tends to raise the waters at that place; but this force must evidently be exerted for a considerable time, before the greatest elevation will take place ; for if the moon's attraction were to cease altogether, when she has passed the meridian, yet the motion already communicated to the waters would make them continue to ascend for some time afterwards; and therefore, they must be much more disposed to ascend when the attractive force is only in a small measure diminished.

The waves of the sea, which continue after a storm has ceased, and almost every other motion of a fluid, will illustrate this idea ; all such effects being easily explained, from the consideration that a small impulse, given to a body in motion, will make it move farther than it would otherwise have done. It is also, upon the same principle, that the heat is not the greatest upon the longest day, but some time afterwards ; and that it is not so hot at twelve o'clock, as at two or three in the afternoon; because there is a farther increase made to the heat already imparted. Instead of its being high water then, when 
Springs, Rivers, and the Sea. 139

the moon is upon the meridian of any place, it will always be found to happen, as far as circumstances will allow, about three hours afterwards ; and the intervals between the flux and reflux, mustbereckoned from that time in the same manner as before.

The sun being nearer the earth in winter than in summer, is nearer to it in February and October than in March and September; and therefore the greatest tides happen not till some time after the autumnal equinox, and return a little before the vernal.

The tide propagated by the moon in the German ocean, when she is three hours past the meridian, takes twelve hours to come from thence to London Bridge; where it arrives by the time that a new tide is raised in the ocean.

These are the principal phenomena of the tides ; and where no local circumstances interfere, the theory and facts will be found to agree. But it must be observed that what has been here said, relates only to such places as lie open to large oceans. In seas and channels, which are more confined, a number of causes concur, which 


\section{Springs, Rivers, and the Sea.}

occasion considerable deviations fiom the general rule. Thus, it is high water at Plymouth about the sixth hour; at the Isie of Wight about the ninth hour; and at London bridge about the fifteenth hour after the moon has passed the meridian. And at Batsha, in the kingdom of Tonquin, the sea ebbs and flows but once a day the time of high water being at the setting of the moon, and the time of low water at her rising. There are also, great variations in the height of the tides, according to the situation of coasts, or the nature of the straits which they have to pass through. Thus, the Mediterranean and Baltic seas have very small elevations; while, at the port of Bristol, the height is sometimes near thirly feet; and at St. Malo's it is §aid to be still greater. 


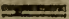

\section{CHAP. IX.}

Of Earths, Stones, Metals, Minerals, and other Fossils.

HAVING taken a view of the air which surrounds, and the water which diversifies the face of our globe, we will now take a survey of the solid substance, or body of our earth.

Those who observe the dispasition of the earth, as it appears in the quarrying or digging of mines, find it generally lying in horizontal layers, or strata of different kinds, like the settlings of waters. The first layer that presents itself, is most commonly the bed of vegetable earth or mould. With this earth the surface of our globe is generally covered. It is this mould which gives rooting and nourishment to plants, so that they may stand and grow in it, and it is as it were the store-house from whence all the living 
creatures of our world have originally their provisions ; for from thence all the plants have their sustenance, and some few animals, and from these all other anipnals.

As this affords to animals and vegetables their support, so the spoils of these, when dead or decayed, return to the dust of the ground, from whence they were formed, and thus keep up an unceasing circulation.

The most common disposition of the layers is, that under the first earth is found gravel or sand; clay or marl; then chalk, or coal, marbles, ores, \&c. This disposition, however, is far from being uniformly continued all over the globe; in different soils the order of these layers vary.

It is wonderful the variety of produc. tions which are found in the different parts of our globe. In the crumbling chalk, the solid marble, the dusty gravel, and even the depths of the most inland valleys, and on the summits of the highest mountains, we behold the spoils of the ocean, exhibited uncler the several appearances of petrified fish, beds of shells, 
and sea plants. The Alps, the Apennines, the Pyrenees, Libanus, Atlas, and Ararat, every mountain of every country under heaven, where search has been made, all conspire in one uniform and universal proof, that the sea has covered their highest summits. If we examine the earth, we shall find the mouse deer, natives of America, buried in Ireland; elephants, natives of Asia and Africa, buried in the midst of England; crocodiles, natives of the Nile, in the heart of Germany; shell-fish, never known but in the American seas, together with skeletons of whales, in the most inland regions of England; trees of vast dimensions with their roots and tops at the bottom of mines and marls, found in regions where such trees were never known to grow, nay, where it is demonstrably impossible they could grow. Such are the awful memorials of the great convulsions and revolutions which have taken place in the natural world ; of countries laid under the rolling waves of the ocean; and of lands rising from the midst of the waters, and becoming the habitations of beasts and of men; so transient and un certain are all earthly things. 
The various bodies which are found by digging in the earth are called fossil substances; under which are comprehended metals, minerals, stones of divers kinds, and sundry bodies that have the texture between earth and stone.

These bodies are divided into four different classes by mineralogists, viz. I. Earth and Stones in general; II. Salts ; III. Inflammables; and IV. Metals.

I. Earth and Stones in general are 1st, mould the support of vegetables; 2nd, clays, which mixed with water harden in the fire, into bricks, delf, china, \&c. 3d, calcareous substances, as chalks, marls, limestones, marbles, convertible by heat into quicklime, and gypsum into alabaster; 4 th, talcs, which are found in flat, smooth laminæ; 5 th, slates also split into laminx; these with a variety of stones from freestone, or sand, to granite, porphyry, flint, and substances still harder, such as precious stones, are known by various properties, and are accordingly applied to different purposes; some, in addition to being serviceable in building, are used as whetstones; some strike fire with steel; others are polished to glitter in the 
dress of the fair, or decorate the furniture of the opulent; and others, melted by fire, form the transparent glass.

Although there seems to be an almost infinite variety of earthly substances scattered on the surface of this globe yet when we examine them chemically, we find that all the earth and stones which we tread under our feet, and which compose the largest rocks as well as the numerous different specimens which adorn the cabinets of the curious, are composed of a very few simple or elementary earths, the principal of which are the calcareous, siliceous, argillaceous, magnesia, terra ponderosa, and a few others which have been discovered lately, but have not been much examined.

Calcareous earth is found in the shells of fishes, the bones of animals, chalk, limestone, marble, and gypsum : but all calcareous earth is supposed to be of animal origin ; and beds of chalk, limestone, or marble, are thought to have been beds of shells formed in the sea, in some pristine state of the earth.

Silex, or siliceous earth is the principal constituent part of a great number of 
the compound earths and stones, forming the immense mass of the solid nucleus of the globe. It is the base of almost all the scintillating stones, such as flint, , rock, crystal, quartz, agate, calcedon, jasper, $\mathcal{E}^{2} c$. The sand of rivers and of the sea-shore, chiefly consists of it.

Argillaceous earth is found in clay, schistus, or slate, and in mica. This species of earth is ductile with water, it then hardens and contracts by heat, se as to be of the greatest use in forming brick, or stones of any required form or size.

Terra ponderosa is generally found in two states, viz. united to vitriolic acid, when it is called calk; or to fixed air, when it is called terra ponderosa aerata. This earth is distinguishable by its great specific gravity, being four times as heavy as water.

Magnesia is found sometimes pure in nature, but it is generally obtained by art from some of its combinations. It gives a peculiar character to the substances of which it forms a part. The stones which contain magnesia in considerable quantity have generally a smooth and unctuous feel, 
a greenish cast, a fibrous striated texture, and a silky lustre. Among them we may mention talc, steatite, serpentine, chlorite, asbestos, \&rc. Pure magnesia does not form with water an adhesive ductile mass. It is in the form of a very white spongy powder and perfectly tasteless.

Stones are formed by the mixtures of the earths together, and of the mixtures of earths with alkalies, and sometimes with acids. Stones bound together by some cement, form rocks. There is also a kind. of stones of a peculiar nature produced by the fire of volcanoes.

The stones in which the acids and alkalies abound are called saline stones, and the mixtures of the earths with each other form stones properly so called. Of stones properly so called, those in which the siliceous earth abounds and predominates are very numerous ; the principal of which we shall briefly notice.

Siliceous mixtures have sufficient hardness to strike fire with steel. Of this description are the precious stones, rock crystal, or quartz, felspar, silex, crysopryse, lapis lazuli, jasper, and schorl. 
Gems, or precious stones, are of various kinds. They are distinguished by their hardness, weight, colour, and splendour, as well as by their property of producing single or double refractions. As their colour is, of all their characters, the most apparent, it is according to this that we shall divide them.

Red gems are the ruby, the vermillion, garnet and girasol. The ruby is a trans. parent stone, the colour of which is more or less red. It is distinguished into four kinds, viz. the oriental ruby, the spinel ruby, the balass ruby, and the Brazilian ruby.

Yellow gems are the topaz, hyacinth and jargon of Geylon. Of the topaz, there are three kinds, the oriental topaz, the $B r a-$ zilian topaz, and the Saxan topaz.

Bhue gems are the sapphire, and the aigue marine. There are two kinds of the sapphire, viz. the oriental sapphire, and the Brazilian. There are also two kinds of the aigue marine, the oriental and the accidental.

Green gems are the emerald of Peru and the chrysolite, of which there are two kinds, viz. the Brazilian, and that of the jewellers. 


\section{Fossils.}

The diamond ought certainly to be placed among the precious stones, but it is different from all those above described. Its combustibility is a property entirely peculiar to itself; the diamond indeed burns in the same manner as phosphorus, disappears without leaving any vestiges of it behind. The diamond is supposed to be pure carbon, and the radical of the carbonic acid.

There are several varieties of the diamond, which differ from each other only in colour; some are of a rose colour, and others red, orange, yellow, green, blue and dark coloured.

Rock-crystal and quartz seem to be the same stone. The name of rock-crystal is given to that which is crystallized, and. of quartz to that which is in a rude mass. The form of these crystals is a hexadral prism, terminated at one of its extremities and sometimes at both, by a summit composed of six triangular faces. In hardness they are inferior to all the other gems. Rock-crystal consists almost entirely of pure silex. Quartz enters into the composition of granite.

Freestone is of the same pature as 
quartz. It is granulated, being composed of small grains of quartz, cemented together, but which have very little adhesion. Felspar is inferior in hardness to quartz. It fuses by the action of heat, and forms white enamel. It is one of the constituent parts of porcelain.

We may mention, under this class, adamantzne sipar, which approaches near to the preceding in its appearance and fracture, but which differs from them considerably, by its great hardness, its form, and gravity. It is so exceedingly hard, that it may be employed to cut the diamond.

Flint is a stone, which is so, hard as to strike fire with steel. Among the different kind of flints, some change their colour according to the directions of the rays of light, and others do not. Of the former there are three, the opal, the cal'seye and the fish-eye.

The kinds of flints which do not change their colour according to the direction of the rays of light, exhibit tints of more or less brightness, and are susceptible of a fine polish. We are acquainted with eight kinds of them, viz. common fint, 
petro silex, agate, calcedony, cornelian, sardony $x$, the jade, and the prasium.

Common flint posesses very little transparency. All the different kinds of it have a dark dull colour, and are concave, or convex, on the fracture. They do not fuse in the fire, but are calcined and become white.

The distinguishing character of petro silex is its semi-transparency, similar to that of wax. It becomes white in the fire, like the common fiint, but it is more fusible, as it runs without any addition.

Agate has a smooth shining fracture, and will take a very high polish; it is much variegated. When exposed to heat, it loses its colour, and becomes opaque, but without fusing.

The calcedony has a milky semi-transparency. Every kind of it takes a fine polish. These stones are white, intermixed sometimes with tints of red, yellow, and blue.

The cornelians are all either entirely, or in part, of a beautiful red colour, but they lose their colour in the fire, and become opaque. They are all susceptible of a fine polish. 
Lapis lazuli is of a beautiful skyblue colour, sometimes mixed with white, and is entirely opaque. It is sometimes mixed with pyrites, from which it has been supposed that it contained gold. If exposed to a strong heat, it fuses, and forms a sort of whitish glass ; when calcined, it dissolves in acids into a kind of jelly. Lapis lazuli, when pulverized, forms that valuable colour known under the name of ultramarine.

Fasper is a stone which exhibits every variety of colour. It is exceedingly hard, and receives a very beautiful and durable polish. When exposed to the action of heat, it does not fuse.

Schorl is a hard stone, fusible in a moderate fire, without any addition. Its crystals exhibit a great variety, in regard to form, appearance, texture, structure, \&c. Schorl, in general, is opaque ; some kinds, however, are transparent, such as Brazilian emerald, the peridot, the tourmalin, Eंc.

The colour of schorl is various; some kinds are black, others violet, and some green. Schorl enters into the composition of porphyry, serpentine, the ophite, granitell, and granite. 


\section{Fossils.}

The primitive earths form stones, as we have mentioned, and stones united by cement form those masses called rocks. We shall notice the six mixtures which are most commonly found in those masses, viz. porphyry, serpentine, ophites granitell, granite, and fint.

Porphyry is composed of felspar in small fragments, of schorl, and a kind of cement, which unites all the parts, and which, in some measure, forms the base. Porphyry is exceedingly hard, and diffcult to be cut; it will, however, take a fine polish. Some kinds of it are red, and others green.

Serpentine is composed of the same substance as porphyry. The only difference is, that the felspar is in larger fragments. The colour of serpentine is various; some kinds are green, others violet, some yellow, and some black.

The ophite is composed of only two substances, viz. black schorl, known under the name of ancient black basaltes, interspersed with greenish felspar, which forms in it long spots. This stone has considerable hardness. 
Granitell is also composed of two substances; black schorl, and white felsper, mixed with some of the green felspar.The only difference then between the granitelles and the ophite is, that the schorl which enters into the composition of the former is not of the same kind as that in the latter.

Granite is composed of felspar, schorl, and quartz. The colour of granite is various ; it is hard, difficult to be work$\mathrm{ed}$, and receives a fine polish.

Flint is a hard opaque stone, susceptible of a very beautiful polish. It appears to be composed of concentric strata, and has considerable brilliancy on its fracture. Flints are never found in continued quarries, like the other stones; they are sound detached, and dispersed throughout the fields. When joined by any kind of cement they form pudding-stones. They become decomposed in the air, for they are found for the most part covered with a crust, of a softer nature than the interior part. Their colour is exceedingly various; some of them are spotted and yariegated with veins, others exhibits the resemblance of plumes, and even of plants. 


\section{Fossils.}

Valconic Productions are chiefly pumice-stones, lava and basaltes.

Pumice-sione is real glass, in the form of small greyish, white, and exceedingly brilliant filaments. These filaments always leave vacuities of greater or less size between them, which occasions great variations in its specific gravity. In general it is lighter than water.

Lawa is that burning matter which runs down, in such prodigious quantities, from volcanoes, when in a state of eruption, and often extends to a great distance. This matter is a semi-vitrified substance, which appears blackish, on account of its density.

Basaltes is blackish and opaque. By the action of heat it may be converted into glass, of a very beautiful black colour. It often crystallizes in prisms, of three, four, five, six, or seven planes. Of some kinds, such as that known under the name of touchstone, the grain is exceedingly fine.

II. Of Salts.-The alkalies, the acids, and the combinations in which they enter in sufficient quantities, are called salts, 
or saline substances; for a saline substance, in its extended chemical sense, means a substance that has some taste, and is soluble in water. These substances, however, do not strictly and exclusively belong to the fossil department, but are obtained also from animal and vegetable substances. They are the most active agents in creation. They give bodies their consistency; preserve them from corruption, and render them savoury.

Alkalies are distinguishable by their acrid, burning, and urinous taste, their causticity, their singular action on the skin and all animal substances, the quality of changing the blue colour of violets to a green, and even a greenish yellow, and deliquescency. We are acquainted with three species,-potash, soda, and ammonia. The first and second have been called fixed alkalies, because they melt and grow red in the fire before they become volatile; the third has been named volatile alkali, from possessing the opposite property.

Potash is known by the following characters :-It is dry, solid, white, and very 


\section{Fossils.}

deliquescent, absorbs water with heat and a peculiar faint smell, combines with siliceous earth by fusion, and forms glass. It is frequently found native with lime, and combined with different acids; but is chiefly obtained from vegetables, in the ashes of which it remains after combustion.

Soda or the mineral alkali, is procured from the ashes of sea-weed, and constitutes the basis of sea-salt. It strikingly resembles potash in form, causticity, fusibility, deliquescency, combination with earthy substances, by means of fusion, action on animal substances, \&c. so that it was long confounded with it, and might have continued to be so, if it did not form very different saits with acids, and yields these acids to potash.

Ammonia, or volatile alkali, differs greatly from the two preceding species in its form of gas when dissolved in calcoric, in its liquid form when dissolved in water, in its pungent and suffocating smell, its solubility in air, \&c. Ammonia is procured by burning animal substances; in Egypt, (from whence, as contained in sal ammoniac we till of late 
imported it) from camels' dung ; but now from bones by distillation.

All Acids appear to be combinations of oxygen or vital air, with elementary substances. Their taste is sour, as their name imports. They change most of the blue vegetable colours red, and have a tendency to combine with earths, alkalies, and metallic substances.

All acids, being compounds of oxygen with different substances, the former principle is the cause of their resemblance and common properties; the latter, being different in each, may serve to characterize each in particular. For this reason those matters which are variable in acids are termed their radicals, or acidifiable principles. Thus all acids are combinations of radicals, or acidifiable substances, different in each species, with oxygen, which is the same in all : whence it follows, that their common properties, their characters as acids, depend on oxygen, which is the acidifying principle; their particular properties, their specific characters arise from their radicals. The word acid, indicating the general and identical nature of these substances, forms their generical name, while the particular. 


\section{Fossils.}

name of the radical contained in each may with propriety designate each particular acid.- Thus sulphur is the radical of the acid we name sulphuric, phosphorus that of the phosphoric, carbon that of the carbonic, and so on.

Acidifiable radicals may contain different quantities of oxygen, and under this point of view they possess two states of acidity. The first is that, in which they contain the least possible quantity of oxy. gen to render them acid. In this their acidity is commonly weak, and they adhere but feebly to the bases with which they are capable of forming salts. The modern methodical nomenclature designates this state of combination and acidity, by giving the names of these weak acids the termination ous. Thus we say the sulphurous, nitrous, phosphorous, or acetous, acid. The second state of acids is that, in which they contain more oxygen, and in general are completely saturated with it. In this they have all the strength and. attraction they are capable of possessing: as acids, and the modern nomenclature expresses it by the termination $i c$. Thus we say the sulphuric, nitric, phosphoric, 
or acetic, acid. With regard to the pro. portion of oxygen united to acidifiable radicals, still greater latitude may be given to the considerations presented above. Each radical may be contemplated in four states: 1 st, containing very little oxygen not sufficient to impart to it the nature of an acid, and in this it is nothing more than an oxyd; such is sulphur coloured red or brown, by exposure to the air, and a degree of heat inadequate to produce inflamation; when it is oxyd of sulphur; 2dly containing more oxygen than in the preceding case, and enough to become an acid, though weak; as in the sulphurous acid ; 3dly, possessing still more oxygen than in the second instance, and having acquired powerful acid properties ; such as the sulphuric acid; 4thly, conjoined with a larger dose of oxygen than is necessary to constitute a powerful acid, an acid in ic; when it is termed an oxygenated acid, or even super-oxygenated.

The acids are generally divided into mineral, vegetable, and animal, acids, according to the nature of their radicals. Though the first class only with propriety claims notice in this place, yet for the in- 
formation of the reader we will enumerate those belunging to each of the above classes.

The mineral acids at present known are the sulphuric (formerly called the vitriolic acid); the nitric acid, called also aquafortis; the muriatic or marine acid, called by artizans the spirit of salt; the carbonic acid, formerly called the acid of charcoal, aerial acid, or fixed air, E'c. the phosphoric acid, which is likewise an animal acid, it being found amongst animal matters as well as among minerals; the acid of borax; the flouric acid, formerly called the acid of spar; the arsenic acid; the molybdic acid; the tungstenic acid; and the chromic acid. The last four are also called metallic acids.

The vegetable acids are the acetic, or vinegar, the acid of tartar, the empyreumatic acid of tartar, the oxalic or acid of sorrel, the acid of galls, the citric or lemon acid, the malic or acid of apples, the benzoic, or the acid of benjamin, the empyreumatic acid of sugar, the acid of camphor, and the suberic or acid of cork. The animal acids are, the acid of milk, the acid of sugar of milk, the formic or a- 
cid of ants, the prussic acid, viz. the colouring matter of prussian blue, which is obtained from dried blood, hoofs, \&c. the sebacic or acid of fat, the bombic or acid of silk-worms, the laccic or the acid of waxy matter, and the zoonic, or the acid extracted from animal matter by means of lime.

For a more full account of these acids we refer the reader to various recent publications, written professedly on the sub. ject of chemistry.

Acids and alkalies, shew strong attractions for each other, and when combined together in such proportion that neither of them predominates, form neutral salts : substances altogether dissimilar to the elements of which they are composed. The salt in common use for instance, is formed of mineral acid and alkali ; either of which, singly, would be hurtful to the human body; and the acid, in particular, would be extremely pernicious.

Each acid produces with each of the three alkalies a particular neutral salt. The number of the last may therefore be found by multiplying the number of the acids which we know, by three, the number of the alkalies. 


\section{Fossils.}

III. Inflammables. - Inflammables are sulphur or bitumens. These substances are both derived from the spoils of vegetables and animals.

Sulphur, known also by the name of brimstone, is a simple combustible substance, which nature frequently presents in a pure state. It is found in the earth in a loose powder, or solid; and either detached or in veins. It is met with in the greatest plenty in the neighbourhood of volcanoes, and is deposited as a crust on stones contiguous to them. It is also met with in mineral waters, coal-mines, $\mathcal{E}^{2} \mathrm{c}$. and also in combinations with most of the metals.

The bitumens are naptha, petrol, mineral tar, asphaltum, jet, cannel-coal, mineral tallow, pit-coal, amber, \&c.

Naptha is a white or yellowish white substance, fluid as water, feels greasy, has a penetrating sinell, and burns with a Iight flame, leaving scarcely any residuum. Petrol, or Petroleum, is a brown semitransparent substance; being naptha, thickened, and altered in coleur and other respects by the air. 
Mineral Tar is petrol farther altered by the air, having become of the colour and consistency of pitch.

Asphaltum, or mineral pitch, is produced by a still farther exsiccation or drying:

$\mathcal{F} t$ is a substance of a full black, hard$\mathrm{er}$, and less brittle than asphalt; and according to Widenman, is a species of coal.

Cannell-coal appears to be next to jet, in gradation, of the compound mineral bituminous substances.

Mineral Tallow is rarely met with, and imperfectly known. It much resembles tallow.

- Mineral Caoutchouc is a substance much resembling, in its elastic properties, the substance from which it takes its name.

Pit-coal, according to Mons. Gensanne and others, is an earth or stone, chiefly of the argillaceous genus, penetrated or impregnated with petrol or asphalt. It has also been supposed to have been formed by vegetables growing in the sea, and by vast forests which have been buried by subsequent revolutions, 
Amber is a bitumen generally of a yellow or brown colour. It is found either under the surface of the ground, among the clay, sand, and iron bog ore, when it is called fossil amber, or is thrown on the shore by the waters of the sea, and is then called mineral amber. It is tasteless, but when rubbed it yields a faint odour, and manifests electric powers.

IV. Metals.-We are at present acquainted with twenty-one metallic substances, essentially different from each other; gold, platina, silver, mercury, lead, copper, iron, tin, zinc, bismuth, antimony, arsenic, cobalt, nickel, manganese, molybdena, wolfram, chrome, uranium, titanium. and tellurium.

Metals exceed all other fossils in specific gravity;* but there exists, in this

* The specific gravity of any body is the proportion which its weight bears to the weight of another body of equal bulk. The established custom is te compare all bodies with water, the specific gravity of which is reckoned one, or unity; so that when the specific gravity of any body, as Gold, for instance, is said to be 19 , Zinc 7 , we mean that equal quantities of Water, Gold, and Zinc weigh respectively 1,19 , and 7 , be they pounds, ounces, grains, or any other weights.

$\mathrm{O} 2$ 
respect, a remarkable difference among themselves. They are completely opaque. They also possess a mirror-like lustre, which is one of their characteristic marks and they present a convex surface when melted in earthen vessels. Besides, they are all insoluble in water. And by these external characters, it is easy to distinguish this class from all other fossils, viz. earths, salts, bitumens, and sulphur.

Metals are concealed in the earth, and form ores, which existing in crevices of rocks, are called veins, and are distinguished into level, or into inclined, direct or oblique, according to the angle they make with the horizon. The part of the rock resting on the vein, is termed, the roof; and that on which the vein rests, the bed of. the vein. And the cavites made in the earth, in order to extract these ores, are called mines.

When nature has bestowed on metals their proper metallic appearance, or they are only alloyed with other metals, they are said to be native. When combined, as they commonly are in mines, with some unmetallic substance, they are said to be mineralized; the substance that sets them 
in that state, is called a mineralizer, and the compound of both, an ore; which term is applicable when stones, or earths, contain metallic substances, whether native or - mineralized, in a notable proportion. Several metals are ductile and mallea$b l e$, and their parts may be displaced from each other by compression, or hammering, without losing their cohesion. Hence, some of them may be stretched out to thin laminæ, or drawn into slender filaments ; as, for instance, gold, silver, plantina, copper, lead, tin, and iron.-Other metals are fragile, or brittle, and do not admit of being stretched and extended; such are antimony, arsenic, cobalt, bismuth, Eंc.

All metals are fusible, but not all in the same degree; thus mercury is melred even by the usual temperature of our atmosphere.-Some metals, as tin and lead, melt even before ignition; others, as silver, gold copper, iron, fuse only after being ignited.

All metals, iron and platina only excepted, melt on a sudden, as soon as they are heated in a due degree; but iron and platina grow soft before they fuse, 
and on this depends their very useful property of becoming capable of being welded.

Almost all metals may be combined by fusion into one seemingly homogeneous mass, and from thence various metallic mixtures, metallic alloys, or compositions arise; which, for their particular properties, are often of very great utility.

If metals be continued in fusion, they lose their brilliancy, and become an opaque powder, or what is termed a metallic oxyd or calx.

All metals, gold, silver, and platina, excepted, are oxyded or calcined in fire with access of air. In this respect, those which cannot be oxyed by fire have received the name of noble metals, to distinguish them from the rest which may be calcined that way, and are called base metals.

Gold is a noble metal, of a yellow colour; and, after platina, the heaviest of metals. Its specific gravity is from 19,258 to $19,-$ 640. Its hardness and elasticity are inconsiderable; but its tenacity is great; and with regard to ductility, or malleability it exceeds all other metallic substances. 
Platina is a noble metal of a white colour; for which reason some called it white gold. In Europe it is known only since the middle of the present century, and brought to us in small irregularly-figured grains, but which are impure, and mostly contaminated with iron. Pure platina exceeds all other metals, even gold in specific gravity, which is found to reach 21,061. It is ductile and malleable ; its hardness and tenacity are greater than those of gold, and it admits of being welded.

Silver is a noble metal, of a white color whose specific gravity is variable from 10,474 to 10,542 ; it is very malleable and ductile, and of a moderate hardness. It fuses in a heat of less intensity than is required by gold ; it is fixed in fire, and is not affected by water nor air, remaining in both unaltered; but by sulphureous vapours it is very soon tarnished.

Mercury, or quicksilver is a base metal of a white colour. Its specific gravity is upon an average $13,674-i$ it is the most fusible of all known metals, and continues in the fluid state even in the cold temperature of our winters; it congeals only at 
40 Farenheit, and shews then some tenacity and ductility.

Lead is a base metal of a bluish white colour. Its specific gravity is from 11,352 to 11,445 ; it is considerably ductile butlittle tenacious and hard, hence it may be extended in thin plates by the hammer but not drawn into fine wire. It has scarcely any elasticity.

Bismuth is a yellowish or reddish white metal, of a foliated fracture, and very brittle, it being even reducible to powder by the hammer. Its specific gravity is from 9,670 to 9,822 . It is somewhat harder than lead but more fusible.

Nickel is a greyish white metal, of a specific gravity between 9,000 and 9,333 It is malleable, and very compact or firm.

Copper is a base metal, of a brownish red colour; sonorous, very tenacious, ductile, and malleable; of a considerable compactness; of a moderate hardness and elasticity; and of an hackly fracture. Its specific gravity varies from 7,788 to 9,000 .

Arsenic is a brittle metal, and on the recent fracture, of a mean colour, betwixt tin-white and lead-grey; but, on expo- 
sure to air, it soon turns black and dull. Its specific gravity is 8,310 ; its hardness is somewhat considerable, and seemingly surpassing that of copper. But its ductility is solittle, and its brittleness so great that it is readily converted into powder by the hammer.

Of all metals Iron exhibits the most varieties and deviations. Its differences in colour, density, fracture, tenacity, ductility, and degree of fusibility, are uncommonly great. - Soft and malleable iron has a greyish-white colour, a light grey, fibrous, hackly fracture. Its specific gravity at a mean rate is 7,700 ; its hardness is not great, but its malleability and tenacity are considerably so; and it has this characteristic property, not possessed by other species of this metal, that whether cold or ignited, it may be extended, forged, and bent, without breaking.

By cast or crude iron, that metal is understood, which is obtained by the first smelting of iron-ores. Such iron is distinguished from ductile iron by its refusing to be extended and forged by the hammer, whether cold or ignited, by its brittleness, and by its fusing in strong heat 
in open fire, without addition, whereby it is rendered capable of being cast into moulds. The colour of crude iron is more or less of a pale grey.

Steel differs from both the ductile and the crude iron.-Its distinguishing property is, that when it is tempered, that is to say, when it is hastily plunged in cold water while ignited to redness, it becomes harder, more brittle, and inflexible; and that, before this tempering or hardening, it is ductile, whether cold or ignited; and also, that after having been hardened, it reassumes its ductility by a fresh igniton and gradual cooling; without quenching.-Its colour is a light grey, its fracture finely granular.

Cobalt is a base metal, of a lead grey colour, brittle and hard, and of specific gravity from 7,000 to 7,700 . This metal is rather of difficult fusion.

Tin is a base metal of a white colour, a little more verging to blue than that of silver-It is very soft, pretty malleable and tractable ; its compactness and elasticity are but slight. When broken or bent, or when compressed betwen the teeth, it makes a peculiar crackling noise, 


\section{Fossils.}

which is one of its characteristic properties. The specific gravity of tin is variable from 7,216 to 7,331 . Its gravity decreases in the ratio of its purity.

Zinc is a white metal, of a radiated. texture, changing into the foliated. It is of a middle kind betwen the malleable and brittle metals, and may be extended. into thin laminx, at least between metallic cylinders in rolling mills. The specific gravity of this metal is from 6,862 to 7,215 .

Antimony has a white colour, resembling that of tin, a foliated radiated texture, and is very brittle. Its specific gravity varies from 6,702 to 6,860 . In the air it loses little of its metallic splendour and it does not rust in the strict sense of the word.

Manganese is a white, hard, brittle metal, whose specific gravity is found to be from 6,850 to 7,000 .

Molybdena has a pale lead-grey colour, a metallic lustre, and a lamellated tracture it is very soft, and marks paper easily, leaving a shining trace. Its specific gravity is between 4,138 and 4,569.

Wolfram is a metallic substance of mod- 
ern discovery, and of a particular kind, whose calx or oxyd is of a yellow colour, and one of the constituent parts of the fossil, called tungsten.

Another distinct metallic substance only a few years since discovered by Klaproth, is the Uranium. The oxyd of $\mathrm{u}$ ranium has a lemon-yellow colour, is fixed in fire, and infusible when alone. $\mathrm{Ig}$ -

* nition changes its colour to a brownish grey.

We are likewise indebted to Klaproth for the discovery of the new metal called by him Titanium or Titanite.-It is contained in the mineral called red shoerl as a native oxyd. The colour of the perfect oxyd of titanium is red; but when kept in violent ignition upon coals, and by a greater degree of disoxydation, it gradu. ally assumes a yellowish, bluish, and blackish hue.

Tellurium is a metal of a white colour like tin,inclining to lead-grey. It is brittle and friable ; possesses a lamellar texture, and considerable metallic lustre; is one of the most easily fusible metals, and exhibits a crystailized surface when slowly cooling after fusion. - Its specific gravity is 6,115 . 
Chrome is a white metal, inclining to grey, very brittle, and crystallizable at an elevated temperature in feathered filaments on the surface.

The minerals to be found in England are both curious and useful. A mber, jet, vitriol and allum are found in considerable quantities; our canal coal approaches nearly to the beauty of jet, and even our common coal fire for firing is of a superior nature. The English earth and gravel are of the best quality; and we have stone, slates, flags, and other fossils necessary for building in great abundance. Tin is another article in which England, from the time of the Phenicians had always had the pre-eminence. The county of Cornwall alone produces more than all the world besides. Our lead ore is richer than in other countries, runs more fluently in the fire, requires less trouble and expense in working, and is when wrought very fine and ductile. Our black lead or wadd, found in Cumberland, is a mineral of great use and value in several branches of trade and arts. Copper and iron are also found here in great plenty, and seve. 
ral ores of these metals, particularly in Anglesey, have of late been discovered, and brought into use, which were unknown before the recent improvements in chemistry. 


\section{gapranstiss \\ CHAP.X. \\ Of Vegetables or Plants}

- NEXT to the earth itself, we may consider those that are maintained on its surface; which though they are fastened to it, yet are very distinct from it : and those are the whole tribe of vegetables or plants. These may be divided into three sorts, herbs, shrubs, and trees.

Herbs are those plants, whose stalks are soft, and have nothing woody in them, as grass, sowthistle, and hemlock. Shrubs and trees have all wood in them; but with this difference, that shrubs grow not to the height of trees, and usually spread into branches near the surface of the earth; whereas trees generally shoot up in one great stem or body, and then, at a good distance from the earth, spread into branches; thus, gooseberries and currants, are shrubs; oaks and cherries, are trees. 
Numerous are the works which have been written, especially in later times, on the science of botany, and various systems, or classifications of plants have from time to time been proposed; but the sexual system of Linnæus is at present generally received. This naturalist has drawn a continued analogy between the vegetable economy and that of the animal; and has derived all his classes, orders, and genera, from the number, situation, and proportion of the parts of fructification. In twenty-four classes, he has comprehended every known genus and species. In considering a plant with a view to its characteristics, or distinguishing features, it is divided by Linnæus into the following parts, making so many outlines, to which the attention of the botanical observer must be directed; 1. Root; 2. Trunk ; 3. Leaves; 4. Props 5. Fructification; 6. Inflorescence. 1. The root consists of two parts, the caudex and the radicula. The caudex, or stump, is the body or knoli of the root from which the trunk and branches ascend, and the fibrous roots descend, and is either solid, bulbous, or tuberous; solid, as in trees 
and other examples; bulbous, as in tulips $\mathcal{E}^{2} c$. tuberous, as in potatoes, $\mathcal{E}^{2} c$. The radicula is the fibrous part of the root, branching from the caudex. 2. The trunk, which includes the branches, is that part which rises immediately from the caudex in either herbaceous, shrubby, or arborescent, and admits of several other distinctions, according to its shape, substance, surface, $\mathcal{E}^{2} c$. 3. The lecives are either simple, as those that adhere to the branch singly, or compound, as when several expand from one footstalk. Leaves are farther described by various terms indicative of their form and outline. 4. The props those external parts which strengthen support, or defend, the plants on which they are found, or serve to facilitate some necessary secretion; as the petlious, or footstalk of the leaf; the pedunculus, or footstalk of the flower, the stipula, or husk, that is, the small leaves that generally surround the stalk at its divisions; the cirrhus, or tendril; the pubes, or down; the arma, or defensive weapon, as thorns. 5. The fructification, or mode, of fruitbearing. 6 . The inflorescence, or mode by which the flowers are joined to the several peduncles. 
In plants there is an infinite diversity; some aquire a long succession of ages to bring them to perfection, while others attain their full maturity in a few hours; some are of immense magnitude, while others are of an inferior stature, descending by gradation till they become too $\mathrm{mi}$ nute to be cognizable by the senses. The mighty baobob of Senegal, described by Adanson, whose stem is 75 feet in circumferance, stands a stately monument on the face of the earth for many thousands of years; while the mushroom, which it much resembles in form, springs up in a day, perfects its seeds, and is withered tomorrow ; and when we carry our views still farther, into that immense profound of minuteness which has but of late been partly laid open to us by the invention of the microscope ; into the class of mosses, which are in some measure cognizable by the naked eye, and still farther into the more minute class of plants denominated mould, which, even in those of the largest species, are too small to have their parts cognizable by the naked eye, and which, when viewed by the best microscopes, discover a series of existences diminish- 
ing by a regular gradation, like stars in the galaxy under the best telescopes, till they are lost in the infinity of minuteness, leaving every reason to believe, that, could the magnifying powers of our instruments be augmented a thousand fold, we should still find ourselves as far from discovering the termination of this series of infinite diminution as we were at the commencement of our imperfect survey. The world that we see, therefore, seems to be but a very small part of that which exists; our feeble optics are capable of taking in scarcely a point of that universe which surrounds us; and our imperfect understandings can scarcely obtain a glimpse of that infinite power and wisdom which regulates the whole. Among this infinity of objects, however, we can clearly perceive the most perfect regularity and order pervading every part; and that all the operations of nature proceed with invariable steadiness to effect the purposes for which they have been designed.

Thus we see that all animate objects, from the largest that has been discovered on this globe, to the smallest that can 
ever be made to be perceptible to us, invariably proceed from other animated objects of the same kind, although they appear at times under such disguised forms as not to be at first sight cognizable by us. This rule applies to vegetables as well as animals. The plant of mould, which, even when it hath attained its full stature, can scarcely be perceived as a point under our microscopes of the highest magnifying power, we have every reason to be satisfied, produces its seeds in as regular order, which ripen at their appointed period with the same regularity as those of the mighty baobob ; but while this remains a stately monument upon the surface of this earth, and sees thousands of generations of men succeed each other, and successively shelter themselves under the protecting shade of its spreading branches, we observe the mould spring up, perfect its seeds, scatter them in imperceptible myriads in the air, and disappear within the short space of one hour: so that during the short period of our existence here many myriads of generations of mould have succeeded each other. Time itself then, when the universe is 
viewed as a whole, can only be considered as a relative object. Shall man then, a being who cannot comprehend fully the nature of a single object around him, dare proudly to lift up his face, and pretend to decide concerning possibilities and the powers of nature! His proper province is to be humble and adore!

The plants with which we are best acquainted may be arranged into three grand divisions. The first are those whose roots and stems remain for many years, which comprehends all the varieties of trees and shrubs. These, for the most part, require several years to bring them to a state of puberty (if that phrase may be admitted), when they begin to put forth flowers, and perfect their seeds; after which time they usually continue to produce an annual crop of flowers and seeds for a long period of time; the fruit in general succeeding the flowers, and perfecting their seeds in the same year; but to this rule there are several exceptions. In a few instances the seeds do not attain to muturity in the same season that the flower is produced; but, continuing upon the tree the whole win. 
ter in an immature state without being killed, they advance in the second season, and then only perfect their seeds; instances of which are to be found in the juniper and orange-tree. Others continue to advance for several years, as usual, without showing fruits; and when at length they reach that state of maturity, they then flower; and, having perfected their seeds, they decay and flower no more, dying down like annual plants ; an example of which is to be found in the cabbage-tree of tropical regions. Some are scarcely ever (perhaps never) known to produce either flowers or seeds of any sort, but admit of being propagated by some other means; instances of which are to be found in the English elm of our own country, the jack, or bread-fruit tree of India; and many others.

The second division of plants are those that have a perennial root, from which stalks are sent forth annually, which usually produce flowers, perfect their seeds in the summer, and die down to the ground at the approach of winter. The stems of these are for the most part of a similar structure and consistence with those of 
The third class, or annuals, from the seeds of which, if sown in the spring; stalks spring up which produce flowers and seeds the same season; after the perfecting of which the stalks decay and die entirely away. Biennials can only be viewed as a diversity of these, that have not sufficient length of season to bring them to perfection in one year.

Whether distinctions similar to these take place among those minute tribes of plants which we call microscopical, it exceeds our power at present to determine. From the short period of their existence, we have been generally inclined to think that they are all siunilar in quality to annuals ; that is to say, that they flower but once, and die down immediately after they have once perfected their seeds. Yet, who dares pretend to say, that the plant of mould, which exists perhaps but one of our hours, may not produce in that period many thousands of successions of ripe seeds, each of which has taken its due season to ripen like those of the baobob, which flourishes on our globe for hundreds of ages! for the same infinite power which 
has cecreed that the total duration of this plant shall be limited to an hour, may have also decreed, that the maturation of its seeds, and the com letion of a period that to it should be similar to that of our year, should be accomplished in the thousandth part of a second of our time.

All plants seem to grow in the same manner: the genial warmth of the sun, the refreshment of the rains, the same soils appear to suit their respective species; and, upon a superficial glance, they seem to have the same common parts. A c? iemical analysis discovers the same constituent principles in all, that is to say, calcareous earth, oil, water, and air, with a portion of iron, to which they owe their beautiful colours. Yet, although composed of similar materials, their juices to the eye, and to the taste, appear as various is their forms. The soporific milk of the poppy, the acrid but equally milky juice of the spunge, the acid of the sorrel, the saccharine sap of the sycamore and mapie, and the resin of the tribe of pines, bear no resenblance to each other.

The inward structure of plants is as 
regular and various as their external forms are elegant and well-proportioned. The root, trunk, branch, leai, flower, fruit and seed, have each its peculiar character and form. No part in the contexture of the smallest fibre is unfinished but is formed with the most minute exactness. The seeds of plants have the appearance of shells, unlike in form, and diversified with spots and stripes. Every seed possesses a reservoir of nutriment, designed for the growth of the future plant. This is the matter prepared by nature for the reproduction and continuation of the whole species. This nutriment consists of starch, mucilage, or oil, within the coat of the seed, or of sugar and subacid pulp in the fruit, which belongs to it. The sections of the various kinds of trees are crossed with the greatest number of regular figures which the imagination can conceive. The lines, which form the texture of fir-trees, are distant ; but those of oak are close and compact.-And this difference of texture may serve to account for their greater or less solidity, and the difference of time requisite for them to arrive $a$ maturity. 
The nourishment of plants is performed chiefly by the tender fibres of the roots, which being spread under-ground, imbibe from the moist earth juice fit for their nutriment, which they transmit to the other parts. The impulse by which the juices rise seems to be capillary attraction; for the roots of all vegetables are supposed but bundles of capillary tubes: and whether we consider earth, water, salt and oil, as the food of plantsor, with Kirwan, that coal is essential to that food-or with Ingenhouz, that it is vital air decomposed into fixt air and azote; still that food must be formed by water into an emulsion, capable of being acted upon by capillary attraction; and as all rosts are but assemblages of these tubes, there can be little doubt but their attraction supplies the plant with its first food; though other causes must assist in carrying it to the tops of the tallest trees, such as dilatation and contraction, by the successive heat and cold of day and night, the muscular action of vascular rings round the tubes irritated to contraction by the stimulant sap, \&c. The interior bark conducts the nourishment supplied by the earth. 
After the sap has thus ascended to the leaves, it there undergoes certain alterations, and is converted into another fluid, called the succus proprizus, or peculiar juice; which, like the blood in animals, is afterwards employed in forming the various substances found in plants. The leaves may therefore be considered as the digesting organs of plants, and as equivalent in some measure to the stomach and lungs of animals. The leaves consequently are not mere ornaments; they are the most important parts of the plant. Accordingly we find, that whenever we strip a plant of its leaves, we strip it entirely of its vegetating powers till new leaves are formed; for when the leaves of plants are destroyed by insects, they vegetate no longer, and their fruit never makes any further progress in ripening, but decays and dries up.

Leaves on one side draw nutriment from the air, and perspire on the other; for plants, as well as animals, perspire, and, in both cases, this furiction is essential to health. The quantity they perspire varies, according to the extent of the surface from which it is emitted, the 
temperature of the air, the time of the day, and the humidity of the atmosphere. Leaves form the greatest part of the surface, and it is found that the quantity of these very materially affect the quantity of perspiration ; and this process is increased or diminished, chiefly, in proportion to the increase or diminution of the foliage of vegetables. The degree of heat in which the plant is kept also varies the quantity of matter perspired; this being greater, in proportion to the greater heat of the surrounding atmosphere. The degree of light has likewise considerable influence in this respect; for plants uniformly perspire most in the forenoon, though the temperature of the air, in which they are placed, should be unvaried. A plant also exposed to the rays of the sun, has its perspiration increased to a much greater degree than if it had been exposed to the same heat under the shade. Finally, the perspiration of vegetables is increased in proportion as the atmosphere is dry, or, in other words, diminished in proportion as the atmosphere is humid. The more vigorous and healthy the plant, the more copious the perspiration; this function, like the 
rest, depending much on the vital enerergy. Excessive perspiration seems to hurt, and even sometimes to destroy, vegetables; defective perspiration is equally injurious. It is also found, that this function is performed, chiefly, if not altogether, by the leaves and young shoots. That it may be properly carried on, all leaves are deciduous; in those trees called ever-greens, there being a constant succession of leaves, to prevent the organ of perspiration from becoming rigid. A quantity of moisture is ahsorbed by plants, when exposed to a humid atmosphere. This absorption, as well as the perspiration, is performed by the leaves; but in what manner has not yet been ascertained. Experiments made by $\mathbf{M}$. Guettard shew, that perspiration is more considerable from the upper, than from the under, surface of the leaves.

Plants in general are known to receive and transpire more, in equal time, than large animals. It has been found by accurate calculation, and repeated experiments, that a plant of the sun-flower receives and perspires in twenty-four hours seventeen times more than a man. 
Some botanists have conceived that plants, as well as animals, have a regular circulation of their fluids. Others think this very improbable. On both sides, recourse has been had to experiments, and from these conclusions perfectly opposite have been deduced; so that no certain conclusion can be drawn on this head.

Light has great effect on vegetation. Plants that grow in the shade, or in darkness, are pale, and without colour ; and the more they are exposed to the light, the more colour they acquire.

Vegetables are not only indebted to light for their colour; their taste and odour are derived from the same source. Hence it happens that hot climates are the native countries of perfumes, odoriferous fruits, and aromatic resins.

The action of light on the organs of plants, causes them to pour out streams of pure air from the surfaces of their leaves, while exposed to the sun; whereas, on the contrary, when in the shade, and at night, they emit air of a noxious. quality.

The various secretions of vegetables, 
as of odour, fruit, gum, resin, wax, honey, \&c. seem brought about in the same manner as in the glands of animals; the tasteless moisture of the earth is converted by the hop-plant into a bitter juice; as by the caterpillar in the nutshell the sweet kernel is converted into a bitter powder. While the power of absorption in the roots and barks of vegetables is excited into action by the fluids applied to their mouths like the lacteals and lymphatics of animals.

The individuals of the vegetable world may be considered as inferior or less perfect animals; a tree is a congeries of many living buds, and in this respect resembles the branches of coralline, which are a congeries of a multitude of animals. Each of these buds of a tree has its proper leaves or petals for lungs, produces its viviparous or its oviparous offspring in buds or seeds; has its own roots, which extending down the stem of the tree are interwoven with the roots of the other buds, and form the bark, which is the only living part of the stem, is annually renewed, and is superinduced up. on the former bark, which then dies, and 
with its stagnated juices gradually hardening into wood forms the concentric citcles, which we see in blockss of timber, which annual rings serve as natural marks to distinguish the age of trees.

The botanist follows nature into her most retired abodes, and views her in her simple state, and native majesty. He remarks some of her productions cisfigured by cultivation in gardens, where amid all the varieties of the apple and the pear, however distinguished by their colour, size and taste, he observes, that there is but one original species of each, and that they have respectively but one radical character. He beholds the wonderful prodigality of nature, cven in the composition of the common daisy, which consists of more than two hundred flowers, each including its respective corolla, germ, pistil, stamina, and seed, as perfectly formed as those of a complete lily, or hyacinth. And he sees this diversity as fully illustrated in the different sorts of grass, a term which, although it com. monly conveys only one notion to the vulgar mind, and one abject to the undiscerning eye, consists of five hundred dif- 
ferent species, each formed with infinite beauty and variety. From others he particularly distinguishes the elegant briza media, so common in the fields, and so remarkable for its delicate hair-like stem, trembling at every breeze ; the anthoxanthum odoratum, which gives its fragrance to the new-mown hay; and the stipa pennata with its waving plumes resembling the feathers of the bird of paradise. The botanist enjoys a pleasing and innocent amusement, most agreeably combined with a love of rural retirement, and which gives a new and growing interest to every walk and ride, in the most delightful season of the year. Indeed man cannot contemplate the vegetable creation without recalling the idea of beauty, sweetness; and a thousand charms that captivate the senses. The perfume of the rose and the stately magnificence of the forest successively catch his attention and delight him.

The number of species of plants already known is about twenty-five thousand ; and botanists suppose that double that number, at least, remain to be discovered. The different vegetable productions aze 
no less useful than numerous. The pur. poses to which the trees of Britain are applied are well known, from the flexible willow, which forms the basket, to the hardy oak, which composes the most substantial parts of a ship of war, guards the British islands from foreign invasion, and displays to the most remote countries the greatness of our maritime power. All possess different qualities, adapted to their different purposes. The meanest, and in their appearance the most unpleasant, have their use; even the thistle is not only the food of some animals, but is serviceable in making glass. There is scarcely a plant which although rejected as food by some animals is not eagerly sought by others. The horse yields the common water hemlock to the goat, and the cow the long-leafed water hemlock to the sheep. The goat again leaves the aconite, or bane-berries to the horse. The euphorbia or spurge, so noxious to man, is greedily devoured by some of the insect tribes. The aloe is a magazine of provisions and of implements to the Indians who inhabit the banks of the Ohia and the Missisippi. Some plants, as 
rhubarb and opium, alleviate the tortures of pain ; and some, as the quinquina, or Peruvian bark, can subdue the rage of the burning fever. Wheat, the delicious and prolific grain which gives to the inhabitants of the northern world their wholesome nutriment, grows in almost every climate. Where excessive heat or othex causes prevent it from coming to perfection, its place is amply supplied by the bread-fruit, the cassavi-root and maize, and more particularly by rice, which is the common aliment of that great portion of mankind who inhabit the warm regions of the earth. Every meadow in the vernal season brings forth various kinds of grass; and this spontaneous and most abundant of all vegetable productions requires only the labour of the husbandman to collect its harvest. The iron-wood, solid as marble, furnishes the Otaheitean with his long spear and massy club. The wild pine of Campeachy retains the rainwater in its deep and capacious leaves not less for the refreshment of the tree itself, than of the thirsty native of a burning soil. The cocoa of the East and West Indies anwers many of the most useful 
purposes of life to the natives of a warma climate. Its bark is manufactured into cordage and clothing, and its shell into useful vessels ; its kernel affords a pleasant and nutritive food, and its milk a cooling beverage ; its leaves are used for covering houses, and are worked into baskets; and its boughs are of service to make props and rafters. The rein-deer of the Laplander, so essential to his support and subsistence, could not survive through the tedious winter, without the lichen rangiferinus, which he digs from beneath the snow. On the bleak mountains of the north, the pine, the fir, the cedar, and man of the resinous trees grow, which shelter many from the snows by the closeness of their foliage, and furnish him in winter with torches and fuel for his fire-side. The leaves of those evergreen trees are filliform, and thus are adapted to reverberating the heat, and resisting the violent winds which beat on elevated situations. All these productions, and the various trees which produce cork and emit rosin, turpentine, pitch, gums, and balsam, either supply some constant necessity, obviate some inconvenience ${ }_{x}$ or 


\section{Plants.}

contribute to some use or gratification of the natives of the soils where they grow, or of the inhabitants of distant climates. 


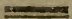

CHAP. XI.

Of Animals.

WE are now come to consider the last, the noblest and the most beautiful part of the creation : the creatures for whom this earth seems to have been entirely formed, and for whose repast or use the whole of its unintelligent productions appear to have been brought forth; these are the animated tenants of our globe.

When we compare animals and vegetables together, each in their most perfect state, nothing can be easier than to distinguish them. The plant is confmed to a particular spot, and exhibits no marks of consciousness or intelligence ; the animal, on the contrary, can remove at pleasure from one place to another, is possessed of consciousness, and a high degree of intelligence. But on approaching the 
contiguous extremities of the animal and vegetable kingdom, these striking differences gradually disappear, the objects acquire a greater degree of resemblance, and at last approach each other so nearly, that it is scarcely possible to decide whether some of those species which are situated on the very boundary, belong to the animal or vegetable kingdom. Indeed we find the vegetable, animal, and mineral kingdoms so closely connected, like the links of a chain, that there is no possibility of finding a disjunction in any part, nor saying with precision where the one ends and the other begins, so nearly do they approach each other in the extremes of each class.

The term animal, in a general sense, is applied to every thing that is supposed to be alive to the sensations of pain and pleasure. Under the name of animal, therefore, are included men, quadrupeds, birds, fishes, reptiles, and insects. Animal literally means a living thing; but plants live. Linnæus has formed a climax of the grand departments of creation. Stones grow; vegetables grow and. live; animals grow, live, and feel. 
Various are the corporeal forms, and great are the peculiarities of organization of the different animals which inhabit the globe; and equally various are their intellectual powers; beginning with man, who forms the highest link in the chain, and descending by an almost imperceptible diminution of mental powers, through an innumerable series of existences, and ending at last in mere animation alone, with a seening privation of all mental perception whatever.

As an animal, man is strikingiy distinguishable from the rest of the creatures of the earth, on account of the ingenuity with which he employs the productions of nature for his accommodation and comfort. He is also particular$1 \mathrm{y}$ distinguishable by the originality of his ideas. Instincts, in common with brutes, make up a part of his character; but he is principally the creature of experience and reflection. When an infant comes into the world it is the most helpless of all creatures; no danger alarms it, nor can it make the smallest effort to preserve itself. A tiger may approach it without occasioning terror; nor would 
it attempt to screen itself when the lion's mouth is opened to devour it. The voice of the mother is not understood for many weeks; and it is but by slow degrees that it acquires knowledge, in consequence of the gradual developement of its reasoning faculties; but as its progress is more slow, so its ultimate attainments are proportionally greater than that of other animals. The chicken, within the first eight days of its life, seems to have made nearly the whole mental acquirements it is ever capable of attaining; but no period of human life can be assigned when the mental progiess of man is at a stand. Man alone is able to form an idea of an abstract proposition or to reason about distant occurrences. He alone can reason from consequences to remote causes, and can from the creature trace an idea of the Creator. A sense of religion, then, is the characteristic peculiarity which decisively marks a separation between man and all other animals.

But as the understanding of man and the structure of his frame will occupy the following chapters, we will in this confine ourselves to a view of the other parts of animated nature. 
Animals, like vegetables, differ in their sizes and powers, with respect to the places of their growth. Those produced in a dry sunny soil, are strong and vigorous, though not luxuriant : those again produced in a warm and moist climate are luxuriant and tender, and much larger than those produced in other countries; as in the internal parts of South America and Africa, particularly in the former place, where the earth worm is near a yard long, and an inch thick; the Serpents sometimes forty feet in length ; the Bats as large as Rabbits; Toads bigger than Ducks ; ind the Spider equal in size to the English Sparrow. But in the frozen regions of the north, animals are scarce; and what few there are, except the Bear, are not above half the size of those in the temperate zone.

A nimals are also found to vary considcrably according to their food or climate: and there are but. few of the animai kingdom, (and these are they that are the most useful) which are found capable of attending man in his peregrinations' over the globe. In uncultivated nature, the animal kingdom exceeds the 
vegetable; but, in a state of improvement, the interest of man so directs it, that the vegetable kingdom should gain the ascendancy; for on a review of the animal and vegetable world, we find but few animals, which are intrinsicaliy serviceable to man; while on the other hand, numbers of them are noxious to his food, and inveterate enemies to his interest.But among the vegetable world, very few are noxious; and the greater part of them yield either food, medicine, or some other valuable article. Therefore, it always has, and will remain to be, the interest of man, to diminish the number of animals, and increase that of vegetables; and in assistance to his endeavours, providence has wisely ordered it, that one animal shall subsist on another; for were they to live entirely on vegetables, myriads would soon become extinct, for want of support.

The number of animals, which are immediately serviceable to man, (exclusive of the smaller, among the birds and fishes, which serve for food) does not extend to one hundred; while, we are acquainted with no less than twenty thousand; 
and even this great number, comprehends but a small portion of animated nature. Not only the earth, air, and sea, teem with myriads of living creatures, but almost every vegetable, and each single leaf, is covered with an endless number of inhabitants, whose various forms and properties have afforded matter of astonishment to the microscopic observer.

Animals are nourished by food, taken in at the mouth, digested in the stomach, and thence, by fit vessels, distributed over the whole body; but of the process by which the various vegetable productions, which form the food of a large portion of animals, is converted into part of the animal, we are totallyignorant. That this change does take place we know, but in what manner we know not any more than the animals themselves do, whose natural organs perform, unknown to them, the functions that are necessary for producing these changes.

The greatest part of animals have five senses, viz. seeing, hearing, smelling, tasting, and feeling. These, and the way of nourishment of animals, we shall more 
particularly consider, as they are common to man with beasts, in the following chapter.

Animals are generally divided into male and female, and some are both male and female, and are called hermaphrodites, as the earth worm and some others. With regard to their manner of propagation, they are divided into oviparous, bringing forth eggs; and viviparous, bringing forth their young alive.

Linnæus divides animals, according to their internal structures. Some have the heart with two ventricles, and hot, red blood:-viz. Quadrupeds and Birds; others have the heart with one ventricle, and cold, red blood, viz. Amphibia and Fishes; the former being furnished with lungs, and the Fishes with gills. Some have the heart with one ventricle, and cold, white serum, viz. Insects and Worms; the former being furnished. with feelers, and the latter with holders. All quadrupeds; which have teats, are distinguished by their teetl. These form the following seven orders; the Primates or Principals, which have four sutting teeth in each jaw ; the Brutre o: 
Brutes, which have no cutting teeth; the Feræ or Wild Beasts, which have six cutting teeth in each jaw; the Glires, or Dormice, which have two clitting teeth both above and below ; the Pecora, or Cattle, which have no cutting teeth above, and six or eight below; the Belluæ; or Beasts, properly so called, which have the fore teeth blunt; and the Cetx, or those of the Whale kind, which have cartilaginous teeth. This is the brief outline of this celebrated Naturalist's arrangement, the names of the different animals, and their respective classes, occupying no less than two large octavo volumes; but the natural division of animated nature, is universally allowed to be the five following classes; Quadrupeds, Birds, Fishes, Insects, and Amphibious Animals; tho' it must be confessed that this distribution is not exactly defined by nature; as there are many animals whose form and qualities render it difficult to reduce them to any one of these classe's.

I. Quadrupeds. Quadrupeds are a large and useful class of animals, whose generic characters are these; their bodies are corered with hair; they have four feet; 
they are viviparous; and the females suckle their young.

Quadrupeds are the most important creatures to man, and deserve his attention more than the inhabitants of either the air, or the water. They inhabit the same soil with man; and among them are found beings possessing a greater share of instinct than the inhabitants of either air or water; they breathe through their lungs, like the human species; like these: they are viviparous; they have also warnz red blood circulating through their veins; and, however mortifying the reflection to human pride, many of them, both in their internal and external form, bear a strong: resemblance to man; the interior structure of some of the ape kind, so nearly resembles that of the human kind, that anatomists can scarcely discover where the peculiarity exists.

Though the characters of Quadrupeds are so obvious, yet as all the parts of nature are united together, to form one grand whole; there are several species, which seem to be of an equivocal nature, and which form the links, uniting different animals together; as the Bat $\mathrm{S}$ 
and Porcupine, the former of which pos sesses wings, and the latter quills, like Birds ; the A rmadillo is covered with a hard shell, by which it seems to partake of the nature of Insects, or Snails ; and the Seal and the Morse, though evidently of the quadruped kind, are furnished with fins, and resicle almost constantly in the water.

Quadrupeds, like all other animals, are wisely adapted by Providence to their respective situations and natures. Those which turn up the ground in pursuit of their food, have sharp snouts : others, which require a keener scent, as dogs, particularly those of the chase, have long noses, whereby the olfactory nerves are more perfect: while others, of a rapacious nature, have short thick noses, whereby their jaws have a greater muscular power, as those of the Lion; and all granivorous animals have a strong tendinous ligament, extending from the head to the middle of the back, to enable them to hold down their heads to the ground; the fore teeth of these animals are also edged, for the purpose of cutting their food; but those of carni- 
vorous animals are sharp, and serve rather as weapons of defence, In both, however, the surfaces of the grinding teeth are unequal and jagged, locking into each other when the jaws are brought into contact. The stomach of carnivorous animals is also small and glandular; and affords such juices as are best adapted to digest and macerate its contents; but those animals which subsist on a vegetable diet, have four stomachs; all which serve as so many laboratories, to prepare the food for the nourishment of the body; and, in general, granivorous animals, whose food is easily procured, have large capacious stomachs, and capable of great dilation; whereas carnivorous creatures have the stomach more contracted, and the intestines curtailed, whereby they are enabled to subsist for a longer time without food. Strong large animals, which are neither tormed for pursuit nor flight, as the Elephant, Phinoceros, Sea-Horse, \&c. have thick massy legs, to support their unweildy bodies. While Deers, Hares, and other creatures, whose safety depends on flight, and who are beset by numberless ene. 
mies, have long, slender, but muscular legs. Those formed for a life of rapacity have their feet armed with sharp claws, which in some species are retractile, as those of the Cat; and, on the contrary, peaceful animals are generally furnished with hoofs, which often serve as weapons of defence ; and the feet of those which subsist on fish, have membranes betwen the toes, the better to enable them to pursue their prey in the watery element.

The larger species of Quadrupeds are, in general, the most harmless and inoffensive; and, as if sensible of their own innocence, they possess the most courage; while the more rapacious animals are inferior to those in size, and also in courage; and, except the Dog, there is no carnivorous quadruped, that will voluntarily attack another animal, when the odds is against him. Thus nature has furnished the most inoffensive animals with superior size and strength ; and opposed to them the carnivorous kinds, which possess more cunning and agility, whereby an equilibrium is preseved between the numbers of the different kinds, 
The carnivorous animals are, in general, confined to their retreats during the day, and commit their depredations by night; when the forest resounds with the tremendous roar of the Lion, the hideous yell of the Tiger; the barking of the Jackal; the dismal cry of the Hyæna; and the hissing of the Serpent. Most of these kinds of animals take their prey by surprise from some ambush, where they lay in wait, more than by a regular pursuit. There are some, however, which pursue in companies, mutually encouraging each other by their cries, as the Jackal, Syagush, Wolf, and Dog. Carnivorous animals will sometimes devour the lesser rapacious species; but they generally prefer the flesh of granivorous creatures, and commit their devastations among the peaceful domestic flocks and herds. -The most defenceless creatures have different methods of providing for their safety. Some find protection in the holes they form in the earth; others are enabled to escape their pursuers by flight; others again unite for their mutual defence, and gain, by numbers, what they want inclividually in strength; and, lastly, others S2 
avoid their enemies, by placing some of their own company as centinels, to warn them of the first approach of danger; a duty in which they are seldom negligent, and for the neglect of which they are invariably punished by the rest.

II. Birds.-Birds, next to quadrupeds seem to demand our attention. The generic characters of this class of animals are these ; the body is covered with feathers, and furnished with two legs, two wings, and a hard horny bill; and the females are oviparous.

Birds are infinitely more numerous in their different kinds than quadrupeds ; but still less so than Fishes. They seem designed by providence for a solitary life; and though inferior to the brute creation in the powers of attack and defence, they possess a greater faculty of escape; and the greater part of them immediately elude their enemies of the quadruped and reptile nature, by an aerial escape; for which all parts of their bodies seem admirably adapted; the external form of the body being sharp before ; swelling gradually, and terminating in a $l_{\text {ge spreading tail, }}$ which renders it buoyant, while the fore part cleaves the air. 
The clothing of these animals is exactly suited to their manner of life. The feathers all tend backwards, and neatly and closely fold over each other, which answer the triple purposes of warmth, speed and security. Those placed next the skin are furnished with a warm soft down; while the exterior ones are arrayed with double beards, longer at one end than the other, and which consist of thin little laminæ, disposed in regular lines, and perfectly even at their edges. The shaft of each feather is formed of a thin hollow tube, which answers the purposes of strength and lightness ; the upper part being filled with a soft pith, to afford nourishment to the beards. They are so placed, that the largest and strongest, or those of the wings and tail, have the greatest share of duty to perform in flight. The upper external side of each single filament, in the beard of the feather, is furnished with hairs on its edges, which lock into those of the next filament, and thus form an entire, but light, smooth surface. Birds are also furnished with certain glands upon their rumps, which contain a quantity of oil, which they press out with their beaks. 
and rub over their feathers; in order to smooth them, and enable them to turn off the water. Aquatic Birds, as the Duck, Goose, $\mathcal{E}^{2} c$. have a greater quantity of this oil ; but those who live principally under cover, and seldom expand their wings, have a less proportion of it ; as the common Hen, whose feathers are impervious to every shower of rain.

Birds possess a perfection of sight far superior to that of either man or brute, which is necessary for their safety and support: Were it less perfect, Birds of rapid flight would strike against every object in their way; and be unable to discover their proper food at a clistance. 'The Kite darts on its prey, from the greatest heights to which it ascends; and the Hawk will discover a Lark, at a distance too great for human perception.

Aquatic Birds have webbed feet, or membranes between their toes, to assist them in swimming; other Birds have their toes disjoined, the better to enable them to catch their prey, or cling to the branches of trees. Birds, with long legs, have also long necks, to enable them to pick up their food; but some Aquatic Birds, as 
the Swan and Goose, have long necks and short legs.

Birds are destitute of urinary bladders yet they have large kidneys and ureters, by which the secretion of urine is performed, and then carried away with the other excrements, in one common canal ; by which means they are less obnoxious to diseases than quadrupeds, who drink much and have a separate passage for the ejection of the fluid excrement.

The greater number of Birds pair at the approach of spring ; and the compact entered into is inviolably observed, for that season at least; but some species enter into this connection for years, and even for life.

All Birds are oviparous, and the Hens of some species will lay eggs though they be not accompanied by the Male; as the common domestic Hen; but eggs of this kind are always sterile, never producing a live animal. Every bird builds its nest in such a manner, and with such materials, as best to answer its own purpose and sit- uation; thus the Wren, which lays a great number of eggs, requires a very warm nest ; as her body is not sufficiently large to 
cover the whole of them; but the Crow and Eagle are less solicitous in the warmth of their nest, as the small number of eggs they lay, and largeness and heat of their bodies, afford the eggs sufficient warmth. The same Bird also, when in a cold climate, lines its nest with more care and warmer materials than in a warmer climate. The male likewise of most birds, during the season of incubation, supplies the place of the female, in her absence from the eggs; and supplies her with food during the time of her sitting.

Those birds which are hatched early in the season, always prove more vigorous and strong, than such as have been delayed till the middle of summer. The number of eggs, which a bird will lay, is not exactly ascertained; but it is well known, that a female Bird, which would have lain but two or three eggs at most, will, on her eggs being removed, lay above ten or a dozen. A common Hen, if properly fed, will produce above a hundred eggs, from the beginning of spring to the end of Autumn. Nature has wisely ordered it, that the smallest and weakest birds; and in general, all those which are 
most serviceable to man, are the most prolific: while the strong and rapacious kinds are marked with sterility.

Birds are in all countries, longer lived than the brute creation; the Linnet will often live fourteen or fifteen years; the Bullinch twenty; the Goose fourscore; while Swans, Eagles, and some others, have been known to live two, or even three hundred years.

The number of species of Birds, which mankind has rendered domestic, are-but few, as the Peacock, Turkey, common Hen, Guinea-Hen, Pigeon, Swan, Goose, Duck, and Guinea-Duck, being only nine, while the number of all the species known exceed fifteen hundred.

III. Amphibious animals are all those who are capable of living either on land or in the water. They are furnished with lungs and air bladders, adequate to this purpose. Such are the Frog, Castor, Otter, Tortoise, Sea-Calf, Alligator, \&c.

Numbers of insects, particularly of the Fly kind, appear to be amphibious; Gnats always drop their eggs in water, where the young are hatched, and live after the manner of fishes; till at length they un- 
dergo a metamorphosis, take wing, quit their natural element, and become inhabitants of the air.

IV. Fishes.--Fishes are a class of creatures that appear, both in structure and sagacity quite inferior to other animals; though capable of enduring famine an amazing length of time, they appear most voracious creatures; a ceaseless desire for food seems the ruling impulse of their actions; and their life one continued scene of violence or evasion.

Most fishes present the same external form; sharp at both ends, and bulky in the middle; which shape is most convenient for their passage through the watery element. Mankind have imitated this form, in the construction of their marine vessels; but the progress of such machines is far inferior to that of fishes; any of which, will, with ease, outstrip a ship in full sail ; play around it, loiter behind, and overtake it.

The instruments of motion in these animals are the fins; of which the general complement is two pair, and three single fins; though some fish possess more, and many less than this number. The 
pectoral fins, are placed at some distance behind the opening of the gills ; and are generally strong and large; answering the same purpose, to a fish, as wings do to a bird in the air; namely, pushing the body forward, like the oars to a boat. They also serve to balance the body of the fish, and prevent the head from sinking, which it would otherwise do. The ventral fins are placed under the belly, towards the lower part of the body; these are always extended flat on the water, in all situations; and serve to raise or depress the body of the animal, rather than assist his progression. The dorsal fin, is situated along the ridge of the back; and serves to keep the fish in equilibrium, and also assists it in its velocity. This fin is very large, in all the flat fish; the pectoral fins of which are proportionably less. The anal fin, extends from the anus to the tail, and serves to keep the body of the animal upright, or in a vertical direction. In some fishes, as before observed, the tail is horizontal, and in others perpendicular.Thus equipped, these animals have the most rapid motions; and perform voy- 
ages, of upwards a thousand leagues ita one season.

Fish are also furnished with a slimy glutinous matter, which overspreads the whole body, and defends them from the corossive quality of the water. Beneath this matter, some have a strong covering of scales, which, like a coat of armour, protects the body from injuries. Beneath which, again, there is an oily substance, which supplies the animal with the necessary warmth and vigour.

Fishes pussess most of the senses in: an inferior degree to land animals.Their sense of smelling, (though furnished with nostrils) is less perfect, than in the other parts of animated nature, as must be evident from the nature of the fluid they inhabit ; this sense in them can only act, from the action of the fluid, tinctured with the odour of the object, upon the olfactory nerves within, in the same manner as the palates of other animals discover tastes. Their sense of taste must also be very imperfect ; their palate being of a hard bony nature; -whereas, in quadrupeds who possess this sense in an exquisite degree, this 
organ is very soft and pliant. From this indiscrimination, fish will frequently swallow the plummet, as well as the bait. Their sense of hearing is still more defective, if they possess this faculty at all, as is evident from the frequent experiments which have been made. No fish, except the whale kind, have the least appearance, on dissection, of any auditory organs. Their sense of sight, is however somewhat more perfect, though inferior to that of most other animals. They are totally destitute of eyelids; the eyes being covered with the same skin that overspreads the rest of the body.

The period to which fishes live, is very little known, though it is generally believed they attain to a considerable age; some of the least exceed in their age that of a man. The method of discovering their ages, is either by examining the transverse coverings of their scales, by means of a microscope ; or by the transverse section of the back bone. Buffon found a carp which by the former method of computation appeared to be 2. hundred years old, allowing one year 
for every covering of the scales; the Skate, and Ray, like other fish which have no scales, have their ages discovered, by seperating the joints of the back bone, and then examining the number of rings which the surface exhibited where it was joined, allowing one year for each ring. Little can be said in favour of the certainty of either of these methods; they however, though not infallible criterions, enable us to make a near approximation to the truth.

The greatest singularity in fishes, is their amazing fecundity. Some are viviparous, and others oviparous ; the latter produce their young, or rather their eggs, in far greater abundance than the former; but at the same time they are more subject to become the prey of other fish, and even of their own species, not excepting the parent itself which excluded them, while they continue in their egg state; consequently but very few of these eggs produce live animals, though produced in such considerable. numbers. A single Cod will produce above nine million of eggs in one season; and many other fish have as pro. portionable an increase. 
V. Insects.-Insects and animals of the worm kind, seem to form the lowest order among the various tribes of living creatures which inhabit our globe. The distinguishing characters of insects are, that their bodies are covered with a sort: of bony substance instead of skin ; and their heads furnished with antenna ot horns. An insect, may more particular. ly be defined a small animal without red. blood, (this matter being. white and cold) bones, or cartilages; furnished with a trunk, or else a mouth, which opens length ways, contrary to the natural order; the eyes destitute of covering; and lungs opening on the sides of the body. This definition will comprehend the whole class of insects of every description. This class of beings is so numerous, and so various, as to exceed the most accurate and unwearied observations.To give the different species of only flies and moths, would be a fruitless attempt ; but to give the history of every species of insect would be utterly impracticable ; so varied are they in their forms, sizes, habitudes, methods of propagation, and manners and duration of life. A gener.

$$
\mathrm{T} 2
$$


al division of them, however, according to their most apparent external differences of form, may be attempted.

The first class of these beings, which present themselves to our observation, appear to be those which are destitute of wings, and are seen crawling about on every plant and spot of earth. Some of these never acquire wings, but continue in this reptile state during their whole lives. These are all oviparous, except the Flea and the Wood-Louse; and properly constitute the first division of insects. Others which hereafter become winged insects, belonging to the following divisions.

The second grand division of insects, are those furnished with wings; but which, when first produced from the egg, appear like reptiles, and have their wings so cased up, as to be quite concealed; but when these cases break, the wings expand, and the animal acquires its perfect form and beauty. Of this nature are the Dragon Fly, the Grasshopper, and the Ear-wig.

The third order of insects, are those of the Moth, and the Butterfly kind, 
which have all four wings each, covered with a mealy substance of various colours, which easily rubs off; and when examined by the microscope, appears to be elegant scales. These insects have a peculiar method of propagation ; they are oviparous: and when first hatched from the egg, are perfect caterpillars, which often shed their skins ; and after having divested themselves of their skins for the last time, assume new coverings called chrysalides, in which state they continue till they come forth in their perfect winged. forms.

The fourth division include those winged insects which originate from Worms, and not from Caterpillars like the former, though they undergo similar transformations. Some of these are furnished with two, and others with four wings each. The wings of animals of this clas $\$$ differ from those of the Moth and Butterfly kind, in being destitute of those scales with which these are furnished. This class includes all the numerous class of Flies, Gnats, Beetles, \&c.

The fifth and last class of insects, contain those which naturalists have termed 
Zoophytes; and are distinguished by their peculiar mode of propagation, su different from the ordinary course of nature. They may be multiplied by dissection; and some of them, though cut in a hundred pieces, will still retain the vital principle in each separate part ; each part shertly becoming a perfect animal; which may again be increased in the same manner. To this class belong the Polypus, the Earth-worm, and all the varieties of the Sea Nettle.

Insects are furnished with all the necessary appendages proper-to each, for the purposes of defence, of flight, or providing for their own subsistence. The different parts of their bodies, are also constructed with admirable skill. The eye, for instance, is differently formed from that of any other creature: it is externally rigid, whereby it is not obnoxious to many injuries ; the cornea is divided in every part into lenticular facets, which, viewed by the microscope, appear like a beautiful piece of lattice-work, each opening reflecting the rays of light so, that when looked through; the object appears inverted, and thereby supplies the place of 
erystalline humour, of which insects are intirely destitute. Larger animals are obliged to turn their eyes towards the object they wish to behold, but many insects, as flies, have their eyes so constructed as to admit the view of every neighbouring object at once. The numbir of eyes are very different in different insects; some have only one ; others have two; spiders have generally eight; and flies have as many as there are perforations in the cornea, which are very numerous. Most insects are furnished with two antennæ, or feelers, which serve to keep their eyes clean. Amphibious insects have their feet formed of flat joints ; and gristles placed on each side of the extremity of the limb, which supply the place of oars, as in the Water-Beetles. Insects formed for leaping, as the Cricket and Grasshopper, have strong, brawny, muscular legs; while those who use their claws in perforating the earth, have these members admirably adapted for this purpose.

Insects and reptiles, though seemingly the most insignificant of animated beings have an important part assigned them to perform in this universe. Though the 
duration of their life be but as a moment and their strength, when compared with that of the larger animals, as nothing yet their power is often irresistible. The strongest animal which treads the earth is frequently driven to madness by the endless irritation these insignificant beings produce; the sun himself is deprived of his light by the shading of their wings, and every leaf that can give support to animal life is often swept, at once, away by their devouring jaws; neither has the ingenuity of man, which subdues the strongest, and reclaims the most ferocious animals, enabled him to devise the means of defending himself from the devastation of these active invaders of his rights. His very existence itself, on many occasions, depends upon his speedily withdrawing beyond the sphere of their active incursions.

If their power be thus irresistible, their utility is not perhaps less conspicuous on this globe. Man has ever been able, on some occasions, to make them become subservient to his will. The bee collects honey for his use ; the moth, under his influence, affords him silk; the cantharis 
an active drug; the cochineal insect the most brilliant of his dyes. Even where they are totally beyond his control they minister indirectly to his wants. Under the form of eggs, maggots, grubs, caterpillars, aureliæ, and flies, they furnish food to innumerable creatures, who augment his comforts in a thousand ways. But it is as the scavengers of this universe that these puny beings become chiefly salutary to man, and all animated nature. Without their unceasing aid in this respect, the air would become quickly tainted with the most noxious effluvia, which would soon put an end to animal existence. To obviate this, the beneficentCreator hath decreed, that a numerous department of this class of beings, while in their reptile state, shall be unceasingly employed in searching for and devouring every thing that has once lived, and is now tending to decay.Under this state of degradation these creatures are doomed to labour for a time with unceasing assiduity: and that nothing might divert their attention from this important business, even for one moment, the distinctions of sex are withheld from them while in this state; nov 
does it seem that these have a single perceptive faculty, unless it be that of striving to preserve their existence, and allay their insatiable appetite for food.Having, at length, however, with the most patient assiduity, performed the mental task that was assigned them, they are then called, by the bounty of the Creator, into another and superior state of existence, in which thev are destined to perform a part the most opposite which can be conceived to that they formerly acted. The unsightly grub, after a temporary death, awakens into new. life ; and deserting the clod it lately inhabited, and nauseating its former food, sports in the sun-beam, and sips the balmy dew ; nor does the butterfly, now arrayed in the most gorgeous attire, seem to claim the most distant alliance with the ugly caterpillar from whence it sprang. The attraction of sex seems to form the chief business of this period of life ; food is neglected as if unnecessary, and its life is deroted to amorous dalliance alone. Having soon provided a numerous progency of voracious labourers, it leaves this transitory scene, to make room for those who are destined 
to supply its important place in the universe.

The changes and transformations of insects are first from the ovum (egg) into the larva (caterpillar or maggot; ) then into the pupa (chrysalis) and lastly into the imago (fly.) Pupa is a name derived from the resemblance of the insect in this state to an infant in swaddling clothes ; and the term is now used in preference tochrysalis. The period of existence in each of these states varies greatly in different species of insects; but in general they continue much longer in the reptile state than in that of the fly. The species of fly called ichneumon remains in the water as a kind. of worm for the space of about two years; in its fly state it seldom continues more than one day. The ephemeron is nearly the same ; and the grub of the cockchaffer remains under ground for about two years also ; in its fly state it in general exists only about two months. 


\section{nowaven \\ CHAP. XII. \\ Of the Human Frame.}

MAN is placed at the head of the animal creation. Animated and enlightened by a ray from the Divinity, he surpasses in dignity every material being. He was made after all other creatures, not only as the most perfect, but as the surperintendent and master of all things ; created "to rule over the fish in the sea, and over the fowl of the air, and over cattle, and over the earth, and over every creeping thing."

The body of a well-shaped man ought to be square, the muscles ought to be strongly marked, the contour of the members. boldly delineated, and the features of the face well defined. In women, all the parts are more rounded and softer, the features are more delicate, and the complexion brighter. To man belong strength and majesty ; gracefulness and beauty 
are the portion of the other sex.-Every thing in both sexes points them out as sovereigns of the earth; even the external appearance of man declares his superiority to other living creatures. His head tends towards the heavens, and in his august countenance beams the sacred ray of sapient reason. He alone sheds the tears which arise from emotions of sensibility, unknown to animals; and he alone expresses the gladness of his soul by laughter. His erect posture and majestic deportment announce his dignity and superiority. He touches the earth only with the extremity of his body; his arms and hands, formed for nobler ends than the correspondent organs of quadrupeds, execute the purposes of his mind, and bring every thing within his reach, which can minister to his wants and his pleasures. By his eyes, which reflect the intelligence of thought, and the ardour of sentiment, and which are peculiarly the organs of the soul, are expressed the soft and tender, as well as the violent and tumultuous passions. They are turned, not towards the heavens, but to the horizon, so that he may behold at 
once the sky which illuminates, and the earth which supports him. Their reach extends to the nearest and the most distant objects, and glances from the grains of sand at his feet, to the star which shines over his head at an immeasurable distance.

1.The human body consists of solid and fluid parts, which in general are called the solids and fluids, or humours of the body. The solid parts are bones, cartilages, ligaments, muscles, tendons, membranes, nerves, arteries, veins, ducts, or fine tubular vessels of various sorts. Of these simple solids the more compound organs of life consist, viz. the brain and cerebellum; the lungs, the stomach, the liver, the spleen, the pancreas, the kidneys, the glands, the intestines, together with the organs of sense, viz. the eyes, the ears, the nose, and the tongue.

The fluid parts of the human body are chyle, blood, saliva or spittle, bile, milk, lympha, the semen, the pancreatic juice, zirine, phlegm, serum, and the aqueous humour of the eyes.

Anatomists have employed much pains in the study of the material part of man, 
and have assigned to each of the above parts their appropriate use in the economy of his frame, but none, perhaps have given so comprehensive and eloquent a description of the structure of man as the late Dr. Hunter. "In order" says this celebrated anatomist, "to acquire a satisfactory general idea of this subject, let us, in imagination, make a man; in other words, let us construct a fabric fit for the residence of an intelligent soul. This soul is to hold a correspondence with all material beings around her; and, to that end, she must be supplied with organs fitted to receive the different kinds of impressions which they will make. In fact, therefore, we see that she is provided with the organs of sense, as we call them : the cye is adapted to light; the ear to sound; the nose to smell; the mouth to taste; and the skin to touch. Farther, she must be furnished with organs of communication between herself in the brain and those organs, to give her information of all the impressions. that are made on them; and she must have organs between herself in the brain and cvery other part of the body fitted 
to convey her commands and infiuence over the whole. For these purposes, the nerves are actually given. They are chords which rise from the brain, the immediate residence of the mind, and disperse themselves in branches through. all parts of the body. They are intended to be occasional monitors against all such impressions as might endanger the wellbeing of the whole, or of any particular part; and this vindicates the Creator of all things in having actually subjected us to those many disagreeable and painful sensations which we are exposed to form a thousand accidents in life. Moreover, the mind, in this corporeal system, must be endued with the power of moving from place to place, that she may have intercourse with a variety of objects; that she may fly from such as are disagreeable, dangerous, or hurtful, and pursue such as are pleasant and useful to her ; and, accordingly, she is supplied with muscles and tendons, the instruments of motion, which are found in every part of the fabric where motion is necessary; but, to give firmness and shape to the fabric; to keep the softer parts in their proper place; to give fixed points for, and proper direction to, 
its motions, as well as to protect some of the more important and tender organs from external injuries, there must be some firm prop-work interwoven through the whole;-and, in fact, for such purposes the bones were given. The propwork must not be made into one rigid fabric, for that would prevent motion. Therefore, there are a number of bones*. These pieces must all be firmly bound together, to prevent their dislocation; and this end is perfectly answered by tha ligaments. The extremities of these bony pieces, where they move and rub upon one another, must have smooth and slippery surfaces of easy motion. This is most happily provided for by the cartilages and mucus of the joints. The interstices of all these parts must be filled up with some soft and ductile matter, which shall keep them in their places, unite them, and at the same time allow them to move a little upon one another; and

* Dr. Keill reckons 245 bones in the human body, other's make them to be 249 , viz. In the sknil 14, in the face and throat 46 , in the trunk 67 , in the arms and hands 62 , and in the legs and feet 60 . 
these purposes are answered by the cellat. lar membrane, or adipose substance.There must be an adequate covering over the whole apparatus, both to give it compactness and to defend it from a thousand injuries; which, in fact, are the very purposes of the skin, and other integuments. Lastly, the mind being formed for society and intercourse with beings of her own kind, she must be endued with powers of expressing and commuaicating her thoughts by some sensible marks or signs, easy to herself and capable of great variety ; and accordingly she is provided with the organs and faculty of speech, by which she can throw out signs with amazing facility, and vary them without end.

"Thus we have built a body which seems to be pretty complete; but, as it is the nature of maiter to be worked upon and altered so, in a very little time, such a living creature must be clestroyed, if there is no provision for repairing the injuries which she will commit upon herself, and those which she will be cxposed to from without. Therefore, a treasure of blood is actually provided in the heart 
and vascular system, full of nutritious and healing particles, fuid, and able to penetrate into the minutest parts of the animal ; impelled by the heart, and conveyed by the arteries, it washes every part, builds up what was broken down, and sweeps away the old useless materials. Hence we see the necessity or advantage of the heart and arterial system.What more than enough there was of the blood to repair the present damages of the machine, must not be lost, but should be returned again to the heart; and for this purpose the veins are actually provided. These requisites in the animal, explain a priori, the circulation of the blood. The old materials, which are become useless, and are swept off by the current of the blood, must be separated and thrown out of the system. Therefore the glands, the organs of secretion, are given for straining whatever is redundant, vapid, or noxious, from the mass of blood; and, when strained, they are thrown out by emunciories, called organs of excretion. But now, as the machine znust be constantly wearing, the operations must be carried on without inter- 
mission, and the strainers must be always employed; therefore, there is actually a perpetual circulation of the blood, and the secretions are always going on. Even all this provision, however, would not be sufficient; for that store of blood would be soon consumed, and the fabric would break down, if there were not a provision made for fresh supplies. These we observe in fact are profusely scattered round her in the animal and vegetable kingdoms; and she is furnished with hands, the fittest instruments that could have been contrived, for gathering them, and for preparing them in a variety of ways for the mouth. But these supplies, which we call food, must be considerably changed; they must be converted into blood. Therefore, she is provided with teeth for cutting and bruising the food, and with a stomach for melting it down ; in short, with all the organs subservient to digestion. The finer parts of the aliments only can be useful in the constitution : these must be taken up and conveyed into the blood, and the dregs must be thrown off. With this view, the intestinal canal is actually given. It separates the nutritious 
part, which we call chyle, to be conveyed into the blood by the system of the absorbent vessels; and the feces pass downward out of the body. Thus we see that, by the very imperfect survey which human reason is able to take of this subject, the animal man, must necessarily be complex in his corporeal system, and in its operations; and in taking this general view of what would appear, a priori, to be necessary for adapting an animal to the situations of life, we observe, with great satisfaction, that man is accordingly made of such systems, and for such purposes. He has them all : and he has nothing more, except the organs of respiration. Breathing it seemed difficult to account for a priori; we only know it to be a fact essentially necessary to life.Notwithstanding this, when we see all the other parts of the body, and their functions so vell accounted for, and so wisely adapted to their several purposes, there would be no cloubt that respiration was so likewise; and, accordingly, the discoveries of Doctor Priestley have lately thrown light upon this function also. "Of all the different systems in the 
human body the use and necessity are not more apparent, than the wisdom and contrivance which has been exerted in putting them all into the most compact and convenient form ; in disposing them so that they shall mutually receive and give helps from one another; and that all, or many of the parts shall not only answer their principal end and purpose, but operate successfully and usefully in a variety of secondary ways. If we consider the whole animal machine in this light, and compare it with any in which human art has exerted its utmost skill (suppose the best constructed ship that ever was built,) we shall be convinced, beyond the possibility of doubt, that there exists intelligence and power far surpassing what human art can boast of. One superiority in the animal machine is peculiarly striking. In machines of human contrivance, or of art, there is nointernal pow er, no principle in the thing itself, by which it can alter and accommodate itself to any injury that it may suffer, or make up any injury that admits of repair ; but in the natural machine, or animal bo$\mathrm{dy}$, this is most wonderfully provided fos: 
by the internal powers of the machine itself ; many of which are not more certain and obvious in their effects, than they are above all human comprehension as to the manner and means of their operation. Thus, a wound heals up of itself; a broken bone is made firm by a callus; a dead part is separated and thrown off; noxious juices are driven out by the emunctories; a redundancy is removed by some spontaneous bleeding; a bleeding naturally stops of itself; and a great loss of blood, from any cause, is in some ineasure compensated by a contracting power in the muscular system, which accommodates the capacity of the vessel to the quantity contained. The stomach gives information when the supplies have. been expended, represents with great exactness the quantity and quality of what is wanted in the present state of the machine, and in proportion as she meets with neglect rises in her demand, urges her petition in a louder tone, and with more forcible arguments. For its protection, an animal body resists heat and cold in a very wonderful manner, and preserves an equal temperature in a burning and iv 
a freezing atmosphere. These are powers which mock all human invention or imitation ; they are characteristics of the Divine Architect!"

Part of the motions of the complicated frame of man, in common with all animated beings, are voluntary, or dependent on the mind ; and part involuntary, or without the mind's direction.

How the incorporeal existence, which we call mind, can operate on matter, and put it in motion, is to us perfectly incomprehensible. When the matomist considers the number of muscles that must be put in motion before any animal exertion can be effected; when he views them one by one, and tries to ascertain the precise degree to which every individual muscle must be constricted, or relaxed, before the particular motion indicated can be effected, -he finds himself lost in the labyrinth of calculations in which this involves him; but when he considers that every one of these muscles must be constricted or relaxed to the precise degree that appertains to each, and no more, and at the same instant of time ; when he recollects, that the smallest jar- 
ring in this respect in any one of these would throw the whole into inextricable disorder; when he considers with what promptitude the whole of this is done in an instant by the mere act of his volition, and how in another instant, by a change in that volition, all these muscles are thrown into a different state, and a new set brought into action, and so on continually as long as he pleases, his mind is lost in the immensity of wonder that this excites. But when he farther reflects, that it is not only he himself that is endowed with the faculty of calling forth those incomprehensible energies, but that the most insignificant insect is vested with powers of a similar sort, he is still more confounded. A skilful naturalist has been able to perceive, that in the body of the poorest caterpillar, which, in the common opinion, is one of the most degraded existences on the globe, there are upwards of two thousand muscles, all of which can be brought into action with as much facility at the will of that insect, and perform their several offices with as much accuracy, promptitude, and precicion, as in the most perfect animal ; and 
all this is done by that insect with an equal consciousness of the manner how, as the similar voluntary actions of man are effected.

Nor are the involuntary motions less mysterious and wonderful. The stomach, the intestines, and all the functions necessary to life, wait not to be called into action by any volition of ours. The heart, placed near the centre of the system, performs its task as well when we are asleep, as when we are awake, by night as by day, and like an unwearied and faithful iabourer, with muscular exertions distributes the vital stream through our cumplicated frame, 'till their wearied functions cease, and the tenement of clay is inhabited no more. How admirably it is calculated to keep up this continued circulation throughout the system may be understood by the following computation by Dr. Keill:- "Each ventricle will at least contain one ounce of blood. The hearts contracts four thousand times in one hour; from which it follows, that there passes through the heart, every hour, four thousand ounces, or three hundred and fifty pounds of blood. Now 
the whole mass of blood is said to be about twenty-five pounds, so that a quantity of blood equal to the whole mass of blood passes through the heart fourteen times in one hour; which is about once every four minutes." Consider what an affair this is when we come to very large arimals. The aorta of a whale is larger in the bore than the main-pipe of the water-works at London-Bridge; and the water roaring in its passage through that pipe, is inferior in impetus and velocity to the blood gushing from the whale's heart. Hear Dr. Hunter's account of the dissection of a whale. "the aorta measured a foot diameter. Ten or fifteen gallons of blood is thrown out of the heart at a stroke, with an immense velocity, through a tube of a foot diameter. The whole idea fills the mind with wonder." It is thus, O great Author of all Things! we discover Thee in thy works.

OF THE FIVE SENSES.

Of Seeing - The organ of seeing is the Eye. It is a curious and most wonderful piece of nature's work, admirably contrived with various coats, miscles, 
vessels, and humours of three several kinds, for the purpose of vision. The first humour of the eye is called the aquer ous humour, being in all respects like water, but of a spirituous nature; for it will not freeze in the greatest cold. The second is called the crystalline humour, being transparent, and more solid than either of the other ; its figure resembles an optic lens, convex on both sides, and its use in the eye is the same. Behind this lies the vitreous or slassy humour; it is very much like the white of an egg; it is in greater abundance than either of the other; it gives the eye its spherical form ; and is thicker than the aqueous, but thinner than the crystalline humour. Next this humour, on the bottom of the eye, is spread a fine curious membrane, called the retina, through which are expanded the mechliary fibres of the optic nerve, which come from the brain. Now the rays of light, which come from all parts of any object, falling upon the aqueous humour of the eye, are through it refracted to the crystalline huhumour, by which, as a double conver lens (kept always at a proper distance by 
the glassy humour) they are all converged and united on the retina ; the impression thereof being communicated to the common sensory of the brain by the optic nerves, doth there present to the mind the species and image of the object.

That, which immediately affects the sight, and produces in us that sensation, which we call seeing, is light.

Light may be considered either, first, as it radiates from luminous bodies directly to our eyes; and thus we see luminous bodies themselves, as the sun, or a flame, \&c. or, secondly, as it is reflected from other bodies; and thus we see a man, or a picture by the rays of light reflected from them to our eyes.

Bodies, in respect of light, may be divided into three sorts ; first, those that emit rays of light, as the sun and fixed stars; secondly, those that transmit the rays of light, as the air ; thirdly, those that reflect the rays of light, as iron, earth, \&c. the first are called huminous; the second pellucid; and the third opaque.

Opaque bodies are of two sorts, specular, or not specular. Specular bodies, or mirrors, are such opaque bodies whose 
surfaces are polished; whereby they, reflecting the rays in the same order as they come from other bodies, shew us their images.

The rays that are reflected from opaque bodies always bring with them to the eye the idea of colour; and this colour is nothing else in the bodies, but a disposition to reflect to the eye more copiously one sort of rays than another. For particular rays are originally endowed with particular colours; some are red, others biue, others yellow, and others green, \&c. Every ray of light, as it comes from the sun, seems a bundle of all these several sorts of rays; and as some of them are more refrangible than others; that is, are more turned out of their course, in passing from one medium to another, it follows, that after such refraction they will be separated, and their distinct colour observed. Of these, the most refrangible are violet, and the least red; and the intermediate ones, in order, are indigo, blue, green, yellow, and orange. This separation is very entertaining, and will be observed with pleasure in holding a prism in the beams of the sun. 
As all these rays differ in refrangibility, so they do in reflexibility, that is, in the property of being more easily reflected from certain bodies, than from others; and hence arise, as hath been said, all the colours of bodies, which are in a manner infinite, as an infinite number of compositions, and proportions of the original colours may be imagined.

The whiteness of the sun's light is compounded of all the original colours mixed in a due proportion.

Whiteness, in bodies, is but a disposition to reflect all colours of light nearly in the proportion they are mixed in the original rays; as, on the contrary, blackness, is only a disposition to absorb or stifle, without reflection, most of the rays of every sort that fall on the bodies.

Besides colour, we are supposed to. see figure; but in truth, that which we perceive when we see figure, as perceivable by sight, is nothing but the termination of colour.

Of hearing.-Next to seeing, hearing is the most extensive of our senses. The Ear is the organ of hearing.

Sounds are brought to the ear from so. 
norous bodies by means of the air $;$ and the external part of the ear is so contrived, by its ridges and hollows, that sounds, being gathered into it as into a tunnel, are thereby directed to the meatus auditorious, through which they pass and strike upon a thin transparent membrane of an oval figure, set a little obliquely across the passage of the ear; behind this membrane there is a pretty large cavity, which, with the said membrane, from its resemblance, is called the tympanum, or drum of the ear. In this cavity are four small bones, which from their form are called malleolus, or the hammer; the incus, or the anvil; the stapes, or stirrup; and the os orbicculure, or circular bone. Within the tympanum there are several other cavities, as the vestibulum, the labyrinth, and the cochlea; these internal cavities are always full of air; wherefore the sounds in the external air striking on the drum, move the four little bones in the tympanum, and these in like manner move the internal air, which maketh an impression on the fine branches of the auditory nerve spread through the vestibulum, the winding tubes of the 
labyrinth, and cochlea ; and thus all refractions and modulations of the exterternal air become perceptible, and consequently all the different sounds they convey become audible, and intelligible to the mind, by the communication of these nerves with the brain, or common sensory. That which is conveyed into the brain by the ear, is called sound, though in truth, till it come to reach and affect the perceptive part, it be nothing but motion. The motion which produces in us the perception of sound, is a vibration of the air, caused by an exceeding short, but quick, tremulous motion of the body from which it is propagated ;" and therefore we consider and denominate them as bodies sounding.

That sound is the effect of such a short, brisk, vibrating motion of bodies from which it is propagated, may be known from what is observed and felt in the strings of instruments, and the trembling of bells, as long as we perceive any sound come from them; for as soon as that vibration is stopped, or ceases in the $m$, the perception ceases also.

of Smelling.-Smelling is another 
sense. The organ of smelling is the Nose The cavity of the nose is divided into two parts, we call the nostrils, by a partition, of which the upper part is bony, and the lower cartilaginous. The upper part of the cavity is covered with a thick glandulous membrane, above which the olfactory nerve is finely branched out and spread over the membrane of the spongy bones of the nose, and other sinous cavities of the nostrils. Whence the exhalations of odours entering the nostrils make their impressions on the fibres of the nerves, which by their communication with the brain, excite in the mind the smell or sensation of odours of erery kind.

Smelling bodies seem perpetually to send forth effluvia or steams, without sensibly wasting at all. Thus a grain of musk will send forth odoriferous particles for scores of years together, without its being spent ; whereby one would conclude that these particles are very small; and yet it is plain, that they are much grosser than the rays of light, which have a free passage through glass; and gros ser also than the magnetic effluvia, which 
pass freely through all bodies, when those that produce smell will not pass the thin membranes of a bladder, and many of them scarce ordinary white paper.

There is a great variety of smells, though we have but a few names for - them; sweet, stinking, sour, rank, and musty, are almost all the denominations we have for odours; though the smell of a violet, and of musk, both called sweet, are as distinct as any two smells whatsoever.

Of Taste.-Taste is the next sense to be considered. The organ of Taste is the Tongue.

The tongue is covered with two membranes ; the external is thick and rugged, especially in beasts; the internal membrane is thin and soft ; upon it appear several papilla or small risings, like the tops of the small horns of snails; these papil$l x$ are made of the extremities of the nerves of the tongue, and piercing the external membrane, are constantly affected by those qualities in bodies, which have their tastes excited in the mind by means of these nervous papillæ; and thus are these papillæ the immediate organ of tasting. 
It may be observed of tastes, that though there be a great variety of them, yet, as in smells, they have only some few general names, as sweet, bitter, sour, harsh, rank, and some few others.

Of Touch.-The fifth and last of our senses is Touch; a sense spread over the whole body, though it be most eminently placed in the ends of the fingers.

By this sense the tangible qualities of bodies are discerned; as hard, smooth, rough, dry, wet, clammy, and the like.

But the most considerable of the qualities that are perceived by this sense are heat and cold.

The due temperament of those two opposite qualities is the great instrument of nature, that she makes use of, in most, if not all her productions.

Heat is considered by some as merely the consequence of a very brisk agitation of the insensible parts of the object which produces in us that sensation, but it is most generally supposed that these effects depend on a certain matter called caloric, or the matter of heat.

Bodies are denominated hot and cold in proportion to the present temperament 


\section{Human Frame.}

of that part of our body to which they are applied; so that feels hot to one which seems cold to another; nay, the same body felt by the two hands of the same man, may at the same time appear hot to the one, and cold to the other. 
260 Human Understanding.

\section{$=$ \\ CHAP. XIIY.}

Of the IIuman Understanding.

THE understanding of Man is what particularly exalts him above the brute creation. Though some of the most sagacious of animals appear, in regard to intellect, in certain points of view, to approximate to the lowest of the human species, yet there can be no doubt that man is much farther exalted above them all, than any one of these excels the next below it ; for though many of the higher orders possess a kind of memo$r y$, and the faculty of reasoning in a certain degree; though "the ox knoweth his owner, and the ass his master's crib," yet, unless it be in recollecting their dependence on others for food, and a few circumstances of a similar nature, ten. ding chiefly to the preservation of exist- 


\section{Human Undersianding. 261}

ence, the intellectual powers of even the highest is extremely circumscribed.The dog is a favoured, and a very sagacious domestic animal: he feels the benign influence of the parlour fire, and enjoys it as much as any of the human species; but he never can be made sensible of the uses to which heat may be applied in changing the nature of bodies which are subjected to its power; he never can be made to conceive how a piece of coal, or a billet of wood, can augment the heat, and continue to support it ; and thus he cannot spontaneously feed the fire when occasion shall require it ; a degree of reasoning which a child acquires almost before it can walk, and which even an idiot knows. In like manner the elephant, the most sagacious of the brute creation, delights in the sugar-cane, and gives evident indications that this is a food which he relishes in the highest degree, and when he once discovers where it is to be found, will expose himself to any danger to obtain it; but no elephant hath ever yet been able to discover that if the joints of these plants be buried to a certain 
depth in newly turned up earth, it will there revive, and send up shoots, which in due time will aford abundance of his favourite food. This kind of reasoning, though it be the most obvious to all mankind, is far beyond the limited faculties of the brute creation. It is man alone who, by comparing facts that fall under his cognizance, and reasoning upon them, has been enabled to subject all nature to his sway. Nor is it alone from the facts that fall under his own observation that he derives this kind of knowledge; by the gift of language he has it communicated to him by others, or transmitted to him from the experience of former ages. While then the different species of animals universally have the same powers and propensities at this moment that they had at the earliest period they were known, the human species are advancing from age to age, and the power of man, of course, gradually extending as his knowledge increases.

Thus is man by the faculties of his mind pre-eminently distinguished from all other animals; but as he comes into the world without any idea or principle, 


\section{Human Understanding.}

263

either speculative or practical, it is only by the cultivation of his intellect that he can fairly claim this superiority; therefore leaving this part of our subject, we will proceed to the consideration of the distinct operations of the human understanding; define its powers, and show the method by which it acquires the stock of its ideas, and accumulates general knowledge.

The primary faculty of the mind is Perception. Perception consists in the attention of the understanding to the objects acting upon it, whereby it becomes sensible of the impressions they make; and the notices of these impressions, as they exist in the mind, are distinguished by the name of Ideas.

Sensation and Reflection are the two fountains or sources from which the understanding is supplied with all its ideas, or materials of thinking.

Sensation is the source of our original ideas, and comprehends the notices conveyed into the mind by impulses or impressions made upon the organs of sense. Such are the perceptions of colours, sounds, tastes, \&c. We derive all 


\section{0ิ4. Human Understanding.}

these ideas, numerous as they are, solely from external objects.

Reflection is the mind's perception of its own faculties and operations. Thus by reflection we acquire the idcas of thinking, doubting, believing, \&ic. which are the different intellectual operations represented to us by our consciousness.

A proper consideration of these two sources of our thou ghts will give us a clear and distinct view of the nature of the mind and the first steps it takes in the path of knowledge. The mind thus stored with its original notices of things, has a power of combining,modifying, and placing them in an infinite variety of lights, by which means it is enabled to multiply the objects of its perception, and finds itself possessed of an inexhaustible stock of materials for reflection and reasoning. And it is to be particularly observed, that among our numerous discoveries, and the infinite variety of our conceptions, we are unable to find one original idea, which is not derived from sensation or reflection; or one complex idea, which is not composed of these original ones.

The ideas with which the mind is thus 


\section{Human Understanding. $265^{\circ}$}

furnished are either Simple or Complex. Simple Ideas are such as exist in the mind under one uniform appearance, and cannot be divided into two or more ideas; for example, a colour, a sound.

Complex Ideas consist of several simple Ideas united in the same representation, appearance or perception; and they either come into the mind thus united from the operation of things without us, as the idea, solidity and figure, is caused by the same ball ; therefore in the complex idea of the ball we conceive such ideas as co-existent and concomitant ; or else when such simple ideas are united by the mind, as in the idea of law, obligation, Eंc.

In the production of Complex Ideas which are formed at the pleasure of the mind, it exerts three voluntary acts, viz. Composition, Abstraction, and Ciomparison. Composition is joining together two or more Simple Ideas, and considering them as one picture or representation. By composition we have the ideas of number, extension, \&c.

Abstraction is separating from a particular idea those circumstances which render it the representative of a single 
266

\section{Human Understanding.}

determinate object, and thereby making it to denote a whole rank or class of things. Hence we acquire Universal Ideas, such as whiteness, beauty, melody, \&c.

Comparison is bringing two or more ideas into the view of the mind, and examining their mutual correspondencies. By comparison we gain our ideas of $R e-$ lations, which are proportional, as equal, more, less, \&c. or natural, as father, mother, \&c. or civil, as king and people, general and army, \&c.

This division of our ideas, as it seems to be the most natural, and truly to represent the manner in which they are introduced into the mind, will be found to include them in all their varieties.

We know that our thoughts, although so numerous and manifold, are all contained within our own breasts, and are invisible. But as men were not created to live solitarily, or independently of each other, we are provided with organs proper for framing articulate sounds, and a capacity of using those sounds as signs of internal conceptions. From hence are derived words and language. For any sound being once determined upon to 


\section{Human Understanding.}

stand as the sign of an idea, custom by degrees establishes such a connexion between them, that the appearance of the idea in the understanding always brings to our remembrance the name by which it is expressed; and in like manner the hearing of the name never fails to excite the idea which it is intended to denote. This connexion between words and ideas, however, is perfectly arbitrary, and dependent on custom.

By language we are enabled to define our ideas. Definition is " the showing the meaning of one word by several other not synonymous terms." And here it may be observed, that Simple Ideas cannot be defined, since definition is resolving the thing to be defined into its most simple ideas ; but Complex Ideas may be defined, because they may be resolved into their simple ideas. Definition furnishes us with the fittest means of communicating our thoughts; for if we were unable to impart our Complex Ideas to each other by the aid of definition, it would in many cases be impossible to make them known. This is evident in those ideas which are solely the offspring of the mind. 
268

\section{Human Understanding.}

For as they exist only in the understanding, and have no real objects in nature, in conformity to which they are framed, if we could not communicate them to others by description, they must be confined to the narrow limits of a single mind. All the beautiful ideas formed by the fancy of a Shakspeare or a Milton, without the faculty of displaying them by words, would never have extended their influence . beyond their own breasts.

All language may be resolved into Nouns and Verbs, with their respective Abbreviations.

Nouns express names of things: they are divided into Substantives, which are the principal things spoken of ; and Adjectives, which denote qualities, or circumstances belonging to them.

Verbs express modes of existence. They are of three kinds, such as denote simple existence; for example, to be ; such as express existence in an active state, for example, to eat: and such as express existence in a passive state; as, to be eaten.

Words which are usually represented as indeclinable particles having no deter- 


\section{Human Understanding. $\quad 269$}

minate signification of their own, are $\mathrm{Ab}$ breviations of Nouns or Verbs, invented for the greater expedition of commuicating our thoughts. Thus If signifies give, and signifies add, being imperatives of corresponding verbs. See this theory of language stated and evinced in Mr.HorneTooke's Diversions of Purley.

Having thus considered our ideas, which are the materials of our knowledge, and our language, which is the manner of our conveying them to others; the last thing is to consider how our ideas are put together, and compared one with the other.

And herein, First, of Knowledge.

Knowledge, which is the highest degree of the speculative faculties, consists in the perception of the connexion and agreement, or disagreement and repug nancy of our ideas.

This perception is either immediate or mediate. Immediate perception of the agreement or disagreement of two ideas, is when, by comparing them together in our minds, we see, or, as it were, we behold their agreement or disagreement. This therefore is called Intuitive Know- 
ledge. Thus we see that red is not green; that the whole is bigger than a part; that two and two are equal to four.

The truth of these and the like propositions we know by bare simple intuition of the ideas themselves, without any more ado; and such propositions are called self-evident.

The mediate perception of the agreement or disagreement of two ideas, is, when by the intervention of one or more other ideas, their agreement or disagreement is shewn. This is called Demonstration or Rational Knowledge. For instance, the inequality of the breadth of two windows, or two rivers, or any two bodies that cannot be put together, may be known by the intervention of the same measure applied to them both; and so it is in our general ideas, whose agreement or disagreement may be often shewn by the intervention of some other ideas, so as to produce demonstrative knowledge, where the ideas in question cannot be brought together, and immediately compared, so as to produce intuitive knowledge.

Secondly, Of fudgment. 


\section{Human Understanding.}

Fudgment is that faculty which is given man to supply the want of clear and certain knowledge, where that cannot be had. It consists in putting ideas together, or seperating them from one another in the mind, when their certain agreement or disagreement is not perceived, but presumed to be so; which is, as the word imports, taken to be so before it certainly appears.

Hence the understanding doth not only know certain truth, but also judges of probability. Probability is always conversant about propositions whereof we have no certainty, as in knowledge, but only some inducements to receive them as true; such as their conformity to our own knowledge, observation and experience; and the entertainment the mind gives this sort of propositions is called assent, opinion or belief.

Of probability there are various degrees, from a moral certainty to the slightest degree of evidence; and the degrees of assent are proportionably various, from the least deviation from the equilibrium to the lowest degree upon the scale of evidence, and even to a moral impossibility. 
Lastly, Of Reason.

Reason is the pre-eminent faculty of the human mind, and is necessary and assisting to all our other inteliectual faculties. By it we enlarge our knowledge and regulate our assent ; for it hath to do both in knowledge and opinion, and is the faculty which finds out the means, and rightly applies them, to discover certainty in the one, and probability in the other. It is Reason which perceivet the necessary and indubitable connexion of all the ideas and proofs one to another, in each step of any demonstration that produces knowledge ; it likewise perceives the probable connexion of all the ideas or proofs one to another, in every step of a discourse to, which it will think assent due; and where the mind does not perceive this probable connexion or no; there men's opinions are not the product of Judgment, or the consequence of Reason, but the effects of chance, and of a mind floating at all adventures, without choice, and without direction, 



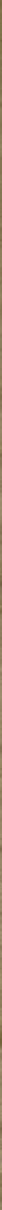



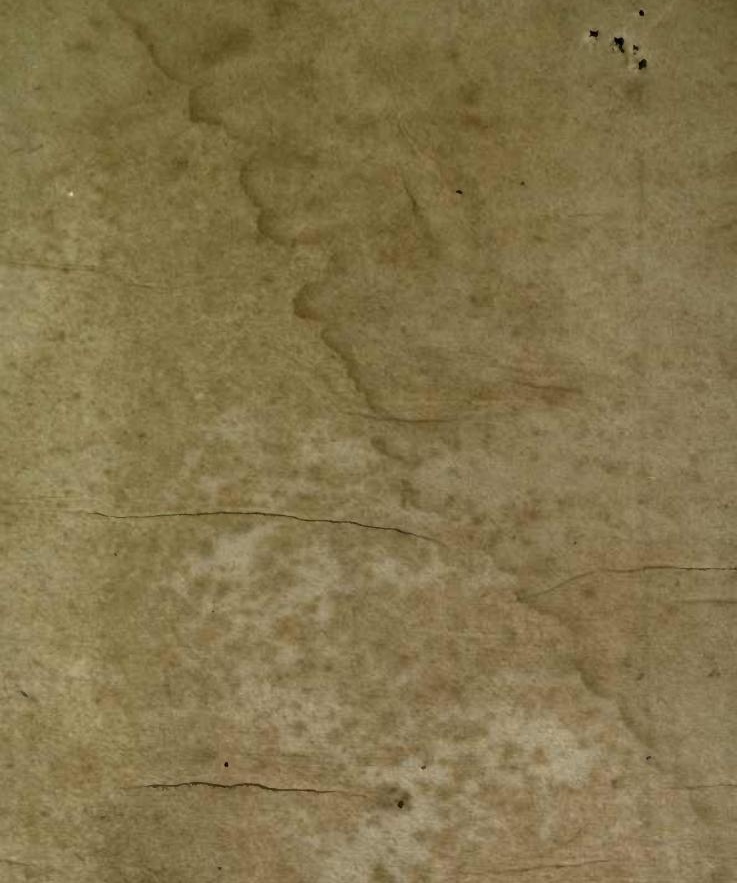

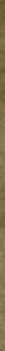

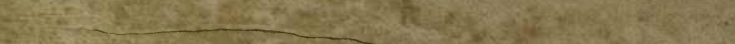

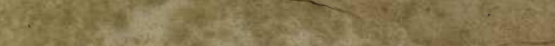

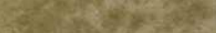

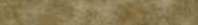

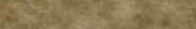

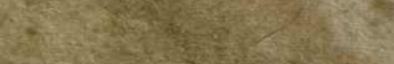

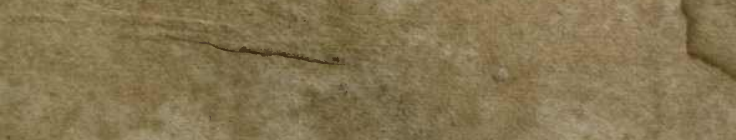

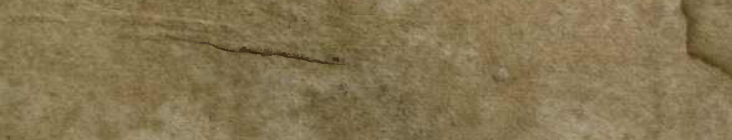

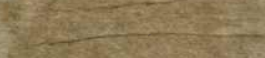
chas

-

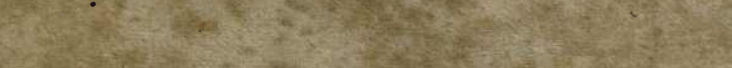

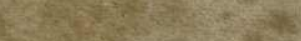

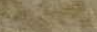




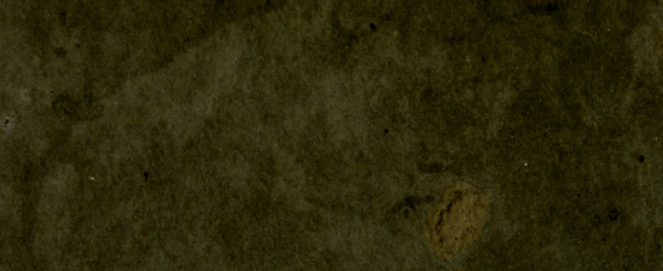

(6ing

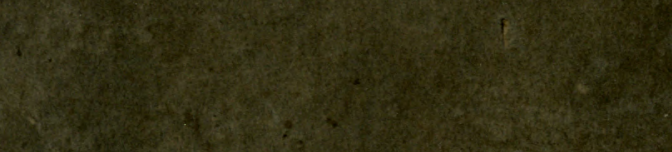

